\title{
Oxidative Stress in NAFLD: Role of Nutrients and Food Contaminants
}

\author{
Clémence Rives ${ }^{1}$, Anne Fougerat ${ }^{1}$, Sandrine Ellero-Simatos ${ }^{1}\left(\mathbb{D}\right.$, Nicolas Loiseau $\left.{ }^{1} \mathbb{(}\right)$ \\ Hervé Guillou ${ }^{1}$, Laurence Gamet-Payrastre ${ }^{1, *}$ and Walter Wahli 1,2,3,*(D) \\ 1 Toxalim (Research Center in Food Toxicology), Université de Toulouse, INRA, EVT, INP-Purpan, UPS, \\ 31300 Toulouse, France; clemence.rives@inrae.fr (C.R.); anne.fougerat@inrae.fr (A.F.); \\ sandrine.ellero-simatos@inrae.fr (S.E.-S.); nicolas.loiseau@inrae.fr (N.L.); herve.guillou@inrae.fr (H.G.) \\ 2 Lee Kong Chian School of Medicine, Nanyang Technological University Singapore, Clinical Sciences \\ Building, 11 Mandalay Road, Singapore 308232, Singapore \\ 3 Center for Integrative Genomics, Université de Lausanne, Le Génopode, CH-1015 Lausanne, Switzerland \\ * Correspondence: laurence.payrastre@inrae.fr (L.G.-P.); walter.wahli@ntu.edu.sg (W.W.)
}

Received: 27 November 2020; Accepted: 15 December 2020; Published: 21 December 2020

\begin{abstract}
Non-alcoholic fatty liver disease (NAFLD) is often the hepatic expression of metabolic syndrome and its comorbidities that comprise, among others, obesity and insulin-resistance. NAFLD involves a large spectrum of clinical conditions. These range from steatosis, a benign liver disorder characterized by the accumulation of fat in hepatocytes, to non-alcoholic steatohepatitis (NASH), which is characterized by inflammation, hepatocyte damage, and liver fibrosis. NASH can further progress to cirrhosis and hepatocellular carcinoma. The etiology of NAFLD involves both genetic and environmental factors, including an unhealthy lifestyle. Of note, unhealthy eating is clearly associated with NAFLD development and progression to NASH. Both macronutrients (sugars, lipids, proteins) and micronutrients (vitamins, phytoingredients, antioxidants) affect NAFLD pathogenesis. Furthermore, some evidence indicates disruption of metabolic homeostasis by food contaminants, some of which are risk factor candidates in NAFLD. At the molecular level, several models have been proposed for the pathogenesis of NAFLD. Most importantly, oxidative stress and mitochondrial damage have been reported to be causative in NAFLD initiation and progression. The aim of this review is to provide an overview of the contribution of nutrients and food contaminants, especially pesticides, to oxidative stress and how they may influence NAFLD pathogenesis.
\end{abstract}

Keywords: steatosis; non-alcoholic fatty liver disease (NAFLD); non-alcoholic steatohepatitis (NASH); food contaminant; macronutrients; micronutrients; oxidative stress; mitochondria; reactive oxygen species (ROS)

\section{Introduction and Background}

\subsection{General Overview}

Non-alcoholic fatty liver disease (NAFLD) frequently co-exists with metabolic syndrome and thus often is defined as the liver expression of dyslipidemia, insulin resistance, and obesity. However, it can also occur in patients with low body mass index $\left(<25 \mathrm{~kg} / \mathrm{m}^{2}\right)$, a condition known as lean NAFLD [1-3]. NAFLD is characterized by fat accumulation in hepatocytes and comprises a spectrum of disease. This spectrum ranges from simple steatosis (non-alcoholic fatty liver or NAFL) to non-alcoholic steatohepatitis (NASH) with inflammation, hepatocyte ballooning, and various levels of fibrosis, associated with a significant risk for progression to cirrhosis and liver cancer (hepatocellular carcinoma (HCC)). In fact, only $20 \%$ of NAFLD patients develop NASH, and $4 \%$ of patients with NAFL and 
$20 \%$ of patients with NASH develop cirrhosis [4]. Over time, up to $5 \%$ of patients with NASH will experience spontaneous regression. NASH is strongly associated with the degree of hepatic fibrosis, which is predictive of the overall mortality in patients with NAFLD [4].

NAFLD prevalence is increasing among children $[5,6]$ and has become the most common chronic liver disease in childhood and adolescence, as it is among adults. NAFLD affects approximately $25 \%$ of the global population [7], but the prevalence varies considerably by region. It is highest in the Middle East (32\%) and South America (30\%) and lowest in Africa (13\%). In North America and Europe, the prevalence is $24 \%$, and it is $27 \%$ in Asia [7]. As the overweight and obesity pandemic drives the development of metabolic conditions promoting NAFLD, the health and economic burdens continuously increase, also fueled by the boom in childhood obesity and an aging population [8,9].

NAFLD is defined as $>55 \mathrm{mg}$ triglycerides (TGs) per gram of liver or the presence of more than 5\% steatotic hepatocytes without histological damage or inflammation. Most commonly, the percentage of hepatocytes presenting lipid accumulation is divided into three ranges: $5 \%$ to $33 \%, 34 \%$ to $66 \%$, and $>66 \%$. Accordingly, the severity of steatosis is considered to be mild, moderate, or severe, respectively [10]. NAFL can progress to NASH that is characterized, in addition to steatosis, by ballooning degeneration of hepatocytes and lobular inflammation. The presence of perisinusoidal fibrosis is generally not considered a prerequisite for NASH diagnosis [11]. A recent study has found that some patients with NAFLD but without NASH may develop progressive fibrosis and have an increased mortality risk regardless of their baseline NASH status [12]. Furthermore, fibrosis progression is faster in lean patients with NAFLD, who can have a higher risk of developing cirrhosis or HCC compared with NAFLD patients who are overweight [13]. This pattern suggests that once the disease has progressed to NASH, obesity may not be the key factor in fibrosis progression [1], but this association remains debated and needs further investigation.

\subsection{Development of NAFLD}

Multiple factors determine NAFLD progression, which has led to the proposed "multiple hit" hypothesis [14]. These hits, which include nutritional factors and the gut microbiota, act in the context of diverse genetic backgrounds. For several years, development of NAFLD was explained by the "two hit" theory, according to which progression to NASH from "simple" steatosis or NAFL required a second "hit," such as oxidative stress and hepatocyte damage. Today's perception of NAFLD is that several different pathways can drive its development, resulting in a heterogeneous range of manifestations characterized by liver and serum lipidomic signatures that reflect disease development and progression. These variants allow for classification of NAFLD into different subtypes, based on the impairments of key pathways that control fatty acid (FA) homeostasis [15]. Pathogenic drivers of NAFL and NASH may arise because of the overwhelmed capacity of the liver to handle an overflow of the primary metabolic energy substrates, carbohydrates, and FAs, leading to the production of toxic lipid species [16]. The substrate overload liver injury model of NASH pathogenesis underscores the pivotal role of free FAs (FFAs) in the disease process during which toxic metabolites promote hepatocellular stress, cellular injury, and death. The activation of hepatic stellate cells and immune cells enhances the fibrogenesis, inflammation, and genomic instability that predispose to cirrhosis and HCC. There are two sources of hepatic free FFAs: lipolysis of TGs in adipose tissue with liver delivery through the bloodstream, and de novo lipogenesis in hepatocytes, which converts excess carbohydrates, especially fructose, to FAs and contributes to the accumulation of hepatic fat in NAFLD [17]. In hepatocytes, these FAs are processed by mitochondrial beta-oxidation and re-esterification to form TGs that are stored in lipid droplets or exported into the bloodstream, carried by very low-density lipoprotein (VLDL). 


\subsection{Determinants of NAFLD/NASH Development}

\subsubsection{Genetic Component}

Clinical observations have unveiled a high variability in susceptibility to NAFLD, with some patients exhibiting NASH and others having NAFL only, despite presenting with well-established risk factors. This variability has been addressed in the last decade after findings revealed an important role for differences in genetic background. A better understanding of the genetic basis of NAFLD should benefit the development of new medications to treat advanced disease [18]. Several genetic polymorphisms associated with NAFLD susceptibility implicate proteins regulating lipid and retinoid metabolism. The most well-documented polymorphism is the Patatin-like phospholipase domain-containing protein 3 (PNPLA3) isoleucine-to-methionine substitution at position 148 (rs738409C > G coding for PNPLA3 I148M). This loss-of-function I148M variant protein has already been reviewed in several publications [1,14,18,19]. PNPLA3 encodes the patatin-like phospholipase domain-containing protein 3, a triacylglycerol lipase that mediates triacylglycerol hydrolysis in adipocytes and hepatic lipid droplets. Significant associations have been identified between PNPLA3 I148M and liver fat, NASH, fibrosis, cirrhosis, and HCC. PNPLA3 I148M accumulates on lipid droplets and evades ubiquitylation so that its degradation is reduced. It remodels liver TGs and increases hepatic retention of polyunsaturated FAs (PUFAs) [16,20]. Furthermore, PNPLA3 has a role in hepatic stellate cell activation in response to fibrogenic stimuli and in the release of retinol by these cells [21].

The next important protein variant is the transmembrane 6 superfamily member 2 (TM6SF2) guanine-to-adenine substitution at position 167 (rs58542926 E > K, coding for TM6SF2 E167K), which also results in a loss of activity. TM6SF2 plays a role in loading TGs to apolipoprotein B 100 in the secretion pathway of hepatic VLDL. Reduced TM6SF2 activity results in triacylglycerol entrapping in lipid droplets [20,22]. Therefore, TM6SF2 E167K increases hepatic TG content while decreasing lipoprotein levels in the serum. Individuals carrying the variant gene have a higher risk for NAFLD but lower risk for cardiovascular disease [23]. Consistent with this finding, knockdown of Tm6sf2 in mice or transient TM6SF2 overexpression alters the serum lipid profiles [24].

Another gene variant is that of the membrane-bound O-acyltransferase domain-containing 7 (MBOAT7) protein that incorporates arachidonic acid into phosphatidylinositol. In hepatocytes, the rs641738 C>T MBOAT7 variant is associated with lower protein levels and changes in phosphatidylinositol species in the plasma. It also is associated with NAFLD severity in individuals of European descent, possibly resulting from changes in the remodeling of the liver phosphatidylinositol acyl-chain [25]. In fact, this variant increases the risk for NAFLD, including inflammation and fibrosis in white patients because of toxic accumulation of PUFAs as a consequence of their altered incorporation into hepatocyte phospholipids [20,25], and HCC in individuals without cirrhosis [26].

Glucokinase regulatory protein (GCKRP) regulates de novo lipogenesis by controlling the flux of glucose into hepatocytes. A missense loss-of-function GCKR variant (rs1260326, GCKR P446L) causes hepatic fat accumulation through stimulation of glucose uptake into hepatocytes, which fuels de novo lipogenesis $[27,28]$.

Finally, polymorphisms within $17 \beta$-hydroxysteroid dehydrogenase type 13 (HSD17B13), a protein expressed at the surface of lipid droplets with retinol dehydrogenase activity, are associated with NAFLD, NASH, fibrosis, and cirrhosis [29,30]. Of interest, the effect of the HSD17B13 variant in NAFLD is greater in carriers of the PNPLA3 I148M variant. This observation suggests that these two risk factors interact in the pathogenesis of NAFLD. Both PNPLA3 and HSD17B13 regulate retinol metabolism, which may suggest that this metabolism in hepatic stellate cells could be involved in the pathogenesis of NAFLD [31]. These protein variants resulting from gene polymorphisms illustrate clearly the genetic contribution to NAFLD susceptibility. 


\subsubsection{Environmental Factors}

In current Western societies, unhealthy diets, lack of exercise, smoking, and alcohol consumption are typical lifestyle risk factors that contribute to NAFLD development [32,33]. In particular, excessive fructose and saturated FA consumption, combined with sedentary lifestyles have contributed to the global increase of obesity and NAFLD. Increasing epidemiological and experimental evidence also suggest that exposure to some environmental contaminants, such as pesticides, participate in NAFLD development and progression.

\section{- Nutrients}

The effects of NAFLD-associated gene polymorphisms, as noted above, indicate complex interactions between genetic and environmental factors in the progression of NAFLD that are not yet completely understood [34-36]. Lifestyle interventions and dietary factors offer benefits in patients with NAFLD without obesity [37]. A healthy diet, together with physical activity, is commonly recommended to patients with NAFLD to improve their condition. Weight loss significantly contributes to controlling disease progression. However, despite clear documentation that dietary and exercise interventions are effective, many patients fail to adhere to the recommendations for different reasons [1,38]. A recent meta-analysis investigating the relationship between the risk for NAFLD in association with different food groups (e.g., vegetables, fruits, red meat, fish, refined grains, whole grains, soft drinks) found that red meat and soft drink intake is positively associated with NAFLD [39]. The impact of specific diets on NAFLD is now well documented, such as the differences in the effects of Westernized versus Mediterranean diets [1,38]. The Western diet (WD), which is particularly rich in saturated fat and added fructose, is associated with a greater risk for and severity of NAFLD [40]. Diets characterized by a high intake of so-called fast foods and rich in saturated FAs, trans-fats, simple sugars, red and processed meats, full-fat dairy products, and soft drinks have a deleterious effect on the liver. In contrast, Mediterranean-type diets, which are low in saturated fat and cholesterol and rich in monounsaturated fats, polyunsaturated omega-3 FAs with a balanced ratio of omega- 6 to omega-3 FAs, a high content of complex carbohydrates, dietary fiber, and plant-based proteins, are beneficial to the liver and associated with lower rates of NAFLD, NASH, and fibrosis [41-44]. A systematic review evaluating the effectiveness of different dietary interventions recently showed that the Mediterranean diet is effective for reducing hepatic steatosis [45]. This diet also can reduce liver fat without changes in weight and may be particularly beneficial for patients with high genetic risk for NAFLD [46-48]. As might be anticipated from these findings, greater adherence to the Mediterranean diet also is associated with less severe NAFLD [49].

Among macronutrients, sugars such as sucrose and high fructose corn syrup significantly increase risk for NAFLD and NASH [50]. Carbohydrates, especially fructose, stimulate de novo lipogenesis, which accounts for $26 \%$ of increased FAs within the liver [51-53]. Among patients with NAFLD, dietary fructose consumption, especially in sweetened beverages, is increased [54] and associated with heightened inflammation and fibrosis [55]. Consistent with this observation, very low-carbohydrate ketogenic diets decrease hepatic lipids and improve histologic parameters including steatosis, inflammation, and fibrosis in people with obesity [56,57]. Dietary lipids are involved in NAFLD but are not the main source of liver fat in NAFLD, as only $15 \%$ of hepatic lipids in NAFLD patients trace to dietary fat [17]. Several studies have shown that high intake of saturated lipids, cholesterol, simple carbohydrates, and animal proteins is a major determinant of NAFLD and contributes to disturbances in energy homeostasis (lipid and glucose metabolism) and to hepatocyte damage [58]. Of note, cholesterol is consistently elevated in human and mouse fibrotic NASH. Its mechanistic link to NASH development has been explored recently [59]. Cholesterol upregulates the transcriptional regulator TAZ (transcriptional co-activator with PDZ-binding motif) and promotes fibrotic NASH through an adenylyl cyclase-calcium $\left(\mathrm{Ca}^{2+}\right)$-RhoA pathway. The importance of this cholesterol-TAZ pathway remains to be demonstrated in human NASH [59]. 
In contrast, dietary PUFAs and fibers have beneficial effects on NAFLD. Saturated FAs increase fat accumulation in the liver, whereas the consumption of monounsaturated FAs (MUFAs) and PUFAs has protective effects against NAFLD [60-62]. PUFAs inhibit hepatic lipogenesis through repression of genes involved in lipid synthesis and glucose metabolism [63-65]. Epidemiological studies indicate that patients with NASH tend to have a higher intake of saturated FAs and cholesterol, whereas their PUFA consumption is lower compared to healthy controls [66].

A single oral dose of saturated FAs increases hepatic TG accumulation and impairs insulin sensitivity in human and mouse liver [67]. Compared to fat and carbohydrates, the role of dietary proteins in NAFLD pathogenesis is poorly studied and remains controversial. A recent study analyzed the effects of isocaloric diets rich in animal proteins or plant proteins for 6 weeks in patients with diabetes and NAFLD and found that both high-protein diets reduced liver fat [68]. However, high consumption of proteins and of red and/or processed meat has been reported in patients with NASH [69,70]. The Rotterdam study further showed that a high animal protein intake is associated with a higher prevalence of hepatic steatosis in overweight and elderly patients [71].

A role for micronutrients in NAFLD is less known, but the liver is important for their metabolism, which is often disturbed in liver diseases. Several micronutrients, such as zinc, copper, iron, selenium, magnesium, vitamins A, C, D, and E, and carotenoids have beneficial effects in NAFLD, mediated by their lipoprotective, antioxidant, antifibrotic, and immunomodulatory properties. However, the appropriate dosage appears to be important because an excess of iron and selenium may increase the severity of NAFLD [38,72]. Hepatic iron accumulation in reticulo-endothelial cells occurs in NAFLD and is associated with disease severity, but observations are often conflicting [73-77]. Similarly, some studies have reported that iron depletion by phlebotomy leads to histological improvements and liver enzyme normalization in NAFLD patients with hyperferritinemia, but results of several studies do not support the use of phlebotomy in these patients [78-80]. A classic intervention in patients with NAFLD is vitamin E supplementation because of increased oxidative stress. However, side effects, including hemorrhagic stroke and prostate cancer, limit the clinical use of vitamin E. Interventions with combinations of micronutrients are potentially interesting because experimental studies in mice have indicated beneficial effects on liver steatosis, body weight gain and hypertriglyceridemia, with findings suggesting that a cost-effective combinatorial micronutrient-based strategy could be tested in humans [81,82].

Probiotics are widely used to promote human health as described in a recent review [83], and prebiotics are nutrients used by host micro-organisms. They modulate the composition of the gut microbiota involved in NAFLD development [84,85]. Impacts of probiotic-based therapies in NAFLD patients are still debated. In one study, treatment of NAFLD patients with a combination of probiotics and prebiotics for 1 year led to faecal microbiome changes without modification of liver fat content and liver fibrosis markers [84]. In another study, NAFLD patients consuming a symbiotic food combining prebiotics and probiotics for 24 weeks presented improved serum steatosis associated parameters and oxidative stress biomarkers [86]. In a third study, treatment of Asian NAFLD patients with probiotics and prebiotics caused a decreased body weight and an amelioration of NAFLD parameters [85].

In animal models, pro- and prebiotic treatments also improved NAFLD development. Rat fed HFD containing the probiotic strain Lactobacillus mali APS for 12 weeks showed a decrease in body weight gain associated with reduced hepatic lipid accumulation and increased antioxidant response; these effects were associated with a decrease of some bacteria species [87]. Standard chow diet enriched with prebiotics (oligofructose or dextrin) induced changes in rat redox status and serum lipid biomarkers suggesting a positive impact of these prebiotics on NAFLD [88]. Cranberry extract could be another promising prebiotic in NAFLD prevention and/or treatment. Mice fed a high fat/high sucrose (HFHS) enriched with cranberry extract for 8 weeks improved all biomarkers of NAFLD [89]. Collectively, these results show that pre- and probiotics can ameliorate hepatic steatosis by modulating lipid metabolism and antioxidant activity. 
The strong association between NAFLD and obesity further reinforces the role of dietary factors in the pathogenesis of NAFLD. Hence, in the absence of an approved drug treatment, as noted, a lifestyle intervention that targets weight loss is the primary therapy for the management of NAFLD. The effectiveness of weight reduction was recently confirmed in a meta-analysis of 22 randomized clinical trials that included more than 2500 patients with NAFLD. The results showed that weight loss intervention always improved their serum and histologic parameters, although no changes in liver fibrosis were observed [90].

In general, patients with NAFLD have a higher daily energy intake compared with healthy controls [91], and calorie restriction leading to weight loss has beneficial effects in these patients [92]. Both acute and chronic calorie-restricted diets with either a low-fat or low-carbohydrate content are associated with reduced liver fat in patients with obesity $[93,94]$. Hypocaloric diets are also effective in improving NAFLD in patients with diabetes and children with obesity $[95,96]$. In experimental models, calorie restriction extends lifespan and reduces the hepatic steatosis associated with obesity $[92,97,98]$.

\section{- Gut microbiota}

Some nutrients known to promote NAFLD, such as fructose, affect the gut microbiota and cause dysbiosis (an altered gut microbiota composition). These changes impair the permeability of the gut barrier and trigger the development of metabolic syndrome and its associated perturbations. In contrast, intake of dietary fiber, probiotics, and prebiotics associated with physical training is effective in improving NAFLD [99-101].

Of note, the gut microbiota is also required for the hepatic clock daily oscillations that regulate metabolic gene expression for optimal liver function [102-104]. In fact, the liver and gut are in close anatomical and functional relation via the portal vein. Diet, gut microbiota, and the liver constitute an axis that can promote either liver health or NAFLD progression. Analyses of the variations in gut microbiota composition in NAFLD have identified specific bacterial species that directly impact NAFLD progression [105]. In support of a beneficial effect, the administration of butyrate, a short chain FA produced by the gut microbiota, improves hepatic inflammation and fat accumulation in NAFLD mouse models [106]. However, despite many animal studies demonstrating a relationship between dysbiosis and NAFLD, only a limited number of cross-sectional human studies have investigated the role of the gut microbiota in NAFLD or NASH, with variable results [107]. Intestinal microbiota dysbiosis also has been associated with other liver diseases in animals and humans, including alcohol-related liver disease, cirrhosis, and HCC [107].

- Food contaminants: the example of pesticides

Pesticides are considered as risk factors for human health. Various epidemiological studies reported a correlation between occupational exposure to these products and the development of pathologies, such as cancers, neurodegenerative diseases, and metabolic disorders [108-111]. Moreover, recent population studies (Nutrinetcohort in France) showed that the consumption of organic food correlated with a significant decreased risk of metabolic disease and cancer [112-114]. In addition, pesticides are bioactive compounds that exert an impact on various pathways underlying diseases [115]. Environmental contaminants are considered to play major roles in the etiology and progression of NAFLD. Endocrine-disrupting compounds were first described as inducing reproductive disorders but can be involved in the etiology of diabetes and other metabolic disorders independently of their hormone signaling effects [116-122]. In addition to contaminants such as polychlorinated biphenyls (PCBs), other compounds such as dioxins [123], bisphenol A [122], and pesticides are suspected to contribute to the increased prevalence of NAFLD.

Organochlorine insecticide levels in serum from adult participants of the National Health and Nutrition Examination Survey have been associated with increased odds ratios for alanine amino transferase (ALT), which may indicate NAFLD [124]. It is noteworthy that most epidemiological studies do not present information linking exposure to pesticide to NAFLD, but rather focus on diabetes and 
obesity $[115,125]$. In epidemiological studies, the serum concentrations of organochloride pesticides have been significantly associated with diabetes, especially in women [126], with a specific metabolic profile including mainly metabolites related to lipid metabolism [127], metabolic syndrome [128], and adiposity [129]. However, no correlation was found between serum levels of the organochloride dichlorodiphenyldichloroethylene (DDE) and the incidence of type 2 diabetes in a population of adults living in urban India [130]. Persistent but also non-persistent pesticides currently in use may also support the development of metabolic diseases [125,131-134]. Experimental studies have allowed identification of the type of pesticides that promote fatty liver disease or changes in global metabolic homeostasis in animal models [123], such as organophosphorus or neonicotinoid or pyrethroid insecticides [135-146], triazine herbicides [147,148], glyphosate herbicides [149-153], or other families [154,155] and fungicides [152,156-161] (Table 1).

Perinatal exposure to some pesticides has been correlated with metabolic changes [162], increased insulin levels in newborns [163], and overweight in childhood [164,165]. Experimental studies evaluating the consequences of pesticide exposure during the critical window of pre- and postnatal development (pregnancy and lactation) confirm that early life exposure to pesticides may have a role in metabolic disruption later in life (Table 1). A metabolic impact of perinatal exposure to pesticides in animal models has been reported for insecticides, such as chlorpyrifos [140,166] and imidacloprid [142]; herbicides, such as glyphosate [150] and 2-4 dichlorophenoxyacetic acid (2,4-D) [155]; and pesticide mixtures $[167,168]$. The metabolic consequences of early life exposure to organophosphate have been reviewed previously $[61,74,169]$. Early life exposure to fungicides has been tied to metabolic disturbances, reduced liver weight, and histopathological changes [170].

Pesticide exposure may lead to NAFLD through an impact on lipid metabolism by (i) modifying FA uptake and efflux [171] and FFA transport, (ii) increasing lipogenesis [172-174] (Table 1), (iii) altering oxidation pathways [175] (Tables 1 and 2), and (iv) interacting with nuclear receptors involved in the control of metabolism [176-178]. Some pesticides may disrupt lipid metabolism [179,180].

Pesticides alter glucose metabolism through the activation of glucose uptake, glycogenolysis, gluconeogenesis (for insecticides, see [136]; for diazinon or monocrotophos-treated animals, see [181-183], or inhibition of the mitochondrial respiratory chain [184]. They also have exerted effects through modulation of carbohydrate response element binding protein (Chrebp) gene expression levels [185] and changes in the expression of peroxisome proliferator-activated receptor (PPAR) $\beta / \delta$ and genes involved in glucose metabolism (FoxO1 and cAMP response element-binding protein, $\mathrm{Creb}$ ) [186]. Pesticides induce insulin resistance by acting on insulin signaling pathways [187]. Liver inflammation was also reported upon exposure to organophosphorus [187,188], organochlorine [189], neonicotinoid [142,143], and pyrethroid insecticides [144,145], and to triazole or imidazole fungicides $[190,191]$ (Table 1). 
Table 1. Metabolic impact of pesticide exposure in normal diet-fed animal models. Acceptable Daily Intake (ADI) values were from https://ephy.anses.fr/ and https://ec.europa.eu/food/plant/pesticides/eu-pesticides-database/. ADI, acceptable daily intake; ALT, alanine aminotransferase; AST, aspartate aminotransferase; BW, body weight; CAR, constitutive androstane receptor; GD, gestational day; HFD, high-fat diet; IL1- $\beta$, interleukin-1 beta LDH, lactate dehydrogenase; MDA, malonaldehyde; NOAEL, no observable adverse effect level; ND, normal diet; NF-kB, nuclear factor kappa B, PND, postnatal day; SOD, Super oxide dismutase; TG, triglyceride, TNF- $\alpha$, tumor necrosis factor alpha; ADI, Acceptable Daily Intake.

\begin{tabular}{|c|c|c|c|c|c|}
\hline Type of Pesticide & Chemical Family & $\begin{array}{c}\text { Active Substance } \\
\text { (ADI mg/kg BW/day) }\end{array}$ & Experimental Model & Metabolic Effects & Refs. \\
\hline \multirow{3}{*}{ Insecticide } & \multirow{3}{*}{ Organophosphorus } & $\begin{array}{l}\text { Diazinon } \\
(0.002)\end{array}$ & $\begin{array}{l}\text { - } \quad \text { ND-fed male rats } \\
\text { Oral daily gavage with } 15 \mathrm{mg} / \mathrm{kg} \text { for } \\
4 \text { weeks }\end{array}$ & $\begin{array}{l}\text { - Increased serum ALT and AST activity, } \\
\text { serum lipid content, peripheral } \\
\text { inflammation biomarkers }\end{array}$ & [188] \\
\hline & & \multirow[b]{2}{*}{$\begin{array}{l}\text { Malathion } \\
\quad(0.03)\end{array}$} & $\begin{array}{l}\text { - ND-fed male rats } \\
\text { - } 28 \text { days }\end{array}$ & $\begin{array}{ll}\text { - } & \text { Increased levels of lipid } \\
\text { peroxidation biomarkers } \\
\text { - } \quad \text { Decreased levels of } \\
\text { antioxidant enzymes } \\
\text { - } \quad \text { Chronic inflammation }\end{array}$ & [192] \\
\hline & & & $\begin{array}{l}\text { - } \quad \text { ND-fed male rats } \\
\text { Oral daily gavage with } 27 \mathrm{mg} / \mathrm{kg} \text { for } \\
30 \text { days }\end{array}$ & $\begin{array}{l}\text { - } \quad \text { Increased liver MDA levels } \\
\text { Decreased liver glutathione levels, } \\
\text { superoxide dismutase, and } \\
\text { catalase activities } \\
\text { Increased liver IL1- } \beta, \text { TNF- } \alpha \text {, and } \\
\text { NF-kB mRNA expression levels }\end{array}$ & [139] \\
\hline \multirow{3}{*}{ Insecticide } & \multirow[b]{2}{*}{ Organophosphorus } & \multirow[b]{2}{*}{$\begin{array}{c}\text { Chlorpyrifos } \\
(0.001)\end{array}$} & $\begin{array}{ll} & \text { ND-fed pregnant rats } \\
\text { - } & \text { Oral gavage with } 1,2.5, \text { or } 4 \mathrm{mg} / \mathrm{kg} \\
\text { BW/day from gestational day } 7 \text { to } \\
\text { postnatal day } 21\end{array}$ & $\begin{array}{l}\text { Increased adiposity and weight gain } \\
\text { only in males with } 2.5 \\
\mathrm{mg} / \mathrm{kg} \text { chlorpyrifos }\end{array}$ & [140] \\
\hline & & & $\begin{array}{l}\text { - } \quad \text { ND-fed female rats } \\
\text { Oral daily gavage with } 1 \text { or } 3.5 \mathrm{mg} / \mathrm{kg} \\
\text { BW/day during gestation and lactation }\end{array}$ & $\begin{array}{ll}\text { - } & \text { Decreased offspring BW gain at PND } 60 \\
\text { - } & \text { Increased fasting glycemia } \\
\text { - } & \text { Increased ALT activity } \\
\text { - } & \text { Decreased plasma TG levels } \\
\text { - } & \text { Change in microbiota composition }\end{array}$ & [166] \\
\hline & Organochlorine & $\begin{array}{l}\text { Endosulfan } \\
\quad(0.006)\end{array}$ & $\begin{array}{l}\text { - } \quad \text { ND-fed male mice } \\
\text { Oral daily gavage for } 2 \text { weeks with } \\
\text { doses ranging from } 0.5 \text { to } 3.5 \mathrm{mg} / \mathrm{kg} \mathrm{BW}\end{array}$ & $\begin{array}{l}\text { - Weight loss } \\
\text { - Changes in various liver metabolic } \\
\text { pathways (energy, amino acid, and } \\
\text { lipid metabolism) } \\
\text { - Gut microbiota alteration }\end{array}$ & [134] \\
\hline
\end{tabular}


Table 1. Cont

\begin{tabular}{|c|c|c|c|c|c|}
\hline Type of Pesticide & Chemical Family & $\begin{array}{c}\text { Active Substance } \\
\text { (ADI mg/kg BW/day) }\end{array}$ & Experimental Model & Metabolic Effects & Refs. \\
\hline \multirow{3}{*}{ Insecticide } & \multirow{3}{*}{ Neonicotinoid } & $\begin{array}{l}\text { Imidacloprid } \\
\quad(0.06)\end{array}$ & $\begin{array}{l}\text { - } \quad \text { ND-fed female rats } \\
\text { Oral daily gavage with } 9 \text { or } 45 \mathrm{mg} / \mathrm{kg} \\
\text { BW for } 4 \text { weeks }\end{array}$ & - Biomarkers of hepatotoxicity & [141] \\
\hline & & $\begin{array}{l}\text { Imidacloprid } \\
\quad(0.06)\end{array}$ & $\begin{array}{l}\text { - } \quad \text { ND-fed pregnant rats } \\
\text { Oral daily gavage with } 1 / 45 \text { th or } 1 / 22 \text { th } \\
\mathrm{LD}_{50} \text { from mating to gestation } \\
\text { and lactation }\end{array}$ & $\begin{array}{l}\text { - Hepatic necrosis and inflammation in } \\
\text { the non-exposed second generation }\end{array}$ & [142] \\
\hline & & $\begin{array}{l}\text { Thiamethoxam } \\
\text { (0.026) }\end{array}$ & $\begin{array}{l}\text { - } \quad \text { ND-fed male rabbits } \\
\text { Oral daily gavage with } 250 \mathrm{mg} / \mathrm{kg} \mathrm{BW} \\
\text { for } 90 \text { days }\end{array}$ & $\begin{array}{l}\text { - Hepatic oxidative stress } \\
\text { and inflammation }\end{array}$ & [143] \\
\hline \multirow{3}{*}{ Insecticide } & \multirow{3}{*}{ Pyrethroid } & $\begin{array}{l}\text { Deltamethrin } \\
\quad(0.01)\end{array}$ & $\begin{array}{l}\text { - } \quad \text { ND-fed male rats } \\
\text { Oral daily gavage with } 15 \mathrm{mg} / \mathrm{BW} \text { for } \\
30 \text { days }\end{array}$ & $\begin{array}{l}\text { - Liver inflammation (increased levels of } \\
\text { serum and liver lipid } \\
\text { peroxidation biomarkers) } \\
\text { - } \quad \text { Changes in antioxidant enzyme activity } \\
\text { - Increased expression of inflammatory } \\
\text { cox2 gene }\end{array}$ & [144] \\
\hline & & $\begin{array}{l}\text { Alpha cypermethrin } \\
\quad(0.00125)\end{array}$ & $\begin{array}{l}\text { - } \quad \text { Female rats } \\
\text { - } \quad \text { Pesticide-enriched diet at } 0.02 \mathrm{mg} / \mathrm{kg} \\
\text { BW/day } \\
\text { - One month before and during gestation }\end{array}$ & $\begin{array}{l}\text { - Increased glucose, cholesterol, TG } \\
\text { levels and AST and ALT activity in } \\
\text { mothers and newborns } \\
\text { - Increased maternal BW and liver } \\
\text { weight in mothers } \\
\text { - } \quad \text { Change in pup liver weight } \\
\text { Increased liver inflammation and lipid } \\
\text { content in both dams and newborns } \\
\text { Increased circulating and liver levels of } \\
\text { oxidative stress biomarkers and } \\
\text { decreased antioxidant status in both } \\
\text { dams and newborns }\end{array}$ & [145] \\
\hline & & $\begin{array}{l}\text { Alpha cypermethrin } \\
(0.00125)\end{array}$ & $\begin{array}{l}\text { - } \quad \text { Pregnant female ND-fed rats } \\
\text { - } \quad \text { Pesticide enriched diet }(1.5 \mathrm{mg} / \mathrm{kg}) \\
\quad 5 \text { months after weaning }\end{array}$ & $\begin{array}{l}\text { - Reduction of body weight, food and } \\
\text { energy intake in offspring } \\
\text { Increase in plasma glucose, urea } \\
\text { cholesterol and creatinine levels in both } \\
\text { male and female rats } \\
\text { - Increase in liver oxidative stress }\end{array}$ & [146] \\
\hline
\end{tabular}


Table 1. Cont.

\begin{tabular}{|c|c|c|c|c|c|}
\hline Type of Pesticide & Chemical Family & $\begin{array}{c}\text { Active Substance } \\
\text { (ADI mg/kg BW/day) }\end{array}$ & Experimental Model & Metabolic Effects & Refs. \\
\hline \multirow[t]{2}{*}{ Insecticide } & \multirow[t]{2}{*}{ Pyrethroid } & \multirow[t]{2}{*}{$\begin{array}{l}\text { Lambda cyhalothrin } \\
\quad(0.0025)\end{array}$} & $\begin{array}{l}\text { - } \quad \text { Ord-fed male rats } \\
\mathrm{mg} / \mathrm{kg} \text { BW for } 7,30,45, \text { or } 60 \text { days }\end{array}$ & $\begin{array}{ll}\text { - } & \text { Increased levels of hepatic stress } \\
\text { biomarkers (MDA, AST, ALT) and } \\
\text { antioxidant enzyme activities } \\
\text { - } \\
\text { Increased liver TNF-alpha and } \\
\text { interleukin gene expression }\end{array}$ & [137] \\
\hline & & & $\begin{array}{l}\quad \text { ND-fed male rats } \\
\text { Gastric intubation with } 1,2,4 \text {, and } 8 \\
\mathrm{mg} / \mathrm{kg} \text { BW for } 6 \text { consecutive days }\end{array}$ & $\begin{array}{l}\text { - Changes in the expression of genes } \\
\text { coding for xenobiotic metabolism } \\
\text { enzymes and for liver oxidation }\end{array}$ & [138] \\
\hline \multirow[b]{2}{*}{ Herbicide } & Triazine & $\begin{array}{l}\text { Atrazine } \\
(0.02)\end{array}$ & $\begin{array}{l}\text { - } \quad \text { HFD- and ND-fed male rats } \\
\text { - } \quad 30 \text { to } 300 \mu \mathrm{gg} / \mathrm{kg} \text { BW/day for } 5 \text { months }\end{array}$ & $\begin{array}{ll}\text { - } & \text { BW gain in HFD- and ND-fed rats } \\
\text { - } & \text { Increased insulin levels in HFD-fed rats } \\
\text { - } & \text { Insulin resistance in ND- and } \\
& \text { HFD-fed rats }\end{array}$ & [148] \\
\hline & Glycine derivate & $\begin{array}{l}\text { Glyphosate } \\
(0.5)\end{array}$ & $\begin{array}{ll}\text { - } & \text { Pregnant ND-fed mice } \\
\text { - } & \text { Oral exposure to } 0.5 \% \text { glyphosate } \\
& \text { solution in drinking water during } \\
\text { gestation and lactation } \\
\text { - } \quad \text { ND-fed male rats } \\
\text { - Oral exposure to } 0.1 \mathrm{ppb} \text { Roundup } \\
\text { formulation (eq to } 0.05 \mu \mathrm{\mu g} / \mathrm{L} \text { glyphosate) } \\
\text { in drinking water for } 2 \text { years }\end{array}$ & $\begin{array}{l}\text { - Decreased body weight in offspring } \\
\text { PND7 and } 21 \\
\text { - Increased lipid levels in offspring in } \\
\text { liver and plasma } \\
\text { - Liver proteome disruption reflecting } \\
\text { steatosis and necrosis }\end{array}$ & {$[150,151]$} \\
\hline \multirow[b]{2}{*}{ Herbicide } & Glycine derivate & Glyphosate (0.5) & $\begin{array}{l}\text { - } \quad \text { ND-fed male rats } \\
\text { Oral daily gavage with } 5,50 \text {, or } 500 \\
\mathrm{mg} / \mathrm{kg} \text { BW for } 35 \text { days }\end{array}$ & $\begin{array}{ll}\text { - } & \text { Increased levels of serum and } \\
& \text { liver MDA } \\
\text { - } & \text { Decreased liver SOD activity } \\
\text { - } & \text { Increased liver catalase activity } \\
\text { - } & \text { Increased liver mRNA expression of } \\
\text { inflammatory genes }\end{array}$ & [153] \\
\hline & Dinitroaniline & $\begin{array}{l}\text { Pendimethalin } \\
(0.125)\end{array}$ & $\begin{array}{l}\text { - } \quad \text { ND-fed male rats } \\
\text { Oral daily gavage with } 62.5,125 \text {, or } 250 \\
\mathrm{mg} / \mathrm{kg} \text { BW/day for } 14 \text { days }\end{array}$ & $\begin{array}{l}\text { - Increased biomarkers of liver lipid } \\
\text { peroxidation and protein carbonylation } \\
\text { Decreased antioxidant } \\
\text { enzyme activities } \\
\text { - Liver hyperplasia and swelling, } \\
\text { occurrence of pyknotic nuclei, activated } \\
\text { Kupfer cells and leukocyte infiltrations, } \\
\text { large cytoplasmic vacuolization and } \\
\text { dilatation in blood sinusoid }\end{array}$ & [154] \\
\hline
\end{tabular}


Table 1. Cont

\begin{tabular}{|c|c|c|c|c|c|}
\hline Type of Pesticide & Chemical Family & $\begin{array}{c}\text { Active Substance } \\
\text { (ADI mg/kg BW/day) }\end{array}$ & Experimental Model & Metabolic Effects & Refs. \\
\hline Herbicide & Dinitroaniline & $\begin{array}{l}\text { 2.4 Dichlorophenoxyacetic } \\
\text { acid }(2,4-\mathrm{D}) \\
(0.02)\end{array}$ & $\begin{array}{l}\text { - } \quad \text { ND-fed pregnant rats } \\
\text { - Co-exposure through drinking water at } \\
126 \mathrm{mg} / \mathrm{kg} \text { BW from GD } 14 \text { to PND } 14 \\
\text { - } \quad \text { Observation at PND } 14\end{array}$ & 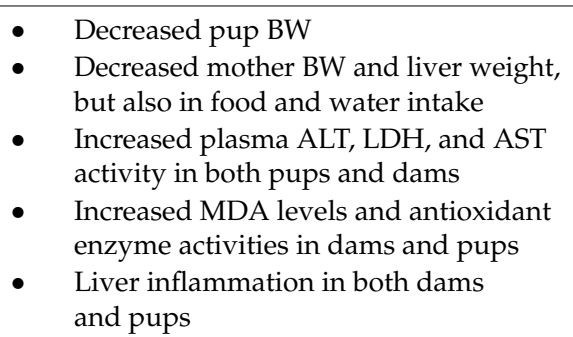 & [155] \\
\hline \multirow{5}{*}{ Fungicide } & \multirow[b]{2}{*}{ Triazole } & $\begin{array}{l}\text { Penconazole } \\
\quad(0.03)\end{array}$ & $\begin{array}{l}\text { - } \quad \text { ND-fed male mice } \\
\text { Oral exposure to } 30 \mathrm{mg} / \mathrm{L} \text { in drinking } \\
\text { water for } 4 \text { weeks }\end{array}$ & $\begin{array}{l}\text { Increased levels of serum ALT, AST and } \\
\text { hepatic TGs, total cholesterol; lipid } \\
\text { droplet accumulation } \\
\text { and inflammation }\end{array}$ & [190] \\
\hline & & $\begin{array}{c}\text { Cyproconazole } \\
(0.02)\end{array}$ & $\begin{array}{l}\text { - } \quad \text { ND-fed WT and humanized CAR } \\
\text { male mice } \\
\text { Pesticide-enriched diet with } 50 \text { or } \\
500 \text { ppm }\end{array}$ & $\begin{array}{ll}\text { - } & \text { Induction of CAR-dependent } \\
& \text { gene expression } \\
\text { - } & \text { Increased liver weight } \\
\text { - } & \text { Hepatic lipid accumulation }\end{array}$ & [157] \\
\hline & Triazole & $\begin{array}{l}\text { Cyproconazole } \\
\quad(0.02) \\
\text { Epoxiconazole } \\
(0.008) \\
\text { Prochloraz } \\
(0.01)\end{array}$ & $\begin{array}{l}\text { - } \quad \text { ND-fed male rats } \\
\text { Pesticide-enriched diet: individual } \\
\text { compounds or mixture (NOAEL/100; } \\
\text { NOAEL; NOAELx10) }\end{array}$ & $\begin{array}{l}\text { - Changes in the expression of hepatic } \\
\text { genes involved fatty acid and } \\
\text { phospholipid metabolism, cytochrome } \\
\text { P450, transporters (Abcb1a, Abcc3) } \\
\text { In most cases, treatment with mixtures } \\
\text { caused stronger effects as compared to } \\
\text { the individual substances }\end{array}$ & [158] \\
\hline & Imidazole & $\begin{array}{l}\text { Imazalil } \\
(0.025)\end{array}$ & $\begin{array}{l}\text { - } \quad \text { ND-fed male mice } \\
\text { - } \quad \text { Pesticide-enriched diet with } 25,50 \text {, or } \\
100 \mathrm{mg} / \mathrm{kg} \text { BW daily for } 4 \text { weeks }\end{array}$ & $\begin{array}{l}\text { - No significant changes in hepatic TG } \\
\text { - Dysbiosis and colonic inflammation }\end{array}$ & [160] \\
\hline & Benzimidazole & $\begin{array}{l}\text { Carbendazim } \\
(0.02)\end{array}$ & $\begin{array}{l}\text { - } \quad \text { ND fed male mice } \\
0.1,0.5 \text {, or } 5 \mathrm{mg} / \mathrm{kg} \text { BW per day in } \\
\text { drinking water for } 14 \text { weeks }\end{array}$ & 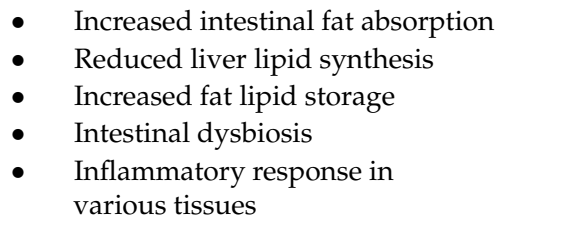 & [191] \\
\hline
\end{tabular}


Table 1. Cont

\begin{tabular}{|c|c|c|c|c|c|}
\hline Type of Pesticide & Chemical Family & $\begin{array}{c}\text { Active Substance } \\
\text { (ADI mg/kg BW/day) }\end{array}$ & Experimental Model & Metabolic Effects & Refs \\
\hline Fungicide & Sulfamide & $\begin{array}{l}\text { Tolylfluanid } \\
\quad(0.1)\end{array}$ & $\begin{array}{l}\text { - } \quad \text { ND-fed male mice } \\
\text { Pesticide-enriched diet with } 100 \text { ppm } \\
\text { for } 12 \text { weeks }\end{array}$ & $\begin{array}{l}\text { - Increased BW and adiposity, glucose } \\
\text { intolerance, and insulin resistance, } \\
\text { impaired circulating levels of leptin } \\
\text { and adiponectin, disturbed fat } \\
\text { oxidation and lipolysis in adipocytes } \\
\text { - No change in liver homeostasis }\end{array}$ & {$[161]$} \\
\hline $\begin{array}{c}\text { Mixture } \\
\text { Insecticide and } \\
\text { fungicide }\end{array}$ & $\begin{array}{l}\text { Triazine } \\
\text { Phenoxybutyric } \\
\text { Carbamate } \\
\text { Quinone } \\
\text { Dithiocarbamate } \\
\text { Carbamate }\end{array}$ & $\begin{array}{c}\text { Cyromazine (0.06), MCPB } \\
(0.01) \text {, Pirimicarb }(0.035), \\
\text { Quinoclamine }(0.002), \\
\text { Thiram }(0.01), \\
\text { Ziram }(0.006)\end{array}$ & $\begin{array}{l}\text { - } \quad \text { ND-fed pregnant female rats } \\
\text { Oral gavage with total dose of } 28,104, \\
\text { or } 210 \mathrm{mg} / \mathrm{kg} / \text { day of the mixture from } \\
\text { GD } 7 \text { to GD } 17 \\
\text { - } \quad \text { Analysis at } 4 \text { months of age }\end{array}$ & $\begin{array}{l}\text { - Decreased birth weight in exposed } \\
\text { male offspring } \\
\text { Increased leptin levels in } \\
\text { female offspring } \\
\text { - Variations } \\
\text { - Change in the expression of } 3 \text { genes in } \\
\text { fat tissues in a sexually } \\
\text { dimorphic manner }\end{array}$ & [167] \\
\hline $\begin{array}{l}\text { Mixture of } \\
\text { insecticide, } \\
\text { herbicide, and } \\
\text { fungicide }\end{array}$ & $\begin{array}{l}\text { Carboxamide } \\
\text { Phthalimide } \\
\text { Organophosphorus } \\
\text { Neonicotinoid } \\
\text { Dithiocarbamate } \\
\text { Carbamate }\end{array}$ & $\begin{array}{l}\text { Boscalid }(0.04) \\
\text { Captan }(0.1) \\
\text { Chlorpyrifos }(0.001) \\
\text { Thiachloprid } \\
\text { Thiophanate }(0.08) \\
\text { Ziram }(0.006)\end{array}$ & $\begin{array}{l}\text { - } \quad \text { ND-fed male and female mice } \\
\text { Pesticide mixture-enriched diet, } \\
\text { exposure to the ADI of each pesticide } \\
\text { for } 52 \text { weeks }\end{array}$ & $\begin{array}{l}\text { - Overweight and glucose intolerance } \\
\text { and steatosis in males } \\
\text { - Liver oxidative stress and alteration in } \\
\text { gut microbiota in females }\end{array}$ & [193] \\
\hline $\begin{array}{l}\text { Mixture of } \\
\text { insecticide, } \\
\text { herbicide, and } \\
\text { fungicide }\end{array}$ & $\begin{array}{l}\text { Chloroacetanilide } \\
\text { Nitrile } \\
\text { Carbamate } \\
\text { Quaternary ammonium } \\
\text { Organophosphorus } \\
\text { Morpholine } \\
\text { Glycine derivative } \\
\text { Neonicotinoid }\end{array}$ & $\begin{array}{c}\text { Acetochlor }(0.0036) \\
\text { Bromoxynil }(0.01) \\
\text { Carbofuran }(0.00015) \\
\text { Chlormequat }(0.04) \\
\text { Ethephon }(0.03) \\
\text { Fenpropimorph }(0.003) \\
\text { Glyphosate }(0.5) \\
\text { Imidacloprid }(0.06)\end{array}$ & $\begin{array}{l}\text { - } \quad \text { ND-fed pregnant rats } \\
\text { Pesticide-enriched diet; exposure at a } \\
\text { nominal dose corresponding to the } \\
\text { same proportion as their respective } \\
\text { environmental exposure value (from } \\
\text { French use) from GD } 4 \text { to GD } 21\end{array}$ & $\begin{array}{l}\text { - } \quad \text { Decreased liver weight in dams } \\
\text { - } \quad \text { Increased liver weight in male offspring } \\
\text { - } \quad \text { male offspring } \\
\text { Changes in liver metabolome (lipid } \\
\text { metabolism biomarkers) and serum } \\
\text { metabolome in fetuses }\end{array}$ & {$[168]$} \\
\hline
\end{tabular}


Of interest, pesticide exposure and a high-fat diet (HFD) (Table 2) [136] interact to modify their effect on metabolic homeostasis [194]. In fact, various chemical families of insecticides seem to be involved, i.e., organochlorine, pyrethroid, neonicotinoid, and organophosphorus compounds (Table $2[148,184,185,195-210])$. Moreover, HFD components may act as a vehicle for pesticides, allowing them to reach target organs more easily, as proposed in $[136,211]$. This finding suggests that a different bioavailability of pesticides in mice fed with an HFD versus normal chow diet may explain, at least in part, dissimilar outcomes with pesticide exposure in different studies.

The fact that some pesticides have antimicrobial activity implies that they affect the composition and metabolic functions of the gut microbiota and may be metabolized by the microbiota [212,213]. For example, the organochloride dichloro-diphenyl-trichloroethane (DDT) is converted to DDD by the rat and human microbiota (Eubacterium limosum) [214]. When administered by oral gavage in mice, DEE, a metabolite of DDT, impacts bile acid metabolism and reduces the relative abundance of Bacteroidetes, Verrucomicrobia, and Actinobacteria, whereas that of Firmicutes and Proteobacteria is increased. Furthermore, genes involved in bile acid synthesis are upregulated in the liver [215]. Many studies mainly using rats have analyzed the impact of other insecticides on the microbiota, and important changes in its composition have been reported (reviewed in [213]). Relatively little is known about how glyphosate, the most widely used herbicide worldwide, affects NAFL in terms of gut microbiota, but glyphosate has a profound effect on both gut microbiota composition [216] and metabolism [217] in rodents. Roundup, whose active compound is glyphosate, is suspected to lead to greater alterations in the gut microbiota composition than glyphosate alone, alterations that are similar to those reported in NAFLD, obesity, and systemic inflammation $[213,218,219]$. Finally, fungicides also cause an important dysbiosis and, one of them, carbendazim, has been associated with hepatic oxidative stress [220]. Overall, pesticides in general are associated with important dysbiosis but the link among pesticides, dysbiosis, and hepatic oxidative stress in NAFLD is not well established, and further studies are warranted. 
Table 2. Metabolic impact of pesticide exposure in high-fat diet-fed animal models. Acceptable Daily Intake (AD)I values were from https://ephy.anses.fr/ and https:/ec.europa.eu/food/plant/pesticides/eu-pesticides-database/. ADI value is not reported for some compounds due to insufficient data (organochlorine compounds, prinomectin, moxidectin, GW4064, PCB). ALT, alanine aminotransferase; BW, body weight; FFA, free fatty acid; CPT, carnitine palmitoyl-transferase; FXR, farnesoid X receptor; GD, gestational day; GIP, glucose-dependent insulinotropic peptide; GLP-1, glucagon-like peptide-1; HFD, high-fat diet; HOMA-IR, homeostasis model assessment of insulin resistance. NEFA, non-esterified fatty acid; NOAEL, no observable adverse effect level; ND, normal diet; PCB polychlorinated biphenyl; PP, pancreatic polypeptide; PUFA, polyunsaturated fatty acid; PND, postnatal day; SFA, saturated fatty acid; TG, triglyceride; UCP, uncoupling protein; VLDL, Very low density lipoprotein; WT, wild type; ADI, Acceptable Daily Intake.

\begin{tabular}{|c|c|c|c|c|c|}
\hline Type of Pesticide & Chemical Family & $\begin{array}{c}\text { Active Substance } \\
\text { (ADI mg/kg BW/day) }\end{array}$ & Experimental Model & $\begin{array}{l}\text { Effects of Pesticide Exposure on Diet-Induced } \\
\text { Metabolic Disorders }\end{array}$ & Refs. \\
\hline \multirow[t]{2}{*}{ Insecticide } & \multirow[t]{2}{*}{ Organochlorine } & \multirow[t]{2}{*}{ DDE } & $\begin{array}{l}\text { - } \quad \text { ND- and HFD-fed male rats } \\
\quad \text { Pesticide-enriched diet for } 4 \text { weeks }\end{array}$ & $\begin{array}{ll}\text { - } & \text { Increase serum ALT and AST levels in ND } \\
\text { - } & \text { Decreased serum TG levels and liver lipid } \\
\text { content in HFD fed animals } \\
\text { - } \\
\text { Increased CPT activity oxidation and lipid } \\
\text { peroxidation in ND- and HFD-fed animals } \\
\text { - } \quad \text { Hepatic oxidative stress in ND- and } \\
\text { HFD-fed animals } \\
\text { - Increased antioxidant enzyme activities more } \\
\text { in ND- than in HFD-fed animals } \\
\text { - Increased UCP2 mRNA levels in ND- and } \\
\text { HFD-fed animals }\end{array}$ & [203] \\
\hline & & & $\begin{array}{l}\text { ND- and HFD-fed male rats } \\
\text { exposed to } 100 \mu \mathrm{kg} / \mathrm{BW} / \text { day DDE in } \\
\text { drinking water for } 12 \text { weeks }\end{array}$ & $\begin{array}{l}\text { - Increased accumulation in fatty acid (SFA and } \\
\text { PUFA) content in both ND- and } \\
\text { HFD-fed animals }\end{array}$ & [204] \\
\hline \multirow[b]{2}{*}{ Insecticide } & \multirow[b]{2}{*}{ Organochlorine } & DDE & $\begin{array}{l}\text { - Oral gavage of ND-fed male mice } \\
\text { for } 5 \text { days } \\
\text { - } \quad \text { One-week resting period } \\
\text { Then oral gavage each week of ND- } \\
\text { or HFD-fed males for } 13 \text { weeks }\end{array}$ & $\begin{array}{l}\text { - } \quad \text { After } 4 \text { and } 8 \text { weeks on the HFD diet, increased } \\
\text { fasting hyperglycemia and liver steatosis } \\
\text { At week } 13 \text {, HFD-induced decrease in fasting } \\
\text { hyperinsulinemia, HOMA-IR values, and } \\
\text { hepatic steatosis }\end{array}$ & [205] \\
\hline & & DDT & $\begin{array}{l}\text { Daily oral gavage of pregnant } \\
\text { female mice from GD } 11 \text { to PND } 5 \\
\text { at } 1.7 \mathrm{mg} / \mathrm{kg} \mathrm{BW} \\
\text { ND- and HFD-fed adult female } \\
\text { offspring for } 12 \text { weeks }\end{array}$ & $\begin{array}{l}\text { - } \quad \begin{array}{l}\text { Reduced body temperature and energy } \\
\text { expenditure and increased body fat in } \\
\text { offspring of ND mothers }\end{array} \\
\text { - } \quad \text { Compared to ND, further HFD-induced } \\
\text { reduction of body temperature } \\
\text { - } \quad \begin{array}{l}\text { HFD-induced changes in brown adipose tissue } \\
\text { gene expression }\end{array}\end{array}$ & [206] \\
\hline
\end{tabular}


Table 2. Cont

\begin{tabular}{|c|c|c|c|c|c|}
\hline Type of Pesticide & Chemical Family & $\begin{array}{l}\text { Active Substance } \\
\text { (ADI } \mathrm{mg} / \mathrm{kg} \text { BW/day) }\end{array}$ & Experimental Model & $\begin{array}{l}\text { Effects of Pesticide Exposure on Diet-Induced } \\
\text { Metabolic Disorders }\end{array}$ & Refs. \\
\hline Insecticide & Organochlorine & Chlordane & $\begin{array}{l}\text { - ND- and HFD-fed male mice } \\
\text { (6 weeks) } \\
\text { - Oral gavage daily at } 1.45 \mathrm{mg} / \mathrm{kg} \mathrm{BW} \\
\text { from week } 4 \text { to week } 6\end{array}$ & $\begin{array}{l}\text { - } \quad \text { No change in BW in ND- and HFD-fed animals } \\
\text { Increase in HFD induced liver metabolic } \\
\text { perturbations (TCA cycle, tryptophan } \\
\text { catabolism, nucleotide, lipid and choline, and } \\
\text { amino acid metabolism) }\end{array}$ & [207] \\
\hline \multirow{4}{*}{ Insecticide } & \multirow[b]{2}{*}{ Pyrethroid } & $\begin{array}{l}\text { Permethrin } \\
\quad(0.050)\end{array}$ & $\begin{array}{l}\text { - } \quad \text { ND- or HFD-fed male mice } \\
\text { - } \quad \text { Pesticide-enriched diet with 50, 500, } \\
\text { or } 5000 \mu \mathrm{g} / \mathrm{kg} \mathrm{BW} / \text { day for } 12 \text { weeks }\end{array}$ & $\begin{array}{l}\text { - Potentiation of HFD-induced BW gain, total } \\
\text { adipose tissue weight, insulin resistance }\end{array}$ & [208] \\
\hline & & $\begin{array}{l}\text { Cypermethrin } \\
(0.050)\end{array}$ & $\begin{array}{l}\text { - } \quad \text { HFD-fed male mice } \\
\text { simultaneously exposed to } 50 \mu \mathrm{g} / \mathrm{kg} \\
\text { BW/day cypermethrin in drinking } \\
\text { water for } 20 \text { weeks }\end{array}$ & $\begin{array}{ll}\text { - } & \text { No change in BW } \\
\text { - } & \text { Increased levels of serum FFA, hepatic } \\
& \text { lipid, TG } \\
\text { - } & \text { Increased liver de novo FFA and TG synthesis } \\
\text { - } & \text { Increased uptake of FFA from blood }\end{array}$ & [185] \\
\hline & \multirow[b]{2}{*}{ Organophosphorus } & \multirow[b]{2}{*}{$\begin{array}{l}\text { Chlorpyrifos } \\
\quad(0.001)\end{array}$} & $\begin{array}{l}\text { - } \quad \text { ND- and HFD-fed male mice } \\
\text { Co-exposure by daily gavage with } 5 \\
\mathrm{mg} / \mathrm{kg} \text { for } 12 \text { weeks }\end{array}$ & $\begin{array}{l}\text { - Increased BW in both ND- and HFD-fed mice } \\
\text { - Impaired glucose metabolism and insulin } \\
\text { resistance in both HFD- and ND-fed mice }\end{array}$ & [209] \\
\hline & & & $\begin{array}{l}\text { - } \quad \text { ND- and HFD-fed male rats } \\
\text { - Co-exposure by daily oral gavage to } \\
0.3 \text { and } 3 \mathrm{mg} / \mathrm{kg} \text { BW for } 9 \text { weeks }\end{array}$ & 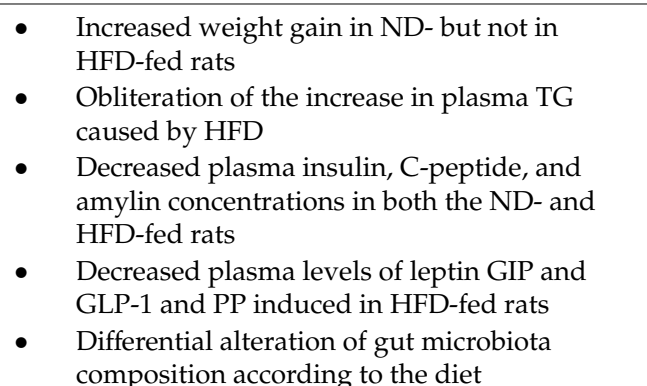 & [210] \\
\hline
\end{tabular}


Table 2. Cont

\begin{tabular}{|c|c|c|c|c|c|}
\hline Type of Pesticide & Chemical Family & $\begin{array}{l}\text { Active Substance } \\
\text { (ADI } \mathrm{mg} / \mathrm{kg} \text { BW/day) }\end{array}$ & Experimental Model & $\begin{array}{l}\text { Effects of Pesticide Exposure on Diet-Induced } \\
\text { Metabolic Disorders }\end{array}$ & Refs. \\
\hline \multirow{3}{*}{ Insecticide } & \multirow{3}{*}{ Organophosphorus } & \multirow[t]{2}{*}{$\begin{array}{l}\text { Chlorpyrifos } \\
\quad(0.001)\end{array}$} & $\begin{array}{l}\text { - } \quad \text { ND- and HFD-fed male mice for } \\
\text { - } \quad \text { weeks } \\
\text { Oral gavage with } 2 \mathrm{~m} / \mathrm{kg} \text { BW/day } \\
\text { chlorpyrifos during the last } 10 \text { days } \\
\text { of the experiment }\end{array}$ & $\begin{array}{l}\text { - } \quad \text { No significant body weight increase in } \\
\text { HFD-fed animals } \\
\text { - } \quad \text { No significant increase in plasma TG in } \\
\text { HFD-fed animals } \\
\text { - Decreased expression of genes involved in } \\
\text { liver lipogenesis in ND- and HFD-fed animals }\end{array}$ & [195] \\
\hline & & & $\begin{array}{l}\text { - } \quad \text { HFD- and ND-fed male mice for } \\
4 \text { weeks } \\
\text { Chlorpyrifos }(2 \mathrm{mg} / \mathrm{kg}) \text { single oral } \\
\text { gavage at the end of the experiment }\end{array}$ & $\begin{array}{l}\text { - Increased TG serum levels in ND fed animals } \\
\text { - Hypoglycemia in HFD-fed animals. }\end{array}$ & [196] \\
\hline & & $\begin{array}{l}\text { Parathion } \\
(0.0006)\end{array}$ & $\begin{array}{l}\text { - Subcutaneous injection of PDN } 1-4 \\
\text { in rats at } 0.1 \text { and } 0.2 \mathrm{mg} / \mathrm{kg} / \text { day } \\
\text { once daily } \\
\text { A } 6 \text { week HFD feeding of } 15 \\
\text { week-old male and female rats }\end{array}$ & $\begin{array}{ll}\text { - } & \text { Increased serum cholesterol levels in fasted } \\
\text { HFD-fed males } \\
\text { - } \\
\text { Decreased serum NEFA levels in fasted } \\
\text { ND-fed females } \\
\text { - Enhancement of HFD-induced BW gain in } \\
\text { females exposed to } 0.1 \mathrm{mg} / \mathrm{kg} / \text { day parathion } \\
\text { - Decreased BW gain in HFD fed females } \\
\text { exposed to } 0.2 \mathrm{mg} / \mathrm{kg} \text { BW parathion }\end{array}$ & [197] \\
\hline \multirow[t]{2}{*}{ Insecticide } & Organophosphorus & $\begin{array}{l}\text { Acephate } \\
(0.03)\end{array}$ & $\begin{array}{l}\text { - } \quad \text { Daily gavage of female rats with } 2.5 \\
\mathrm{mg} / \mathrm{kg} \text { BW/day from pregnancy day } \\
7 \text { until lactation day } 21 \\
\text { - } \quad \text { Overfeeding of pups by decreasing } \\
\text { the number of pups per nest } \\
\text { - } \quad \text { Analysis at PND } 90\end{array}$ & 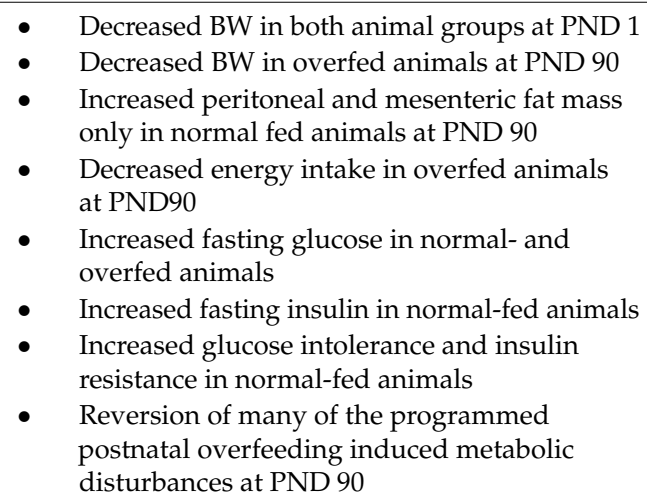 & [198] \\
\hline & Neonicotinoid & $\begin{array}{l}\text { Imidacloprid } \\
\quad(0.06)\end{array}$ & $\begin{array}{ll}\text { - } & \text { ND- and HFD-fed male mice } \\
\text { - } & \text { Pesticide-enriched diet } \\
\text { - } & \text { Exposure to dose ranging from TDI } \\
& \text { to NOAEL for } 12 \text { weeks }\end{array}$ & $\begin{array}{l}\text { Potentiation of HFD-induced weight gain, } \\
\text { insulin resistance, and adipocyte size and } \\
\text { impaired glucose metabolism }\end{array}$ & [199] \\
\hline
\end{tabular}


Table 2. Cont

\begin{tabular}{|c|c|c|c|c|c|}
\hline Type of Pesticide & Chemical Family & $\begin{array}{l}\text { Active Substance } \\
\text { (ADI mg/kg BW/day) }\end{array}$ & Experimental Model & $\begin{array}{l}\text { Effects of Pesticide Exposure on Diet-Induced } \\
\text { Metabolic Disorders }\end{array}$ & Refs. \\
\hline \multirow{2}{*}{$\begin{array}{l}\text { Insecticide } \\
\text { antiparasitic }\end{array}$} & \multirow{2}{*}{ Avermectin } & $\begin{array}{l}\text { Abamectin (0.0025) Doramectin, } \\
\text { (0.0005) Ivermectin }(0.010), \\
\text { Eprinomectin Moxidectin GW4064 }\end{array}$ & $\begin{array}{l}\text { HFD-fed male mice simultaneous } \\
\text { exposed to } 1.3 \mathrm{mg} / \mathrm{kg} \text { B avermectin } \\
\text { analogs by intraperitoneal injection } \\
\text { for } 14 \text { days }\end{array}$ & $\begin{array}{l}\text { Suppression of HFD-induced metabolic } \\
\text { disturbances in mice by most compounds, } \\
\text { excepting eprinomectin and moxidectin }\end{array}$ & [200] \\
\hline & & $\begin{array}{l}\text { Ivermectin } \\
\quad(0.010)\end{array}$ & $\begin{array}{l}\text { - } \quad \text { HFD fed WT and FXR null mice } \\
\text { simultaneous exposed to ivermectin } \\
\text { by intraperitoneal injection at } 1.3 \\
\mathrm{mg} / \mathrm{kg} \text { BW/day for } 14 \text { days }\end{array}$ & $\begin{array}{l}\text { - Decreased serum levels of glucose and } \\
\text { cholesterol, high-density lipoprotein and } \\
\text { low-density lipoprotein and VLDL cholesterol } \\
\text { levels, in wild-type mice } \\
\text { - } \quad \text { Ivermectin effects suppressed in FXR null mice }\end{array}$ & [201] \\
\hline Fungicide & Strobilurin & $\begin{array}{l}\text { Azoxystrobin } \\
\quad(0.2)\end{array}$ & $\begin{array}{l}\text { - } \quad \text { HFD-fed male mice for } 13 \text { weeks } \\
\text { Oral gavage at } 25 \mathrm{mg} / \mathrm{kg} \text { BW/day at } \\
\text { week } 8 \text { for } 5 \text { weeks }\end{array}$ & $\begin{array}{ll}\text { - } & \text { Reduction in BW } \\
\text { - } & \text { Improvement of glucose tolerance } \\
\text { - } & \text { Decrease liver TG accumulation } \\
& \text { liver lipogenesis }\end{array}$ & [184] \\
\hline \multirow[t]{2}{*}{ Herbicide } & \multirow[t]{2}{*}{ Triazine } & \multirow[t]{2}{*}{$\begin{array}{l}\text { Atrazine } \\
(0.02)\end{array}$} & $\begin{array}{l}\text { HFD-fed male mice simultaneously } \\
\text { exposed to atrazine in drinking } \\
\text { water at } 100 \mu \mathrm{g} / \mathrm{kg} \mathrm{BW/day} \mathrm{for} \\
20 \text { weeks }\end{array}$ & $\begin{array}{l}\text { - } \quad \text { No change in BW } \\
\text { - Increased levels of serum FFA, hepatic lipids, } \\
\text { and TG } \\
\text { - Increased liver de novo FFA and TG } \\
\text { synthesis pathways } \\
\text { - Increased uptake of FFA from blood }\end{array}$ & [221] \\
\hline & & & $\begin{array}{l}\text { HFD- and ND-fed male rats } \\
\text { simultaneously exposure to } \\
\text { atrazine in drinking water with } 30 \\
\text { to } 300 \mu \mathrm{g} / \mathrm{kg} \mathrm{BW/day} \mathrm{for} 5 \text { months }\end{array}$ & $\begin{array}{l}\text { - } \quad \text { Body weight gain in HFD- and ND-fed rats } \\
\text { - Increased insulin levels in HFD-fed rats } \\
\text { - Insulin resistance in ND- and HFD-fed rats }\end{array}$ & [148] \\
\hline Mixture & POP & $\begin{array}{l}\text { Organochlorine pesticide and } \mathrm{PCB} \\
\text { mixture }\end{array}$ & $\begin{array}{l}\text { - Leptin-deficient ob/ob ND fed } \\
\text { male mice } \\
\text { Oral gavage twice weekly for } 7 \\
\text { weeks at environmentally } \\
\text { relevant levels }\end{array}$ & $\begin{array}{l}\text { - Increased steatosis in ob/ob mice } \\
\text { Increased hepatic triglyceride content in } \\
\text { ob/ob mice }\end{array}$ & [202] \\
\hline
\end{tabular}


Other environmental factors can affect NAFLD development and progression. Although the effect of active smoking on NAFLD development remained controversial [222] a recent systematic review and meta-analysis from 20 observational studies revealed a slight but significant association between active and passive smoking and NAFLD [223]. The link between a modest alcohol consumption with NAFLD development is described in a very recent review [224].

- Aim of the review

There is currently no effective pharmacological therapy for the treatment of NAFLD. Weight loss, achieved through lifestyle changes including diet modifications and exercise, remains the most effective strategy for NAFLD management. However, these lifestyle interventions are difficult to maintain for most patients. Vitamin E and the anti-diabetic agent Pioglitazone are the two classic therapies currently used to treat NAFLD patients but they can both induce adverse effects and their benefit on liver fibrosis is either absent or still not clear. Most of the other molecules that are under investigation target the metabolic comorbidities of NAFLD such as obesity, insulin resistance, and dyslipidemia [225]. A better understanding of the development and progression of this complex pathology will allow the development of novel therapeutic strategies for the treatment of NAFLD.

As is well known, alterations in lipid metabolism are key to the development of NAFLD and its progression. They can affect different reactive oxygen species (ROS) generators, such as mitochondria, endoplasmic reticulum (ER), and nicotinamide adenine dinucleotide phosphate (NADPH) oxidase (NOX) [226]. Although many aspects of the contributions of these disturbances to NAFLD remain unexplored, much progress has been accomplished in recent years. Knowledge is accumulating on how increased ROS generation triggers changes in insulin sensitivity and the activity of key enzymes of lipid metabolism, innate immune system signaling, and the level of inflammatory responses. Our review addresses the mechanisms and consequences of excessive ROS production in the liver that drives NAFLD progression, and the roles of nutrients and food contaminants in these processes (Figure 1).

Our discussion on the roles of oxidative stress on NAFLD development covers knowledge gained from both animal models, mainly rodent models, and humans. It is important to keep in mind, while reading the review, that rodents and humans NAFLD are not equivalent, although the FDA encourages the use of appropriate animal models for developing new treatments against pre-cirrhotic NASH [227]. The current animal models mimicking the progression of the human NAFLD phenotype rely on genetic alterations, chemically induced liver damage or diets deficient in essential nutrients. Therefore, they do not fully match, mechanistically and biochemically, the lifestyle-associated NAFLD in humans [228]. There are several models used currently, each presenting advantages and limitations $[229,230])$. A useful animal model, from a clinician's view point, should reflect the important metabolic deteriorations seen in human NAFLD patients including hyperglycemia and insulin resistance, hyperlipidemia, and obesity with liver fat accumulation. Fatty liver should show progression from simple steatosis to the inflamed liver stage with ballooning and fibrosis monitored by histopathological examination and quantified by recognized scoring systems. The progression should be relatively fast allowing the evaluation of candidate drugs and nutritional interventions. Despite relentless efforts and the advances made in recent years, the ideal rodent model comprising all desirable characteristics is not yet available. Therefore, studies in different models are necessary to perform all the analyses required for a better understanding of human NAFLD progression. 


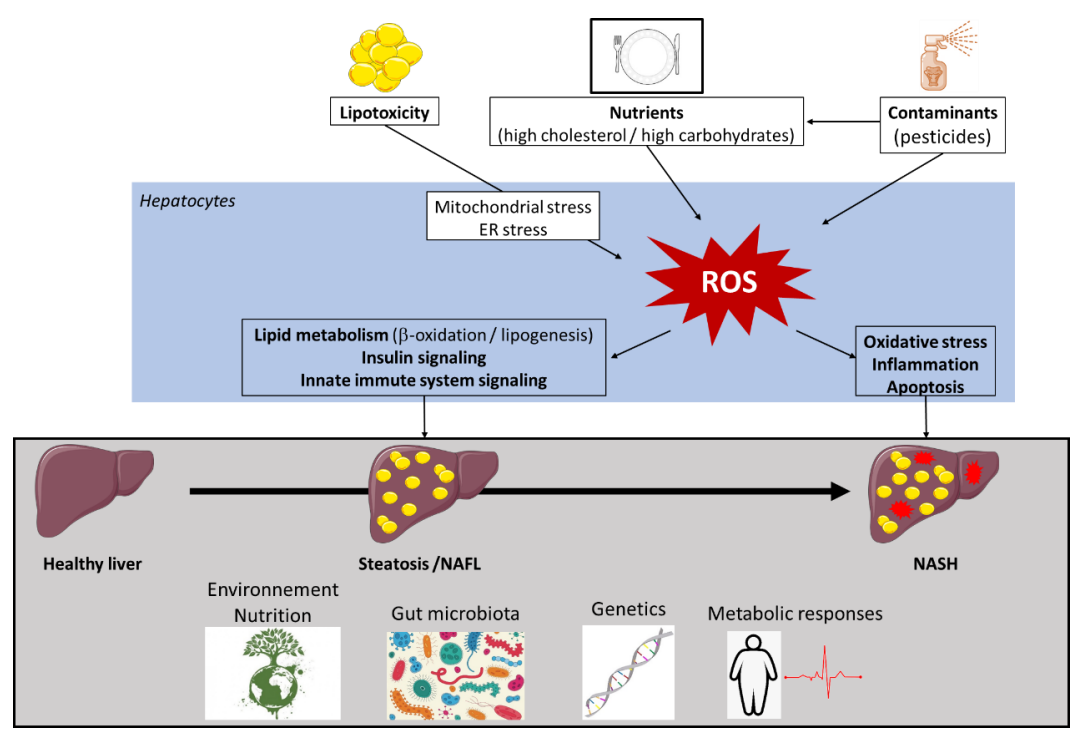

Figure 1. Factors involved in non-alcoholic fatty liver disease (NAFLD) pathogenesis. Multiple causes, including metabolic factors, gut microbiota, and environmental factors, operate in the context of the specific genetic background of individuals for the development of non-alcoholic fatty liver disease (NAFLD). Lipid overload induces lipotoxicity that affects different reactive oxygen species (ROS) generators, such as mitochondria, peroxisomes, and endoplasmic reticulum (ER). As environmental factors, solid and liquid foods and their contaminants contribute to ROS production. ROS generation triggers changes in insulin sensitivity, the activity of key enzymes of lipid metabolism, innate immune system signaling, inflammatory responses, and liver apoptosis. High levels of ROS enhance oxidative stress, thus creating a vicious circle. Collectively, these conditions contribute to NAFLD development and progression. Other abbreviations: NAFL, non-alcoholic fatty liver; NASH, non-alcoholic steatohepatitis.

\section{Methods}

We performed a PubMed search of the literature. Studies that were not published in English or published in the grey literature were excluded. We tried to focus on articles published during the last 10 years. We established a list of keys words (below) and combined them according to each author's dedicated chapter in order to get a representative overview of the literature. Each author reviewed the chapter of the other co-authors. Furthermore the corresponding authors, worked on the homogeneity and uniformity of the different chapters. The following lists of keywords were used:

(i) "Oxidative stress" OR "oxidative phosphorylation" OR "oxidation-reduction potential" OR "reactive oxygen species" OR "ROS" OR "reactive nitrogen species " OR “RNS" OR "redox stress" OR "peroxidation" OR "free radicals" OR "lipotoxicity" OR mitochondria OR endoplasmic reticulum OR glutathione OR antioxidant pathways OR Nrf2 OR SIRT OR SOD OR GPX OR Catalase

(ii) "metabolic hepatitis" OR "metabolic liver" OR "Non Alcoholic Fatty Liver Disease" OR "Nonalcoholic Fatty Liver Disease" OR "Fatty Liver" OR “Nonalcoholic Fatty Livers" OR "Nonalcoholic Liver" OR "Nonalcoholic Fatty" OR “Nonalcoholic Fatty Liver" OR "Nonalcoholic Steatohepatitis" OR "Nonalcoholic Steatohepatitides" OR "Steatohepatitides" OR "Nonalcoholic Steatohepatitis" OR "cirrhosis" OR "carcinogenesis" OR “hepatocarcinoma" OR "hepatocellular carcinoma" OR "carcinoma" OR "hepatoma" OR malignant hepatoma"

(iii) "mice" OR "mouse" OR "mus musculus" OR "clinical studies" OR "therapeutic"

(iv) "pesticides" OR "herbicides" OR "insecticides" OR "fungicides" OR "plant protection product"

(v) "oxidant" OR "antioxidant" OR "diet" OR "cholesterol" OR "fructose" OR "nutrients" OR "micronutrients", "macronutrients" OR "fat" OR "western diet" OR "sugars" OR "fibers" OR "vitamins" OR "fatty acid". 
(vi) "Probiotic" OR "microbiota" OR “dysbiosis".

\section{Role of Oxidative Stress in NAFLD Pathogenesis}

Oxidative stress is defined as an imbalance between the cellular levels of antioxidants and that of pro-oxidants, including ROS and reactive nitrogen species (Figure 2), which causes cellular damage and, in most cases, cell death. In healthy physiological conditions, cells maintain a basal level of ROS to promote the balanced redox signaling required for various processes such as cell metabolism, cell differentiation and survival, immune defense, and modulation of transcription factor activity and epigenetic state [226]. Upon oxidative stress, the antioxidant enzyme superoxide dismutase (SOD) generates hydrogen peroxide $\left(\mathrm{H}_{2} \mathrm{O}_{2}\right)$ from the superoxide radical $\left(\mathrm{O}_{2}{ }^{-}\right)$, which is then processed to oxygen $\left(\mathrm{O}_{2}\right)$ and water $\left(\mathrm{H}_{2} \mathrm{O}\right)$ through glutathione peroxidase $(\mathrm{Gpx})$ or catalase enzyme activities (Figure 2) [231]. Within cells, ROS are mainly produced in the mitochondria, the peroxisomes, and the ER, but cytoplasmic production of ROS also occurs. High levels of ROS alter these organelles, further enhancing oxidative stress and creating a vicious circle.

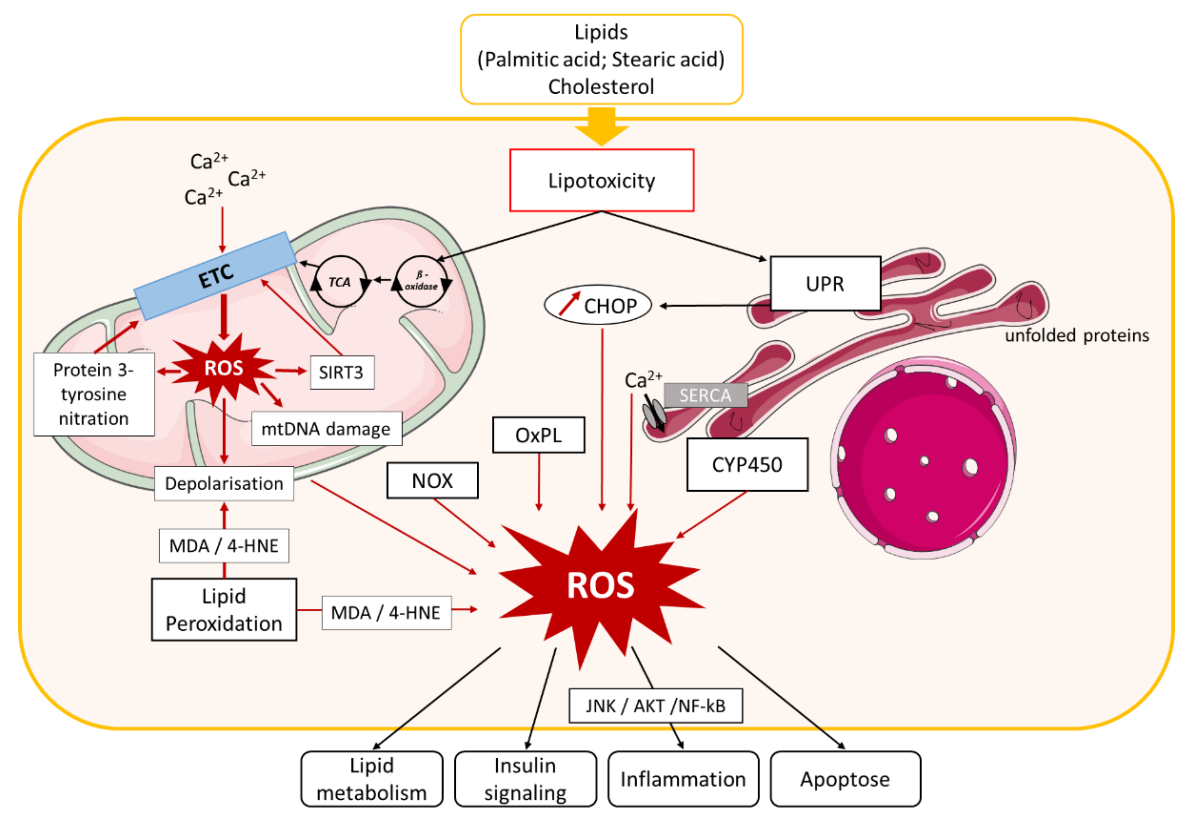

Figure 2. Role of oxidative stress in NAFLD. Lipid and cholesterol accumulation in hepatocytes causes lipotoxicity, resulting in activation of different pathways involved in oxidative stress. Lipid entry and alteration of mitochondrial $\mathrm{Ca}^{2+}$ homeostasis cause electron transport chain (ETC) dysfunction that leads to mitochondrial reactive oxygen species (ROS) production, which in turn induces Sirtuin (SIRT)3 expression, protein 3-tyrosine nitration, mitochondrial DNA damage, and membrane depolarization. SIRT3 and protein nitration also cause ETC dysfunction and exacerbate mitochondrial ROS production. Mitochondrial biogenesis dysfunction additionally induces ROS production. Lipotoxicity activates endoplasmic reticulum (ER) stress, leading to ROS production by (i) unfolded protein response (UPR) activation, which stimulates C/EBP homologous protein (CHOP) expression and (ii) $\mathrm{Ca}^{2+}$ homeostasis dysfunction. ROS generation in cytoplasm is induced by nicotinamide adenine dinucleotide phosphate (NADPH) oxidase (NOX) enzyme activation, oxidized phospholipids (OxPL), several cytochrome p450 enzymes (CYP450), and lipid peroxidation. ROS accumulation in hepatocytes leads to impairment of several pathways involved in NAFLD development, such as lipid metabolism, insulin signaling, inflammation, and apoptosis. Other abbreviations: mtDNA, mitochondrial DNA; TCA, tricarboxylic acid cycle; MDA, malondialdehyde; 4-HNE, 4-hydroxynonenal; SERCA, ER calcium pump sarco/endoplasmatic reticulum $\mathrm{Ca}^{2+}$-ATPase; JNK, c-Jun N-terminal kinase; NF-kB, nuclear factor-kappa B. 


\subsection{Evidence for a Role of Oxidative Stress in NAFLD}

Oxidative stress promotes activation of enzymatic or non-enzymatic-mediated antioxidant mechanisms that counteract ROS production. Both clinical and experimental studies show that these antioxidant pathways are modulated during NAFLD progression. In fact, activity of the antioxidant enzymes SOD and Gpx increases in patients with NAFLD (Figures 2-5) [232]. In vitro, hepatic stellate cells deficient for the glutathione peroxidase 7 (Gpx7) isoform present increased expression of profibrotic and pro-inflammatory genes in response to FFA exposure. Consistent with these results, overexpression of GPX7 in these cells decreases ROS generation and expression of profibrotic and pro-inflammatory genes. In vivo, Gpx7 deficiency exacerbates choline-deficient, L-amino-defined, high-fat diet-induced NASH fibrosis [233]. The expression of glutaminase 1 (GLS1) is increased in both NASH preclinical mouse models and clinical NASH liver biopsies. GLS1 promotes glutamine fueling of anaplerotic mitochondrial metabolism resulting in increased ROS production. In methionine choline-deficient (MCD) diet-fed mice, GLS1 inhibition decreases hepatic TG accumulation by restoring VLDL TG export and diminishes oxidative stress by lowering ROS production. GLS1 deficiency in this model is also associated with decreased lipid peroxidation [234]. Paraoxonase-1 is a liver antioxidant enzyme that hydrolyses peroxide and lactones associated with lipoproteins. In a cohort of 81 patients with NAFLD, the serum Paraoxonase-1 concentration was decreased, which could reflect higher oxidative stress in these patients [235].

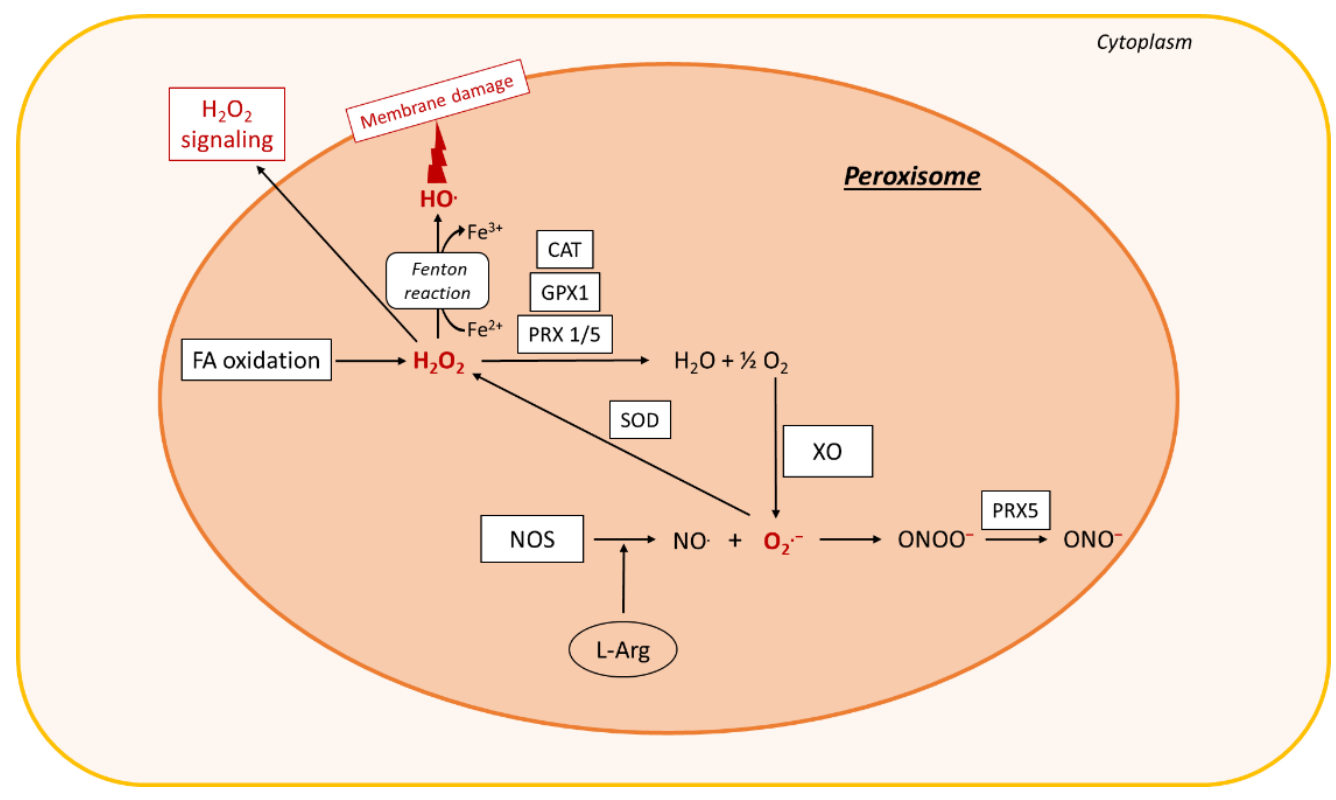

Figure 3. ROS production in peroxisomes. In peroxisomes, fatty acid (FA) oxidation leads to the formation of $\mathrm{H}_{2} \mathrm{O}_{2}$, which is decomposed by the antioxidant enzymes GPX1, CAT, or peroxiredoxin (PRX) 1 or 5, leading to the formation of $\mathrm{O}_{2}$ and $\mathrm{H}_{2} \mathrm{O} \cdot \mathrm{O}_{2}$ can react with $\mathrm{XO}$ to produce $\mathrm{O}_{2}{ }^{-}$. Nitric oxide synthase (NOS) interaction with L-arginine (L-Arg) leads to the formation of NO, which interacts with $\mathrm{O}_{2} \cdot{ }^{-}$to form $\mathrm{ONOO}^{-}$. $\mathrm{ONOO}^{-}$is converted by Prx5 to a peroxynitrite radical ONO . SOD2 dismutates $\mathrm{O}_{2} \cdot{ }^{-}$to $\mathrm{H}_{2} \mathrm{O}_{2}$. The Fenton reaction also occurs in peroxisomes and leads to membrane damage. The $\mathrm{H}_{2} \mathrm{O}_{2}$ is then exported to the cytoplasm, where it acts as a signaling molecule that exacerbates oxidative stress. Other abbreviations: $\mathrm{XO}$, xanthine oxidase; CAT, catalase; GPX1, glutathione peroxidase 1; $\mathrm{SOD}$, superoxide dismutase; $\mathrm{Fe}^{2+}$, ferrous iron; $\mathrm{O}_{2}$, oxygen; $\mathrm{H}_{2} \mathrm{O}$, water; $\mathrm{NO}$, nitric oxide; $\mathrm{ONOO}^{-}$, peroxynitrite; $\mathrm{HO}$, hydroxyl radical; $\mathrm{ONO}$, peroxynitrite radical; $\mathrm{O}_{2}{ }^{-}{ }^{-}$, superoxide; $\mathrm{H}_{2} \mathrm{O}_{2}$, hydrogen peroxide. 


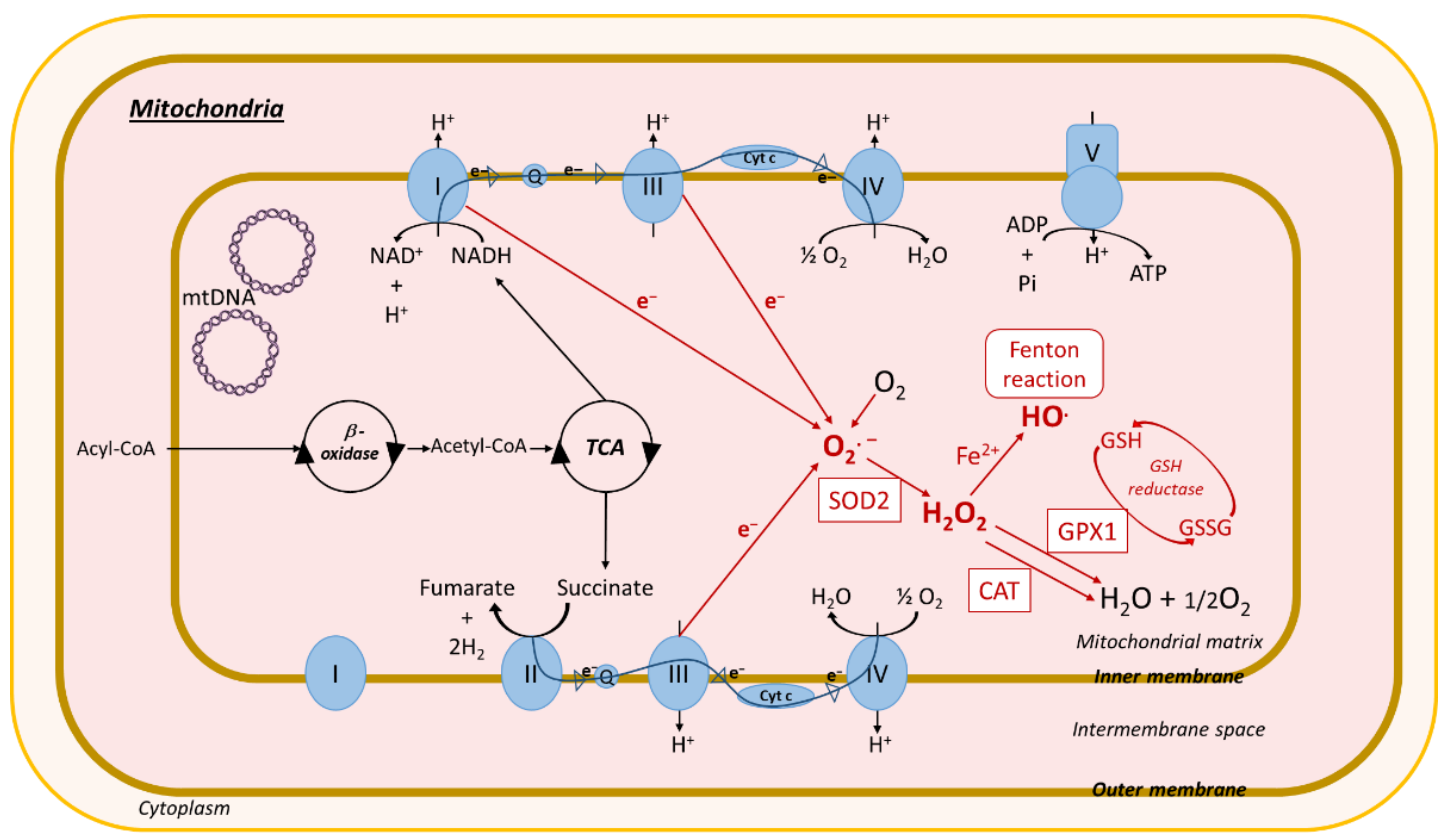

Figure 4. ROS production in mitochondria. Acyl-CoA imported into the mitochondria is converted by $\beta$-oxidation into acetyl-CoA, which enters the tricarboxylic acid cycle (TCA), resulting in the production of nicotinamide adenine dinucleotide (NADH) and succinate. Mitochondria have two respiratory chains composed of different complexes: (i) complexes I (NADH-ubiquinone oxidoreductase), III (cytochrome b-c1), and IV (cytochrome $c$ oxidase). Complex I reduces NADH to NAD ${ }^{+}$and $\mathrm{H}^{+}$after electron (e-) release, and (ii) complexes II (succinate-quinone oxidoreductase), III, and IV. Complex II catalyzes the dehydrogenation and oxidation of succinic acid into furamate and $2 \mathrm{H}_{2}$ after e-release. Released electrons pass through complexes and other molecules in the mitochondria inner membrane ubiquinone (Q) and cytochrome c (cyt c). Complex V (F1F0-ATP synthase) uses the chemiosmotic proton gradient to power the synthesis of ATP from adenosine-diphosphate (APD) and Pi. In red: impairment of the electron transport chain results in the leakage of $\mathrm{e}-$ that react directly with oxygen to form the superoxide anion radical transformed in $\mathrm{H}_{2} \mathrm{O}_{2}$ through SOD2 activity. $\mathrm{H}_{2} \mathrm{O}_{2}$ can react with $\mathrm{Fe}^{2+}$ to form $\mathrm{OH}$ (Fenton reaction). $\mathrm{H}_{2} \mathrm{O}_{2}$ is processed into $\mathrm{H}_{2} \mathrm{O}$ and $\mathrm{O}_{2}$ by the antioxidant enzymes GPX1 and catalase. Mitochondrial ROS production causes oxidative mtDNA, lipid, and protein damage. Other abbreviations: CAT, catalase; GPX1, glutathione peroxidase 1; SOD2, superoxide dismutase; $\mathrm{Fe}^{2+}$, ferrous iron; $\mathrm{O}_{2}$, oxygen; $\mathrm{H}_{2} \mathrm{O}$, water; $\mathrm{HO}$, hydroxyl radical; $\mathrm{O}_{2}{ }^{-{ }^{-}}$, superoxide; $\mathrm{H}_{2} \mathrm{O}_{2}$, hydrogen peroxide; ATP, adenosine-triphosphate; $\mathrm{Pi}$, inorganic phosphate; $\mathrm{NAD}^{+}$, nicotinamide adenine dinucleotide; $\mathrm{H}^{+}$, hydrogen; mtDNA, mitochondrial DNA; GSH, glutathione; GSSG, oxidized glutathione; ROS, reactive oxygen species.

The peroxisomal antioxidant enzyme catalase plays a key role in protecting cells from oxidative damage by reducing $\mathrm{H}_{2} \mathrm{O}_{2}$ concentration (Figure 3). In HFD-fed mice deficient for catalase, lipid accumulation and oxidative stress are exacerbated [236]. These mice develop an imbalanced redox status in peroxisomes because of increased $\mathrm{H}_{2} \mathrm{O}_{2}$ levels, which in turn induces ER stress in the liver. Catalase inhibition in HepG2 cells increases ROS production by peroxisomes, causing ER stress and FA accumulation [237]. In line with this observation, human liver cells with impaired peroxisome biogenesis show decreased ER stress, oxidative stress, and apoptosis [238].

Expression of genes encoding antioxidant enzymes and regulators of the glutathione pathway (glutamate-cysteine ligase catalytic subunit, glutamate-cysteine ligase modifier subunit, GPX2) is regulated by the transcription factor erythroid2-like 2 (Nrf2) [239]. Upon oxidative stress, Nrf2, which is anchored in the cytoplasm via binding to Keap1, dissociates from it and translocates into the nucleus, where it interacts with specific DNA sequences called antioxidant response elements in the promoter of its target antioxidant enzyme genes [240]. Nrf2 expression is increased in the 
first stage of NAFLD in preclinical models [241], and pharmacological activation of Nrf2 in mice fed a high-fat and high fructose diet decreases NASH parameters (insulin resistance, weight gain, TG, ALT) via the transcriptional regulation of genes involved in inflammation, apoptosis, fibrosis, ER stress, and oxidative stress [239]. Consistently, Nrf2 deficiency in mice fed an MCD or an HFD promotes progression of steatosis to NASH by increasing oxidative stress, inflammation, and hepatic FA accumulation [242,243]. In addition, Nrf2-deficient mice fed an HFD develop a more severe NASH phenotype than their WT counterparts [241]. In in vivo and in vitro models of NAFLD, the reduction of Nrf2 expression by microRNA is associated with a decreased expression of its target genes, heme oxygenase, $\operatorname{Sod} 2$, and $\mathrm{NAD}(\mathrm{P}) \mathrm{H}$ dehydrogenase quinone 1 and an increase in ROS production [244]. Nrf2 also directly affects lipid metabolism by activation of genes involved in FA oxidation (acyl-CoA Oxidase 2, carnitine palmitoyltransferase 1), TG export (apolipoprotein $\mathrm{B})$, and the lipogenic transcription factor sterol regulatory element binding transcription factor 1 (Srebp-1) [239]. Nfr2 deficiency in HFD-fed mice diminishes phosphorylation of acetyl-CoA carboxylate (ACC), a rate-limiting enzyme of hepatic FA synthesis, and thus increases its activity [241]. Collectively, these data indicate that alterations in antioxidant pathways are associated with NAFLD, suggesting a role of oxidative stress in disease progression.

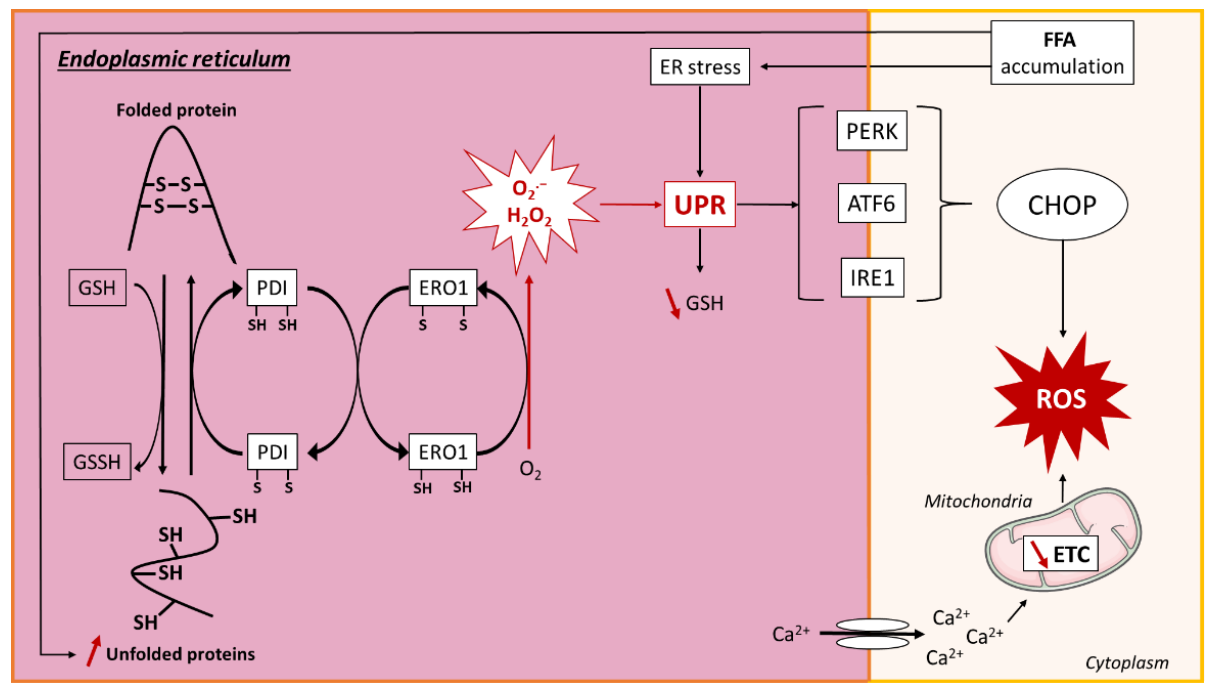

Figure 5. ROS production in endoplasmic reticulum. Lipid overload causes accumulation of unfolded proteins in the endoplasmic reticulum (ER) by the reduction of reduced glutathione (GSH) to oxidized glutathione (GSSH), resulting in the breakage of protein disulfide bonds $(\mathrm{SH})$. The ER resident proteins, protein disulfide isomerase (PDI) and ER oxidoreductin 1 (ERO1), are involved in disulfide bond formation and superoxide $\left(\mathrm{O}_{2}{ }^{-}\right)$and hydrogen peroxide $\left(\mathrm{H}_{2} \mathrm{O}_{2}\right)$ release through electron transfer. ROS production and ER stress activate the unfolded protein response (UPR), which leads to a decrease in GSH. UPR is regulated by three transmembrane proteins: protein kinase RNA-like ER kinase (PERK), activating transcription factor 6 (ATF6), and inositol-requiring signaling protein 1 (IRE1), which promote the transcription of CCAAT/enhancer-binding protein homologous protein $(\mathrm{CHOP})$ that further induces ROS generation. ER stress is associated with reduced sarco/endoplasmatic reticulum $\mathrm{Ca}^{2+}$-ATPase (SERCA) activity, leading to calcium leakage and decreased mitochondrial electron transport chain (ETC) activity, resulting in ROS production. Other abbreviations: $\mathrm{O}_{2}$, oxygen; FFA, free fatty acid; ROS, reactive oxygen species; $\mathrm{Ca}^{2+}$, calcium.

\subsection{Mechanisms of Oxidative Stress in NAFLD}

\subsubsection{Mitochondria-Mediated Oxidative Stress}

Mitochondria are intracellular sites of oxygen $\left(\mathrm{O}_{2}\right)$ consumption. In case of energy imbalance, such as lipid accumulation, mitochondria ROS production increases considerably because of mitochondrial respiratory chain alteration and a reduction in electron capture through various 
mechanisms discussed below (Figure 4). Generation of mitochondrial ROS results in impairment of the mitochondrial membrane potential generated by proton pumps and activation of the JNK (c-Jun N-terminal kinase) and AMPK (5' AMP-activated protein kinase) pathways. All of these mechanisms enhance oxidative stress and lipid accumulation and promote inflammation, thereby contributing to the development of obesity and metabolic diseases, including NAFLD [245].

Mitochondrial ROS production results from dysfunction in complexes I and II of the mitochondrial respiratory chain. Various mechanisms leading to this dysfunction and ROS production have been described in NAFLD. In ob/ob mice, the quantity of mitochondrial respiratory chain complex I is decreased. In this model, mitochondrial oxidative stress causes mitochondrial DNA (mtDNA) damage, resulting in the reduction of mtDNA-encoded subunits of respiratory chain complex I. mtDNA is in the mitochondrial matrix near the mitochondrial respiratory chain where most ROS are generated. Thus, it is particularly prone to oxidative damage compared with nuclear DNA, which is more protected inside the cell nucleus. Furthermore, mtDNA lacks protective histones, which together with the absence of an mtDNA repair system, makes it more susceptible to damage [246]. Mitochondrial complex I dysfunction can also arise from mitochondrial protein 3-tyrosine nitration by peroxynitrite anion. Peroxynitrite originates from a combination of nitric oxide (NO) with superoxide $\left(\mathrm{O}_{2} \cdot{ }^{-}\right)$, which are both elevated in ob/ob mice and in patients with NAFLD. In vitro, incubation of mitochondrial proteins from wild-type (WT) mice with peroxynitrite induces their 3-tyrosine nitration, which results in decreased complex I activity and mitochondrial oxygen consumption. This decrease is amplified by reduced expression of prohibitin, a protein that protects mitochondrial complexes against degradation [246]. Complex I or II activity is also regulated by the mitochondrial histone deacetylase sirtuin (SIRT) 3. Mice fed an HFD have decreased SIRT3 expression, which results in a higher level of membrane transport chain complex I acetylation, causing mitochondrial dysfunction. MCD-fed mice deficient in SIRT3 develop more severe liver lesions, inflammation, and fibrosis compared with WT mice [247]. The proper functioning of the mitochondrial respiratory chain requires ATP, and in turn, impaired ATP production leads to transport chain complex dysfunction. In NAFLD, oxidative phosphorylation (OXPHOS) and the TCA cycle are disturbed, which causes impaired ATP production leading to an alteration in mitochondrial respiration and ROS production. In patients with NASH, antioxidant capacity and ATP production decreases, which enhances hepatocellular damage and insulin resistance, promoting NAFLD progression [248].

Mitochondria are dynamic organelles, and fission and fusion are crucial for maintaining their function under environmental stress. Both processes are regulated by specific proteins, Fis- 1 and Drp-1 for fission and Mfn-2 for fusion, which show decreased expression in WD-fed mice, suggesting that mitochondrial dynamism is affected in NAFLD [249]. ROS accumulation in mitochondria leads to modification of several mechanisms associated with oxidative stress and NAFLD development. Phosphorylated JNK under lipotoxicity or ER stress conditions phosphorylates SH3-domain binding protein 5 at the outer mitochondrial membrane, leading to the inactivation of mitochondrial c-Src, which regulates the phosphorylation of respiratory chain components. This Src inactivation alters electron transport, which promotes increased ROS release [250]. Phosphorylated JNK is also associated with insulin resistance, which further suggests its involvement in NAFLD development [251]. Oxidative stress induced in HFD-fed mice causes liver damage through mitochondrial membrane potential alteration [245]. ROS accumulation in mouse models of NAFLD affects mitochondrial depolarization potential through the formation of aldehydes (malondialdehyde [MDA] and 4-hydroxynonenal [4-HNE]) by lipid peroxidation or an increase in mitochondrial sensitivity to $\mathrm{Ca}^{2+}$.

Mitochondrial depolarization is a dysfunction that appears early in NAFLD development and contributes to mitochondrial homeostasis deregulation. In fact, WD-fed mice show mitochondrial depolarization at an early stage of NASH, with an increased protein level of PINK1 (PTEN-induced kinase 1), a mediator of mitochondrial autophagy (mitophagy), which is associated with mitochondrial dysfunction. In these situations of mitochondrial depolarization, the mitophagic burden increases, mitochondrial biogenesis declines, and mitochondrial depletion occurs after 2 to 6 months. 
These alterations are thought to be important in promoting steatosis, inflammation, and progression to fibrosis [249].

The $\mathrm{ROS}_{2} \mathrm{O}_{2}$, produced by mitochondria, activates AMPK through modification of the ATP/ADP ratio [252], which further regulates antioxidant enzyme gene expression through $N r f 2$ activation [253]. The AMPK pathway may be activated by an antioxidant component Peroxiredoxin 5 (Prx5). Indeed, in HepG2 cells exposed to FFAs, mitochondrial Prx5 activates the AMPK pathway to regulate the activity of lipogenic enzymes (ACC, SREBP-1, FA synthase) [254]. AMPK stimulates glucose and FA oxidation by induction of $C P T-1$ and acyl-CoA dehydrogenase expression via PPAR gamma coactivator 1-alpha and PPAR $\alpha$ [253]. Thus, although the AMPK pathway represents a protective response against oxidative stress and lipid accumulation, prolonged oxidative stress alters this pathway, leading to lipid accumulation and further enhanced oxidative stress. A recent study showed that the AMP kinase pathway is inhibited in NASH, leading to the activation of caspase 6-associated cell death [255]. Similarly, other antioxidant responses may have deleterious effects. Early upregulation of uncoupling protein-2 $(U C P-2)$ during steatosis protects hepatocytes against ROS production through ATP production, whereas a further increase in UCP-2 during NASH leads to chronic ATP depletion [256].

Overall, in NAFLD, mitochondria are an important source of ROS because of alterations in complex I and II activity that initially lead to the activation of antioxidant mechanisms. However, during prolonged oxidative stress, these mechanisms participate in oxidative damage and enhance mitochondrial oxidative stress, thus contributing to the development of NAFLD (Figure 4).

\subsubsection{ER-Mediated Oxidative Stress}

The ER is an organelle connected to the nuclear membrane in eukaryotic cells and is abundant in hepatocytes because of their high metabolic activity. It has multiple functions including protein synthesis, folding, modification, and trafficking, and synthesis of lipids and steroid hormones. Alteration of ER homeostasis, i.e., ER stress, can induce oxidative stress (Figure 5). The ER stress response is defined by activation of the unfolded protein response (UPR) pathway. Prolonged ER stress increases the PKR-like ER protein kinase (PERK) and activated transcription factor (ATF) 6 pathways that both lead to ROS generation through the proapoptotic C/EBP homologous protein (CHOP), a specific protein of the ER stress response (Figure 5). CHOP is involved in oxidative stress induction in mouse models of type 2 diabetes and MCD-induced steatohepatitis [226,257]. Recently, ER stress was shown to be involved in lipogenesis and in the transition of NAFLD to NASH through caspase 2 induction [258]. ER also contributes to the regulation of calcium $\left(\mathrm{Ca}^{2+}\right)$ homeostasis and particularly $\mathrm{Ca}^{2+}$ storage in the ER lumen. In animal models of diabetes and obesity, the decreased activity of the ER $\mathrm{Ca}^{2+}$ pump sarco/endoplasmic reticulum $\mathrm{Ca}^{2+}$-ATPase (SERCA) in hepatocytes leads to ER stress and induces apoptosis [257]. Moreover, impaired $\mathrm{Ca}^{2+}$ homeostasis in the ER induces mitochondria dysfunction [226].

Other studies have provided evidence for the involvement of the $\mathrm{Ca}^{2+}$ flux in oxidative stress and ER stress induction. In Buffalo rat liver (BRL-3A) cells exposed to a high FFA concentration to mimic NAFLD, induction of oxidative stress stimulates transcription and translation of the protein calcium release-activated calcium channel protein 1 (Orai1), a plasma membrane protein involved in the $\mathrm{Ca}^{2+}$ cytosolic flux. The resulting increase in $\mathrm{Ca}^{2+}$ entry into the cell activates nuclear factor-kappa $\mathrm{B}(\mathrm{NF}-\mathrm{kB})$ signaling, which further exacerbates the $\mathrm{Ca}^{2+}$ flux, mitochondrial impairment, and ROS generation, enhancing ER stress. Other mechanisms activated by lipid accumulation and $\mathrm{Ca}^{2+}$ homeostasis impairment in the liver also enhance ER stress in NAFLD. For instance, in a mouse model of MCD-induced steatohepatitis, increased expression and activation of liver protein kinase C $\delta$ (PKC $\delta$ ) are associated with ER stress activation. Similar results have been obtained in vitro in mouse hepatic cells cultivated in a palmitic acid-enriched MCD medium. In addition, PKC $\delta$ deficiency reduces MCD- and palmitic acid-induced ER stress activation, hepatic TG accumulation, and cell death [259]. These effects may involve CHOP, because in a human hepatic cell line (L02) exposed to palmitic acid, PKC $\delta$ deficiency reduces ER stress through decreased $C H O P$ expression. In this model, PKC $\delta$ silencing 
also increases SERCA activity, which improves $\mathrm{Ca}^{2+}$ homeostasis [260]. In HFD-fed rats, increased plasma FFA is associated with increased expression of markers of oxidative stress and ER stress, as well as Orai1 and NF-kB [261]. Mitochondria and peroxisome functional alterations also can induce ER stress. For example, an imbalance in redox signaling in peroxisomes upon catalase inhibition induces FA accumulation, which leads to ROS production and ER stress [237] (Figure 5).

To summarize, ER stress induced by lipid accumulation during NAFLD promotes ER ROS production and calcium homeostasis disruption that both act to increase oxidative stress during disease progression (Figure 5). ER stress also modulates expression of proteins involved in lipid and glucose metabolism, thus contributing directly to hepatic lipid accumulation [262]. Finally, in addition to mitochondria and ER, the peroxisomes, which are important in $\mathrm{H}_{2} \mathrm{O}_{2}$ production by peroxisomal FA oxidation, contribute to oxidative stress in NAFLD (Figure 3) $[226,237,238,263]$.

\subsubsection{Cytoplasmic Production of ROS}

Patients with NAFLD present with altered expression of cytochrome P (CYP)450 enzymes, which are involved in detoxification, FA oxidation, inflammation, and oxidative stress (Figure 6) [264]. In these patients, for example, increased serum lipid peroxidation correlates with a higher level of CYP4A11. In contrast, in the hepatocyte cell line HepG2 exposed to FFA, CYP4A11 inhibition led to reduced ROS production associated with decreased lipid accumulation and reduced pro-inflammatory cytokine levels, such as tumor necrosis factor $\alpha$ (TNF- $\alpha$ ), interleukin (IL)-6, and IL-1 $\beta$ [265]. In HFD-fed mice, CYP4A deficiency reduces hepatic ER stress, apoptosis, insulin resistance, and steatosis, suggesting a role for CYP4A in NAFLD pathogenesis. CYP2E1, which is expressed in ER, mitochondria, and cytosol, is increased in experimental models of NAFLD and in patients with NASH, resulting in ROS generation and inactivation of SOD and catalase $[236,266]$. CYP2E1 has a high NOX activity that promotes lipid peroxidation $[265,266]$. Furthermore, overexpression of CYP2E1 in mice is associated with severe steatohepatitis and upregulation of antioxidant enzymes (SOD2, catalase, and GPX) [267]. CYP1A1 induces ROS production by the reduction of $\mathrm{O}_{2}$ to $\mathrm{H}_{2} \mathrm{O}_{2}$ and $\mathrm{O}_{2}{ }^{-}$. It also has a role in $\omega$-hydroxylation of PUFAs. The expression of CYP1A1 is enhanced in oleic acid-stimulated HepG2 cells. In these same cells, CYP1A1 small interfering RNA inhibits lipid peroxidation, whereas overexpression of CYP1A1 stimulates lipid peroxidation and reduces SOD expression. Collectively, these observations unveil a regulatory role for CYP1A1 in hepatic lipid peroxidation [264].

CYP450 epoxygenase-derived epoxyeicosatrienoic acids (EETs) are a class of lipid mediators that are abundant in liver and that mediate cytoprotective and anti-inflammatory properties. A CYP450-induced EET increase in HFD-fed mice protects against NAFLD progression. Moreover, overexpression of the CYP2J2 leads to higher EET levels in serum that are associated with decreased hepatic TG levels, inhibition of the NF- $\mathrm{B} / \mathrm{JNK}$ signaling pathway, and increased antioxidant enzyme levels. Treatment of HepG2 cells with EET protects against palmitic acid-induced lipotoxicity, oxidative stress, and inflammation [268].

In cytosol, ROS are also produced by many enzymes including xanthine oxidase (XO), cyclo-oxygenase lipoxygenase, and NOX (Figure 6) $[226,269,270]$. NOX-mediated $\mathrm{H}_{2} \mathrm{O}_{2}$ production causes liver damage [271] and induces a pro-inflammatory response [269]. Patients with NAFLD have a higher NOX2 activity and increased NOX2-derived peptide, a marker of systemic NOX activation [271,272]. In one cohort of children with NAFLD, NOX2 activity increased in parallel with disease severity [271]. Furthermore, HFD-fed mice deficient in NOX2 develop steatosis but not NASH because of reduced OXPHOS dysfunction [273]. In agreement with this finding, NOX2-induced cellular oxidative stress causes inhibition of OXPHOS activity induced by FFA treatment [270]. Modulation of NOX expression also has been reported in experimental models. HFD-fed mice fed have increased NOX expression and activity [273], and NOX1 expression is increased in a mouse model of obesity [274], leading to ROS generation associated with nitrotyrosine protein expression that counteracted oxidative damage [275]. NOX1 also induces ROS production in a mouse model of steatosis [274]. 


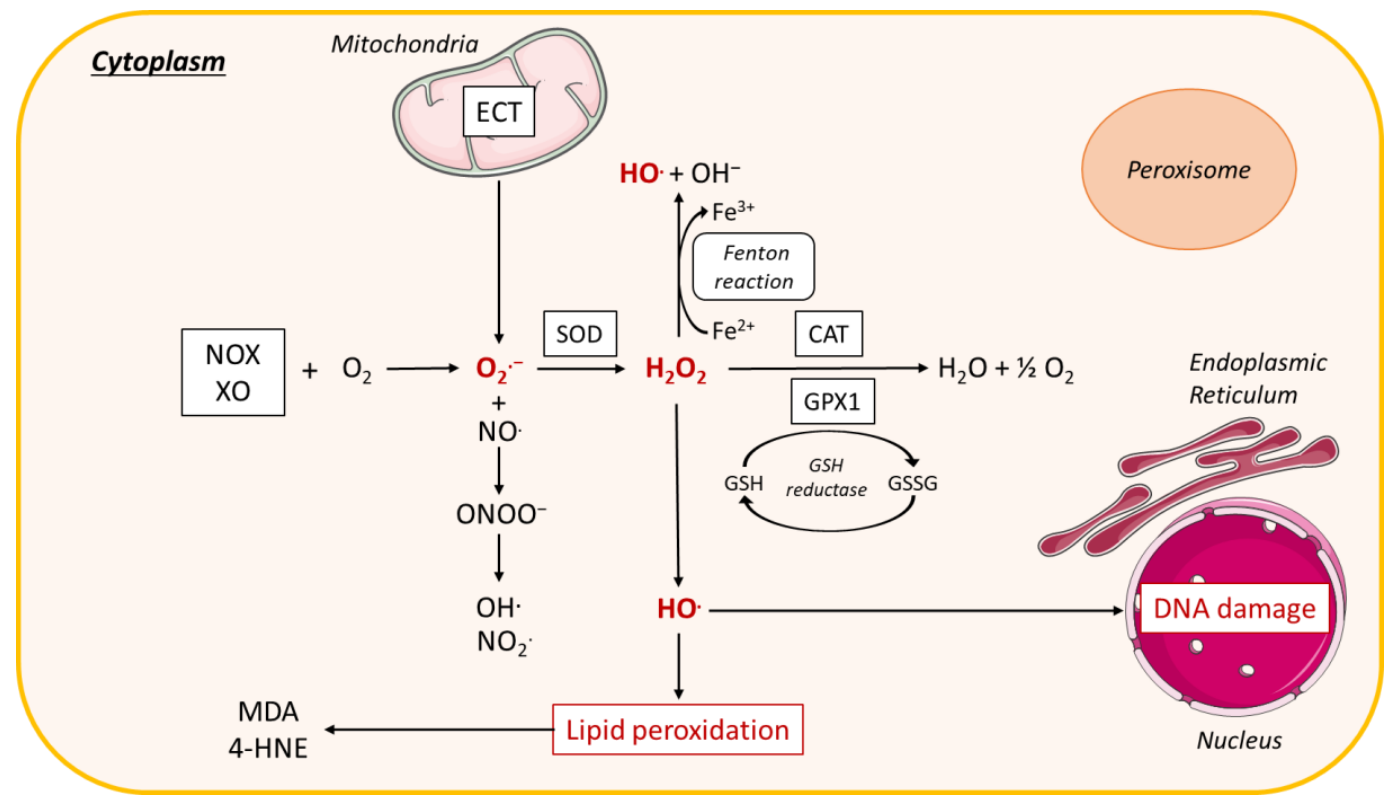

Figure 6. ROS production in the cytoplasm. In the cytoplasm, interaction of NADPH oxidase (NOX) and xanthine oxidase $(\mathrm{XO})$ with oxygen $\left(\mathrm{O}_{2}\right)$ leads to the formation of superoxide radical $\left(\mathrm{O}_{2}{ }^{-}\right)$. $\mathrm{O}_{2} \cdot{ }^{-}$dismutation by the antioxidant enzyme superoxide dismutase (SOD) forms hydrogen peroxide $\left(\mathrm{H}_{2} \mathrm{O}_{2}\right)$, which is decomposed to $\mathrm{O}_{2}$ and water $\left(\mathrm{H}_{2} \mathrm{O}\right)$ by the enzyme catalase (CAT) or the enzyme glutathione peroxidase 1 (GPX1), leading to the oxidation of reduced GSH into glutathione disulfide (GSSG). Reactive nitrogen species (RNS) are derived from nitric oxide ( $\mathrm{NO}$ ) and superoxide $\left(\mathrm{O}_{2} \cdot{ }^{-}\right)$ produced via specific enzymes such as NADPH oxidase; the reaction of $\cdot \mathrm{NO}$ with $\mathrm{O}_{2} \cdot{ }^{-}$produces peroxynitrite $\left(\mathrm{ONOO}^{-}\right)$. $\mathrm{ONOO}^{-}$can react with other molecules to form additional types of RNS including nitrogen dioxide $\left(\mathrm{NO}_{2} \cdot\right)$ as well as other types of chemically reactive free radicals $(\cdot \mathrm{OH})$. $\mathrm{H}_{2} \mathrm{O}_{2}$ forms a hydroxyl radical (HO·), which causes lipid peroxidation leading to malondialdehyde (MDA) and 4-hydroxynonenal (4-HNE), or interacts with DNA causing DNA damage. $\mathrm{H}_{2} \mathrm{O}_{2}$ can also react with ferrous iron $\left(\mathrm{Fe}^{2+}\right)$ to form hydroxyl radical $(\mathrm{OH} \cdot)$ and $\mathrm{OH}^{-}$, called the Fenton reaction. Other abbreviations: NADH, nicotinamide adenine dinucleotide; $\mathrm{H}_{2} \mathrm{O}_{2}$, hydrogen peroxide; DNA, Deoxyribonucleic acid; $\mathrm{XO}$, xanthine oxidase; $\mathrm{ECT}$, electron transport chain; $\mathrm{H}_{2} \mathrm{O}$, water.

In humans, NOX4 mRNA expression is upregulated in the liver of patients with NASH $[275,276]$. The NOX4 single nucleotide polymorphism rs3017887 is associated with increased ALT levels in liver biopsies from patients with NAFLD, indicating hepatocyte damage [269]. In a mouse model of diet-induced NAFLD, hepatocyte-specific deletion of NOX4 or its pharmacological inhibition reduces oxidative stress and fibrosis. Cell culture findings show that NOX4 promotes oxidative stress by ER stress activation [276]. In summary, increased NOX isoform expression and activity are associated with NAFLD and lead to oxidative stress induction via ROS generation concomitant with activation of ER and mitochondrial stress (Figures 4 and 5).

Oxidized phospholipids (OxPLs) play a role in oxidative stress induction through generation of cellular ROS, which promote fibrosis and inflammation that result in NASH progression. OxPLs are produced upon overnutrition or in patients with NAFLD. Treatment of primary hepatocytes from $\mathrm{Ldlr}^{-/-}$hyperlipidemic mice with an OxPL mixture promotes ROS accumulation in the cytoplasm and all organelles, resulting in mitochondrial dysfunction [277]. Treatment of the immortalized human hepatic stellate cell line with OxPLs stimulates fibrogenic gene expression [278]. Furthermore, in a mouse model of NASH, the neutralization of OxPL decreases inflammatory mechanisms [277]. Toll-like receptor (TLR)-4 and TLR-2 are expressed in Kupffer cells and stellate cells, which are associated with fibrosis. Mice fed an HFD supplemented with lecinoxoids (synthetic OxPLs), which inhibit these TLRs, show reduced liver fibrosis and inflammation (reduced IL-1B and IL-6) [279]. Furthermore, the neutralization of OxPL in a mouse model of NAFLD inhibits progression to HCC [277]. 
Iron metabolism, which is modified in patients with NAFLD [75,280-282], leads to ROS generation because of the ability of the ferrous iron to catalyze the production of $\mathrm{OH}^{-}$from $\mathrm{H}_{2} \mathrm{O}_{2}$, known as the Fenton reaction [257] (Figures 2-4). This point is further developed below in Section 5.

\subsubsection{Gut Microbiota and Liver Oxidative Stress}

Mice lacking the gut microbiota (germ-free mice) display an altered hepatic pool of glutathione [283]. The gut microbes also alter levels of amino acids and $\mathrm{N}$-acetylated amino acids circulating in the mouse portal vein, affecting host amino acid and glutathione metabolism in the intestine and the liver [284]. A recent study showed that the gut microbiome induces the Nrf2 antioxidant response pathway in the liver [285] and that exogenous administration of Lactobacilli could amplify this response and protect against oxidative liver injury. Of great interest, these authors identified a Lactobacilli-derived metabolite (namely 5-methoxyindoleacetic acid) that could activate hepatic Nrf2 and in part mediate these beneficial effects. The relevance of this gut-liver mechanism in humans remains to be studied.

Unhealthy eating modifies the gut microbiota, as others have reviewed [286,287]. This dysbiosis participates in the development of metabolic diseases and plays a major role in NAFLD pathogenesis [288,289]. In fact, the development of NAFLD correlates with (i) dysbiosis; (ii) a leaky intestinal barrier; (iii) impaired mucosal immunity; (iv) bacteria and bacterial components reaching the liver through the portal vein, as well the bacterial metabolites such as lipopolysaccharides, trimethylamine-N-oxide, N,N,N-trimethyl-5-aminovaleric acid, and endogenous ethanol; and (v) impaired bile acid homeostasis [286,287]. These alterations participate in increased hepatic inflammation and oxidative stress and promote NAFLD development and progression to NASH.

Altogether, whereas the role of oxidative stress in NAFLD pathogenesis has been demonstrated in both clinical and animal studies, the underlying mechanisms are complex and not completely understood. Alterations in mitochondrial respiratory complex activity because of lipid accumulation in NAFLD make the mitochondria the main source of ROS in this condition. ER stress, cytochromes, NOX, and OxPLs are also key components in ROS generation. The consequences of ROS production in NAFLD are enhanced oxidative stress and altered lipid metabolism, which further promote lipid accumulation. In addition, increased ROS production may modulate insulin signaling and inflammatory processes, thus promoting insulin resistance and inflammation, which are important features of NAFLD progression [226] (Figure 2); however, the specific mechanisms underlying oxidative stress-promoted NAFLD need further study. Furthermore, several environmental factors, such as the nutrients and contaminants discussed below, affect oxidative stress in NAFLD.

\section{Oxidative Stress in NAFLD: Role of Nutrients}

An unhealthy lifestyle is strongly associated with NAFLD. Of note, dietary constituents are key factors in NAFLD pathogenesis. Such factors include a high intake of calories and an excessive consumption of saturated fats, refined carbohydrates, and animal proteins. Several nutrients are well known to affect the metabolic pathways leading to hepatic fat accumulation in the first steps of NAFLD development. Accumulating data also support the idea that diet-mediated alterations include increased ROS production and oxidative stress, which are key factors in the progression of NAFLD to NASH, as noted above (Figure 7). Given the essential role of nutrition in the etiology of NAFLD, several epidemiological studies have evaluated its association with dietary habits.

\subsection{Dietary Oxidants in NAFLD}

A correlation between consumption of different nutrients and oxidative stress has been previously shown in patients with NASH. Intake of saturated fat is associated with a lower ratio of reduced to oxidized glutathione (GSH/GSSG), suggesting a pro-oxidant effect. In contrast, consumption of fiber, MUFAs, PUFAs, vitamin E, selenium, and folate protect against oxidative stress [290]. 


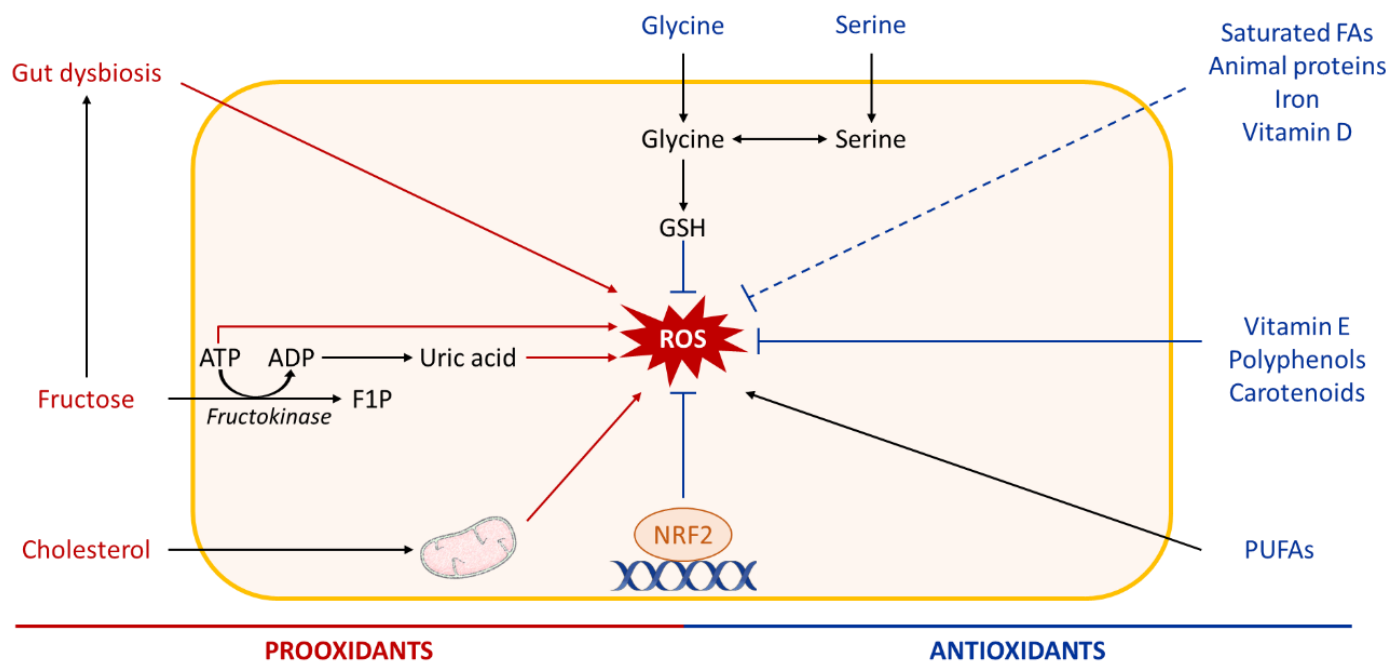

Figure 7. Role of nutrients in hepatic ROS production. High intake of diets rich in fructose or cholesterol promotes hepatic oxidative stress. Fructose metabolism leads to adenosine triphosphate (ATP) depletion and uric acid production, which both trigger reactive oxygen species (ROS) generation in the liver. High fructose consumption can also cause gut dysbiosis, which influences the liver oxidative status. Dietary cholesterol induces mitochondrial dysfunction and further mitochondrial ROS production. In contrast, several micronutrients such as vitamins, polyphenols, carotenoids, some amino acids (glycine, serine), and others have antioxidant properties and may be beneficial in NAFLD. Other abbreviations: ADP, adenosine diphosphate; F1P, fructose-1-phosphate; Nrf2, nuclear factor erythroid-2-related factor 2; GSH, reduced glutathione; FAs, fatty acids; PUFAs, polyunsaturated fatty acids.

HFDs induce obesity, insulin resistance, and hepatic steatosis. As noted above, an excess of lipids in hepatocytes is associated with lipotoxicity and mitochondrial overload, resulting in impaired FA catabolism and ROS production. Increased exogenous FA delivery by liver perfusion or by HFD increases mitochondrial oxidative metabolism, resulting in hepatic oxidative stress during NAFLD in mice [248]. Of interest, FA storage as TG, which avoids accumulation of hepatic FFAs, protects against hepatic lipotoxicity and oxidative stress [291]. In line with this observation, the level of TG and free cholesterol increases in the liver in patients with NAFLD, whereas the level of FFAs is unaltered [292].

A limited number of studies have assessed the relationship between dietary saturated FA intake and oxidative stress. Medium-chain saturated FAs have shown antioxidant effects in rats through reduced lipid peroxidation and increased activity of antioxidant enzymes [293,294]. In contrast, saturated FAs in the steatotic rat liver induce hepatocyte ER stress and apoptosis [295]. In elderly Japanese patients, a correlation has been reported between high consumption of saturated FAs, particularly short-chain saturated FAs and medium-chain saturated FAs, and decreased urinary 8-hydroxy-2'-deoxyguanosine (an oxidative stress marker) and ameliorated hypertension [296]. Overall, the effect of saturated FAs on oxidative stress in NAFLD remains unclear and needs further investigation. Differences in FA chain lengths may contribute to differences in their effects on oxidative stress: short-chain saturated FAs and medium-chain saturated FAs may be antioxidant, whereas long-chain saturated FAs increase oxidative stress.

In addition, a high ratio of omega- 6 to omega- 3 FAs reduces mitochondrial respiratory functions and increases ROS levels in human hepatoma cells. Decreasing this ratio prevents diet-induced NASH and hepatic oxidative stress in rats $[297,298]$.

FAs are not the only compounds that accumulate in the mitochondria. Cholesterol is consistently elevated in human and mouse fibrotic NASH, and its mechanistic link to NASH development has been explored recently [59]. In hepatocytes from a NAFLD rat model, mitochondrial cholesterol accumulation decreases mitochondrial glutathione, which is crucial for scavenging ROS produced during mitochondrial metabolism, and sensitizes mitochondria to inflammatory cytokines [299]. 
Mice fed a high-cholesterol diet show a modified transcriptome, including modulation of several pathways involved in cell death and oxidative stress. Cholesterol accumulation increases ROS generation, leads to expression of antioxidant genes such as SOD2, and modifies expression of genes regulating the glutathione pathway (decreased GPx-1, increased GPx-4) [300]. In addition, oxidation of free cholesterol generates oxysterols, which are elevated in NAFLD and may participate in lipid synthesis and inflammation [301]. In patients with NASH, cholesterol accumulation decreases mitochondrial membrane permeability and induces defective mitochondrial GSH transport from cytosol to the mitochondria [256].

Interactions among different lipid classes may play a role in oxidative stress induction. For example, dietary fat and cholesterol act in synergy to promote NAFLD progression through impairment of mitochondrial function and biogenesis. Mice fed a high-fat, high-cholesterol diet develop more severe liver lesions, including inflammation and fibrosis, and show mitochondrial dysfunction such as altered respiration, increased $\mathrm{H}_{2} \mathrm{O}_{2}$ production, and impaired ATP homeostasis, compared to each diet (high fat or high cholesterol) fed separately [302,303]. The combination of dietary cholesterol with PUFAs leads to high levels of oxidized peroxiredoxins and protein carbonyls, indicating severe hepatic oxidative stress [304]. Of interest, a ketogenic diet increases rat liver antioxidant capacity [305].

In the liver, fructose is mainly metabolized by fructokinase, which uses ATP to phosphorylate fructose into fructose-1-phosphate. Thus, fructose metabolism decreases ATP levels, resulting in oxidative stress induction and uric acid generation, which also has pro-oxidative effects $[50,306]$. Fructose drinking in rodents also induces gut microbiota changes and CYP2E1-dependent intestinal oxidative stress, which both lead to endotoxemia and increased severity of steatohepatitis with fibrosis [307]. Rats fed a diet rich in fructose for 3 weeks show decreased catalase activity and GSH levels in the liver, whereas the level of NOX and the content of protein carbonyl groups, a marker of oxidative stress, are increased [308,309]. These effects are associated with changes in carbohydrate metabolism and increased hepatic TGs, suggesting a switch towards lipid synthesis rather than mitochondrial oxidation, which may protect against ROS production [309]. A fructose-rich diet also causes oxidative damage to hepatic lipids, proteins, and mitochondrial DNA, as shown by increased lipid peroxidation and nitrotyrosine levels in the liver and higher levels of plasma 8-hydroxydeoxyguanosine generated by oxidative damage to DNA. In addition, administration of the antioxidant lipoic acid or an inhibitor of NOX protects against fructose-induced hepatic insulin resistance, oxidative stress, and inflammation, reinforcing the relationship between hepatic oxidative stress and high fructose intake $[308,310]$. Fructose intake also enhances hepatic oxidative stress of maternal HFD offspring because of decline in the antioxidant defense system [311].

In patients with NASH and hyperferritinemia, iron reduction by a combination of iron-restricted diet and phlebotomy reduces serum iron and ferritin levels, liver enzymes, and hepatic oxidative damage to DNA [312]. In preclinical models, iron excess leads to hepatic TG accumulation, but the effect on oxidative stress is controversial. For example, dietary iron supplementation enhances HFD-induced hepatic steatosis and inflammation, whereas no change in hepatic oxidative stress is observed [313]. In contrast, iron supplementation in genetically obese mice causes hepatocellular ballooning and hepatic oxidative stress by increasing lipid peroxidation and decreasing expression of antioxidant genes [314]. A recent study indicated that the hepatocyte-specific deletion of the iron chaperone, poly $\mathrm{r}(\mathrm{C})$ binding protein 1 (PCBP1), results in liver iron depletion, hepatic steatosis and inflammation, increased lipid peroxidation, and activation of the Nrf2 and glutathione pathways. Both an iron-restricted diet and treatment with vitamin $\mathrm{E}$ can prevent steatosis and hepatocyte damage associated with PCBP1 deficiency, suggesting that iron mediates its toxic effects in part through the production of ROS [315]. Liver biopsies of 222 patients (men and women) with NAFLD showed that serum ferritin levels, which are biomarkers of iron metabolism, are positively associated with a higher NAFLD activity score [316]. The relation between ferritin level and NAFLD is mostly significant in men and associated with hepatic iron deposition, fibrosis, and NASH [77,317]. A correlation between ferritin level and NAFLD development also has been observed in a cohort of postmenopausal women [317]. 
Collectively, observations from dietary interventions show that cholesterol and fructose promote oxidative stress in NAFLD pathogenesis. Meat processing of meat also causes protein oxidation, which may be associated with oxidative stress [318]. In addition, the interactions among different types of lipids may play a role in the induction of oxidative stress during disease development. The pro-oxidant effects of saturated lipids, animal-based proteins, and iron are not well understood and need further investigation in experimental and large-scale clinical studies. Although excess of certain nutrients is clearly associated with oxidative stress induction in NAFLD, other nutrients have antioxidant properties. Below, we discuss the antioxidant role of these nutrients in preventing NAFLD development.

\subsection{Dietary Antioxidants in NAFLD}

Several meta-analyses have demonstrated the effectiveness of omega-3 PUFA supplementation in the dietary management of NAFLD, especially for liver fat content, although a detailed mechanism of its effect on liver inflammation and fibrosis is still unclear [319-323]. Omega-3 PUFAs reduce liver TG accumulation mainly through regulation of hepatic lipid metabolism and inflammation [324]. In experimental studies, supplementation with omega-3 PUFAs, such as eicosapentaenoic acid (EPA) and docosahexaenoic acid (DHA), reduces HFD-induced steatosis in part through induction of antioxidant responses [325]. Furthermore, omega-3 PUFA supplementation reduces hepatic oxidative stress in HFD-fed mice, as shown by a decreased GSSG/GSH ratio and protein carbonylation content in the liver [326]. Omega-3 PUFA supplementation also reduces the WD-induced NOX pathway [327] and can decrease oxidative stress through indirect mechanisms such as Nrf2 upregulation because the oxidation products of DHA and EPA are potent Nrf2 activators [328]. Dietary DHA is more efficient than EPA in reducing WD-induced NASH and hepatic oxidative stress [327,329]. In humans, the effects of PUFAs on oxidative stress in NAFLD are less clear. According to a recent systematic review of clinical trials, the effect of omega-3 PUFAs on oxidative stress in human NAFLD is inconclusive and varies from study to study depending on the oxidative stress marker measured [323].

MUFAs are the main FAs found in extra-virgin olive oil, which is associated with the prevention of diet-induced liver oxidative stress [330]. However, a specific mechanism is unknown, and antioxidant compounds such as phenols, which are present in high quantity in extra-virgin olive oil, are more likely responsible for these beneficial effects [331].

A few dietary amino acids affect NAFLD pathogenesis in several ways, including gut epithelium integrity, inflammation, fibrosis, and glucose homeostasis. We will only briefly address amino acids here because a recent review has described their effects in some detail [332]. Branched-chain amino acids repress inflammation, apoptosis, and fibrosis by downregulation of the transforming growth factor- $\beta$ and $\mathrm{Wnt} / \beta$-catenin pathway, and steatosis and mitochondrial dysfunction by downregulating FA synthase and upregulating mTOR. Glutamine attenuates inflammation by upregulating PPAR $\gamma$. The $\alpha$-amino acids citrulline and arginine downregulate TLR- $4, \mathrm{TNF} \alpha, \mathrm{IL}-6$, and endotoxins, which ameliorates inflammation and apoptosis, and serine increases AMPK activity to repress steatosis and mitochondrial dysfunction. Serine is also a GSH precursor, and its supplementation has been reported to decrease hepatic steatosis in a proof-of-concept human study [333]. Of interest, glycine supplementation increases thermogenic activity in hepatic mitochondria, mitigates liver steatosis, improves insulin sensitivity, and reduces serum lipid levels by repressing p38, JNK, and TLR-4, and increasing glucagon-like peptide-1/glucagon [332]. Methionine also has an important hepatic impact because compromised levels in methyl-group donors result in alterations promoting the development of NAFLD in animal models and humans. In mice, both dietary methionine deficiency and high methionine supplementation induce anomalies associated with NAFLD progression, including an effect on lipid metabolism and one-carbon metabolic pathways disturbances. Oxidative and ER stress is also increased [334].

Choline, which is not an amino acid, is also an essential methyl donor, and its deficiency results in impaired VLDL secretion and hepatic fat accumulation and liver damage, including impaired 
mitochondrial function. The result is reduced FA oxidation and stimulated production of ROS with downstream deleterious effects. Of interest, the MCD diet has become a classical diet for triggering $\mathrm{NASH}$. The absence of two main ingredients, methionine and choline, alters mitochondrial $\beta$-oxidation and VLDL synthesis [335], causing relatively rapid fatty liver development, together with oxidative stress and modifications in NASH-promoting adipokine and cytokine profiles, contributing to liver injury [336]. MCD-fed rodents undergo significant weight loss and present with decreased serum TG, cholesterol, glucose, insulin, and leptin [337]. These effects are a limitation of this diet model because the metabolic profile it induces is very different from that of human NASH, which must be considered when using the MCD in studies [338].

Taurine is a sulfur-containing $\beta$-amino acid that is not used for protein synthesis. The main sources of taurine are fish, meat, and dairy. It has several health benefits, and people also take it as a supplement to improve physical performance. In a mouse NAFLD model, taurine treatment alleviated HFD-induced reduction of catalase and SOD activity, and, in HepG2 cells, it suppresses FA-induced lipid accumulation and reduces ROS production in concert with the FA-induced alteration in mitochondrial membrane potential. These findings supporting an antioxidative effect of taurine show that it can attenuate NAFLD progression in animals [339].

Micronutrients are required in microgram or milligram quantities for physiological functions, such as cellular metabolism and tissue function [340]. These compounds, including vitamins, minerals, and phytochemicals, are also important in NAFLD pathogenesis [72,341], mainly through modulation of anti-inflammatory and antioxidant pathways. Liver plays an essential role in micronutrient metabolism by contributing to their uptake, transport, and storage, and by producing binding, transport, and regulatory proteins required for their action at the cellular level [72]. Micronutrients with antioxidant capacity include vitamin D, vitamin E, and phytochemicals such as carotenoids and polyphenols.

Vitamin D is often deficient in liver diseases and is associated with NAFLD and NASH in epidemiological studies. In fact, the anti-inflammatory, antifibrotic, and antiproliferative effects of vitamin D on NAFLD and NASH have been documented in both human cohorts and animal models [342-345]. Preclinical models have provided critical information for designing possible related therapeutic strategies for the treatment of NAFLD/NASH [342].

Vitamin E supplementation in adults with NAFLD does not improve fibrosis but ameliorates hepatic steatosis and inflammation [346]. Animal studies show that vitamin E improves NAFLD/NASH by repressing oxidative stress and inflammation [347]. We have recently reviewed the impact of vitamin E on NAFLD/NASH more extensively [348].

Natural polyphenols found in vegetables, fruits, coffee, and wine are a class of phytochemicals that include several different compounds sharing a common phenolic structure. They are classified as flavonoids and non-flavonoids. Their beneficial effects mainly trace to their antioxidant properties, and they also influence glucose and lipid metabolism and exert anti-inflammatory, antifibrogenic, and antitumoral effects [349]. In addition, they reduce de novo lipogenesis by regulating the activity of SREBP-1c and stimulate FA $\beta$-oxidation possibly via activation of AMPK [350]. Furthermore, several compounds of the polyphenol family, including green tea catechins, curcumin, resveratrol, and quercetin, appear to reduce liver enzymes, lipid peroxidation, and inflammation markers [342]. Carotenoids also have beneficial effects on the liver, mainly through their antioxidant capacity and by regulating expression of genes involved in inflammation and lipid metabolism [351]. Furthermore, many other natural products present in the diet confer hepatoprotective effects by mechanisms related to improved gut dysbiosis and ameliorated intestinal barrier permeability, and inhibiting steatosis by mechanisms acting on inflammation, oxidative stress, fibrosis, and apoptosis [286].

\subsection{Gut Microbiota and Dietary Antioxidants in NAFLD}

Natural dietary supplements can support microbiota homeostasis or improve it when it is disturbed [286,287]. The use of probiotics (Lactobacillus and Bifidobacterium) can ameliorate 
NAFLD [352-355]. Similarly, liver health can be supported by well-planned consumption of several classes of food-derived compounds that are possibly involved in microbiota maintenance. Among these are functional oligosaccharides (fructo-oligosaccharides, galacto-oligosaccharides, and chitosan oligosaccharides) $[275,356,357]$. Dietary fiber is another, catabolized through fermentation by the lower gastrointestinal tract microbiota to short-chain FAs comprising butyrate, propionate, and acetate that ameliorate NAFLD pathogenesis [358,359]. The microbiota can convert functional amino acids, such as L-tryptophan, to indoles and its derivatives, which improve gut and liver health. In preclinical studies, oral administration of another amino acid, L-glutamine, has been proved protective against diet-induced NASH progression [287,360]. Carotenoids improve the gut barrier and immune homeostasis and, as noted, are known for their anti-inflammatory and antioxidant properties [361]. Polyphenols repress insulin resistance, oxidative stress, and inflammation and stimulate FA $\beta$-oxidation, which collectively confer a protective effect against NAFLD. The $\omega-3$ PUFAs have a broad range of beneficial effects in preclinical and clinical studies in preventing or treating NAFLD. They improve intestinal barrier integrity and thus reduce bacterial translocation, ameliorate bile acid homeostasis, and repress liver inflammation via activation of the nuclear farnesoid X receptor [287].

These effects of various compounds in interaction with the gut microbiota indicate that nutritional interventions offer promise in NAFLD/NASH prevention and treatment and that their implementation will evolve toward personalized dietary therapies with consideration of each patient's genomic, metabolic, and microbiotic profile. The doses of individual micronutrients appear to be important, with some doses offering benefits and others resulting in side effects [72]. In addition, oxidative stress is an important factor in cancer initiation but may also offer some beneficial toxicity against cancer cells. Thus, antioxidants could have harmful effects in patients with HCC, for instance. More studies investigating the long-term effects and outcomes in patients with advanced NASH and liver cancer are needed [362].

\section{Oxidative Stress in NAFLD: Role of Pesticides}

Insecticides, herbicides, and fungicides have shown pro-oxidative properties in various organs and tissues, including the liver (Table 3). Among the insecticides, neonicotinoid, pyrethroid, organophosphorus, and organochlorine compounds are the most often studied. Neonicotinoid-associated effects in various organs include the production of ROS [183], and reactive nitrogen species (RNS) [363]. Studies assessing the role of oxidative stress in permethrin- and deltamethrin-induced toxicity in animal models concluded that the toxicity of these compounds is mainly the result of their pro-oxidative properties. Consistent with this finding, natural antioxidants diminish deltamethrin-induced oxidative stress damage [364,365]. Permethrin-mediated ER stress was recently reported in hepatic cell lines [366]. Other pyrethroid pesticides also exhibit pro-oxidative properties in the liver, as shown in Table 3 [367-371], and various organophosphorus and organochlorine insecticides cause oxidative stress in animal liver [136,183,371,372]. Furthermore, several studies have reported the pro-oxidative properties of some herbicides $[151,153,154,221,373-376]$ and chemical families of fungicides (carbamate, benzimidazole, strobilurin, azoles, triazoles [159,377-383]) (Table 3). Liver oxidative stress is also reported in animals exposed to a mixture of pesticides $[168,193,384]$ (Tables 1 and 3). Collectively, these data underscore the pro-oxidative properties of insecticides, herbicides, and fungicides.

ROS can be produced from several sources during metabolism, as a result of biotransformation reactions of pesticides (herbicides, insecticides, fungicides, miticides) by CYP450 enzymes, which catalyze the oxidation reactions [192,385-387]. For example, oxidative stress generated by exposure to the insecticide permethrin is linked to the detoxifying activities of CYP450 enzymes, and other enzymes involved in oxidation and hydrolysis processes [364]. Organochlorine compounds such as DDT lead to an increased ROS production through activation of CYP450 gene expression involved in its detoxifying pathway in exposed rat liver [211]. The biotransformation reactions of organophosphorus compounds, during which an excess of free radicals is generated, also produces ROS [187]. 
Table 3. Impact of pesticide exposure on oxidative stats in in vivo models. Acceptable Daily Intake (ADI) values were from https://ephy.anses.fr/ and https: //ec.europa.eu/food/plant/pesticides/eu-pesticides-database/. ALT, alanine aminotransferase; AST, aspartate aminotransferase; BW, body weight; CYP, cytochrome P450; EROD, ethoxyresorufin-O-deethylase; MDA, malondialdehyde; GPX, glutathione peroxidase; GSH, reduced glutathione; GSSG, oxidized glutathione; GST, glutathione-S-transferase; IL-1 IL-6, Interleukin 1 and 6; ROS, reactive oxygen species; SIRT, sirtuin; SOD, superoxide dismutase; TNF $\alpha$, Tumor necrosis factor $\alpha$.

\begin{tabular}{|c|c|c|c|c|c|}
\hline Type of Pesticide & Chemical Family & $\begin{array}{c}\text { Active Substances } \\
\text { (ADI mg/kg BW/day) }\end{array}$ & Experimental Model & Oxidative Impacts & Refs. \\
\hline \multirow{4}{*}{ Insecticide } & \multirow{4}{*}{ Pyrethroid } & \multirow[b]{2}{*}{$\begin{array}{l}\text { B cypermethrin enantiomers } \\
\qquad(0.0016)\end{array}$} & $\begin{array}{l}\text { - } \quad \text { Zebrafish } \\
\text { - Pesticide in water at } 0.1 \text { to } 4 \mu \mathrm{g} / \mathrm{L} \\
\text { for } 4 \text { days }\end{array}$ & $\begin{array}{l}\text { - Changes in MDA content and in antioxidant } \\
\text { enzyme activities for some, but not } \\
\text { all enantiomers }\end{array}$ & [367] \\
\hline & & & $\begin{array}{l}\text { - } \quad \text { Male mice } \\
\text { faily oral gavage at } 5 \mathrm{mg} / \mathrm{kg} \mathrm{BW} \\
\text { for } 2,4 \text {, or } 6 \text { weeks }\end{array}$ & $\begin{array}{l}\text { - Increased hepatic ROS, GSH, and MDA } \\
\text { levels (1S-cis enantiomer) } \\
\text { - Changes in catalase and, to a lesser extent, } \\
\text { SOD activities }\end{array}$ & [368] \\
\hline & & \multirow{2}{*}{$\begin{array}{l}\text { Bifenthrin } \\
\quad(0.015)\end{array}$} & $\begin{array}{l}\text { - } \quad \text { Male and female rats } \\
\text { - } \quad \text { Daily gavage with } 5.8 \mathrm{mg} / \mathrm{kg} \mathrm{BW} \\
\text { for } 20 \text { or } 30 \text { days }\end{array}$ & $\begin{array}{l}\text { - } \quad \text { Increased liver MDA content } \\
\text { - Decreased liver antioxidant enzymes activity } \\
\text { (at } 30 \text { days) }\end{array}$ & [369] \\
\hline & & & $\begin{array}{l}\text { - } \quad \text { Male and female mice } \\
\text { - } \quad \text { Daily intraperitoneal injection of 2, } \\
4, \text { or } 8 \mathrm{mg} / \mathrm{kg} \text { BW for } 7 \text { days }\end{array}$ & $\begin{array}{l}\text { - Increased MDA and ROS levels, and SOD } \\
\text { activity at } 4 \text { or } 8 \mathrm{mg} / \mathrm{kg} \mathrm{BW}\end{array}$ & [370] \\
\hline Insecticide & Pyrethroid & $\begin{array}{l}\text { Lambda-cyhalothrin } \\
\quad(0.0025)\end{array}$ & $\begin{array}{l}\text { - } \quad \text { Male rats } \\
\text { Daily oral gavage with } 1,2,4 \text {, or } 8 \\
\mathrm{mg} / \mathrm{kg} \text { for } 6 \text { consecutive days }\end{array}$ & $\begin{array}{l}\text { - Increased total hepatic CYP content and } \\
\text { EROD activities } \\
\text { - Decreased GST and GPX and increased SOD } \\
2 \text { enzyme activities } \\
\text { - Increased expression of CYP genes and genes } \\
\text { involved in inflammatory processes, } \\
\text { oxidative stress, and apoptosis } \\
\text { - No change in ROS levels }\end{array}$ & [138] \\
\hline Insecticide & $\begin{array}{c}\text { Pyrethroid or } \\
\text { organophosphorus }\end{array}$ & $\begin{array}{l}\text { Deltamethrin (DTM) } \\
\quad(0.01) \\
\text { Or } \\
\text { Chlorpyrifos (CPF) } \\
(0.001)\end{array}$ & $\begin{array}{l}\text { Male rats fed a pesticide-enriched } \\
\text { diet for } 16 \text { weeks containing either } \\
\text { to chlorpyrifos alone }(1 \text { or } 15 \mathrm{mg} / \mathrm{kg} \\
\text { food/day) or deltamethrin alone }(5 \\
\text { or } 35 \mathrm{mg} / \mathrm{kg} \text { food/day) or the } \\
\text { mixture of chlorpyrifos and } \\
\text { deltamethrin at } 1 \mathrm{mg} / \mathrm{kg} / \text { day or } 5 \\
\mathrm{mg} / \mathrm{kg} / \text { day }\end{array}$ & $\begin{array}{l}\text { - Increased hepatic MDA content } \\
\text { - Changes in antioxidant enzyme activities in } \\
\text { rat fed CPF- or DTM- or } \\
\text { mixture-enriched diet }\end{array}$ & [371] \\
\hline
\end{tabular}


Table 3. Cont.

\begin{tabular}{|c|c|c|c|c|c|}
\hline Type of Pesticide & Chemical Family & $\begin{array}{l}\text { Active Substances } \\
\text { (ADI mg/kg BW/day) }\end{array}$ & Experimental Model & Oxidative Impacts & Refs. \\
\hline \multirow{3}{*}{ Herbicide } & \multirow{3}{*}{ Glycine derivate } & \multirow{3}{*}{$\begin{array}{l}\text { Glyphosate } \\
\quad(0.5)\end{array}$} & $\begin{array}{l}\text { - Male rats } \\
\text { Intraperitoneal injection every } 2 \text { days of } 50 \\
\mathrm{mg} / \mathrm{kg} \text { BW in the presence of absence of } 20 \\
\mathrm{mg} / \mathrm{kg} \mathrm{BW} \text { quercetin for } 15 \text { days }\end{array}$ & $\begin{array}{ll} & \text { Increased liver MDA content } \\
\text { - } & \text { Increased } \mathrm{H}_{2} \mathrm{O}_{2} \text { generation } \\
\text { - } & \text { Decreased liver metallothionein content } \\
\text { - } & \text { Decreased enzymatic antioxidant activity } \\
& \text { and non-enzymatic component level } \\
\text { - } & \text { Effects were suppressed in quercetin } \\
& \text { co-treated animals }\end{array}$ & [373] \\
\hline & & & $\begin{array}{l}\text { - Male rats } \\
\text { BW for } 25 \text { days }\end{array}$ & $\begin{array}{l}\text { - Increased serum MDA level at } 50 \mathrm{mg} / \mathrm{kg} \text { BW } \\
\text { - } \quad \text { Decreased hepatic SOD activity and } \\
\text { increased } \mathrm{H}_{2} \mathrm{O}_{2} \text { production at the highest } \\
\text { assessed dose } \\
\text { - Increased liver IL-1, IL-6, TNF-alpha, GPX2, } \\
\text { caspase, and SIRT1 mRNA levels }\end{array}$ & [153] \\
\hline & & & $\begin{array}{l}\text { - } \quad \text { Male rats } \\
\text { Oral exposure to Roundup through drinking } \\
\text { water }(0.05 \mu \mathrm{g} / \mathrm{L} \text { glyphosate) for } 2 \text { years }\end{array}$ & $\begin{array}{l}\text { Induction of oxidative stress (glutathione } \\
\text { metabolism) determined through analysis of } \\
\text { liver proteome and metabolome }\end{array}$ & [151] \\
\hline \multirow{5}{*}{ Herbicide } & Glycine derivate & $\begin{array}{l}\text { Glyphosate } \\
\quad(0.5)\end{array}$ & $\begin{array}{l}\text { - Caenorhabditis elegans } \\
\text { A } 30 \text {-min exposure to } 2.7 \%, 5.5 \% \text {, or } 9.8 \% \\
\text { glyphosate formulation (TouchDown } \\
\text { containing } 52.3 \% \text { glyphosate) }\end{array}$ & $\begin{array}{ll}\text { - } & \text { Inhibition of the mitochondrial electron } \\
\text { transport chain } \\
\text { - } \quad \text { Inhibition of proton gradient } \\
\text { - } \quad \text { Inhibition of ATP and } \mathrm{H}_{2} \mathrm{O}_{2} \text { production } \\
\text { - Upregulation of GST4 gene expression }\end{array}$ & [374] \\
\hline & Triazine & $\begin{array}{l}\text { Atrazine } \\
(0.02)\end{array}$ & $\begin{array}{l}\text { - } \quad \text { Male mice } \\
\text { Daily intraperitoneal injection of } 100 \text { to } 200 \\
\mathrm{mg} / \mathrm{kg} \text { BW for } 1 \text { week }\end{array}$ & $\begin{array}{l}\text { - } \quad \text { Decreased BW } \\
\text { - Slight but significant increase in hepatic SOD } \\
\text { activity at the highest dose }\end{array}$ & [221] \\
\hline & Aryloxy acid & $\begin{array}{l}\text { 2,4 dichlorophenoxyacetic } \\
\text { acid }(2,4 \mathrm{D}) \\
(0.02)\end{array}$ & $\begin{array}{l}\text { - Male rats } \\
\text { Daily oral gavage with } 15,75, \text { or } 150 \mathrm{mg} / \mathrm{kg} \\
\text { BW for } 28 \text { days }\end{array}$ & $\begin{array}{ll}\text { - } & \text { Increased liver weight } \\
\text { - } & \text { Increased serum levels of TG and } \\
\text { - } & \text { In-density lipoprotein cholesterol } \\
\text { - } & \text { Increased levels of saturated fatty acid and } \\
\text { - } & \text { Changes in antioxidant enzyme activities }\end{array}$ & [375] \\
\hline & \multirow{2}{*}{ Dinitro-aniline } & $\begin{array}{l}\text { Trifluralin } \\
(0.015)\end{array}$ & $\begin{array}{l}\text { - Male rat isolated mitochondria } \\
\text { - Exposure to } 1 \text { to } 100 \mu \mathrm{M}\end{array}$ & $\begin{array}{l}\text { - } \quad \text { Impairment of oxidative phosphorylation } \\
\text { - } \quad \text { Mitochondrial swelling } \\
\text { glutathione in levels }\end{array}$ & [376] \\
\hline & & $\begin{array}{l}\text { Pendimethalin } \\
\quad(0.125)\end{array}$ & $\begin{array}{ll} & \text { Male rats } \\
-\quad & \text { Daily oral gavage at } 62.5,125, \text { or } 250 \mathrm{mg} / \mathrm{kg} \\
& \text { BW for } 14 \text { days }\end{array}$ & $\begin{array}{l}\text { - Decreased liver glutathione content } \\
\text { - Decreased liver SOD, catalase, and } \\
\text { GST activities }\end{array}$ & [154] \\
\hline
\end{tabular}


Table 3. Cont.

\begin{tabular}{|c|c|c|c|c|c|}
\hline Type of Pesticide & Chemical Family & $\begin{array}{l}\text { Active Substances } \\
\text { (ADI mg/kg BW/day) }\end{array}$ & Experimental Model & Oxidative Impacts & Refs. \\
\hline \multirow[t]{4}{*}{ Fungicide } & Carbamate & $\begin{array}{l}\text { Thiophanate-methyl } \\
\text { (0.08) }\end{array}$ & $\begin{array}{l}\text { - } \quad \text { Male rats } \\
\text { - Single intraperitoneal injection of } 300 \text { to } 500 \\
\text { mg/kg BW } \\
\text { - Observations } 3 \text { days later }\end{array}$ & $\begin{array}{l}\text { - Increased antioxidant enzyme activity } \\
\text { - } \quad \text { Decreased liver GSH and vitamin C levels }\end{array}$ & [388] \\
\hline & Strobilurin & $\begin{array}{l}\text { Azoxystrobin } \\
\quad(0.2)\end{array}$ & $\begin{array}{l}\text { - Male and female zebrafish } \\
\text { - } \quad \text { Dilution in water at } 1,10 \text {, or } 100 \mu \mathrm{g} / \mathrm{L} \\
\text { - } 28 \text { days of exposure }\end{array}$ & $\begin{array}{l}\text { - Induced liver ROS production and } \\
\text { MDA level } \\
\text { - Changes in antioxidant enzymes activities }\end{array}$ & [378] \\
\hline & Strobilurin & $\begin{array}{l}\text { Azoxystrobin }(0.2) \text { or } \\
\text { picoxystrobin }(0.043)\end{array}$ & $\begin{array}{l}\text { - Zebrafish fertilized eggs exposed in water to } \\
0.25,2.5,25, \text { or } 250 \mathrm{mg} / \mathrm{L} \text { azoxystrobin and } 0 \text {, } \\
0.02,0.2,2 \text {, or } 20 \mathrm{mg} / \mathrm{L} \text { picoxystrobin for } 24, \\
48,72,96 \text {, or } 144 \mathrm{~h} \\
\text { - Adult male and female zebrafish exposed for } \\
28 \text { days to the above doses }\end{array}$ & $\begin{array}{l}\text { - Significant increased antioxidant enzyme } \\
\text { and detoxifying enzyme activities } \\
\text { Increased content of MDA in the larval } \\
\text { zebrafish study } \\
\text { The effect on activities of the antioxidant and } \\
\text { detoxification enzymes differed between the } \\
\text { sexes in adult zebrafish liver, with male } \\
\text { zebrafish more sensitive to azoxystrobin than } \\
\text { female zebrafish }\end{array}$ & [379] \\
\hline & Triazole & $\begin{array}{l}\text { Propiconazole } \\
\quad(0.04)\end{array}$ & $\begin{array}{l}\text { - } \quad \text { Male rats } \\
\text { Daily gavage at the equivalent level of no } \\
\text { observed effects level } \mathrm{X} 1, \mathrm{X} 3 \text {, or X5 for } \\
28 \text { days }\end{array}$ & - Changes in antioxidant enzyme activities & [380] \\
\hline \multirow{4}{*}{ Fungicide } & \multirow{3}{*}{ Triazole } & \multirow{2}{*}{ Propiconazole } & $\begin{array}{l}\text { - } \quad \text { Male mice } \\
\text { Pesticide-enriched diet (2500 ppm) or } \\
\text { intraperitoneal injections for } 4 \text { days }\end{array}$ & $\begin{array}{ll}\text { - } & \text { Decreased GSH/GSSG ratio } \\
\text { - } & \text { Decreased cytochrome } c \text { reductase activity } \\
\text { - } & \text { Increased protein oxidation }\end{array}$ & [381] \\
\hline & & & $\begin{array}{ll} & \text { Male mice } \\
\text { - } & \text { Pesticide-enriched diet at 500, 1250, or } 2500 \\
& \text { ppm for } 4 \text { days }\end{array}$ & $\begin{array}{l}\text { - } \quad \text { Reduced glutathione levels } \\
\text { - }\end{array}$ & [382] \\
\hline & & $\begin{array}{l}\text { Tebuconazole } \\
\quad(0.03)\end{array}$ & $\begin{array}{l}\text { - Male rats } \\
\text { Daily oral gavage at } 10,25, \text { or } 50 \mathrm{mg} / \mathrm{kg} \\
\text { peroral for } 28 \text { days }\end{array}$ & $\begin{array}{ll}\text { - } & \text { Increased hepatic levels of various } \\
\text { CYP proteins } \\
\text { - Increased antioxidant enzyme activities } \\
\text { - } & \text { Decreased glutathione content }\end{array}$ & [383] \\
\hline & Imidazole & $\begin{array}{c}\text { Imazalil } \\
(0.025)\end{array}$ & $\begin{array}{l}\text { - } \quad \text { Male mice } \\
\text { Environmental doses in drinking water for } \\
15 \text { weeks }\end{array}$ & $\begin{array}{l}\text { - } \quad \text { Increased levels of ROS and MDA } \\
\text { - } \quad \text { Changes in SOD activity } \\
\text { - } \\
\text { ecreased level of GSH in the liver }\end{array}$ & [159] \\
\hline
\end{tabular}


Table 3. Cont.

\begin{tabular}{|c|c|c|c|c|c|}
\hline Type of Pesticide & Chemical Family & $\begin{array}{l}\text { Active Substances } \\
\text { (ADI mg/kg BW/day) }\end{array}$ & Experimental Model & Oxidative Impacts & Refs. \\
\hline Fungicide & Dithiocarbamate & $\begin{array}{l}\text { Maneb } \\
(0.05)\end{array}$ & $\begin{array}{l}\text { - Female mice } \\
\text { Daily intraperitoneal injections to } 1 / 2,1 / 4,1 / 6 \text {, } \\
\text { or } 1 / 8 \text { of the } \mathrm{LD}_{50} \text { for } 7 \text { days }\end{array}$ & $\begin{array}{ll}\text { - } & \text { BW loss } \\
\text { - } & \text { Increased serum AST and ALT activities } \\
\text { - } & \text { Decreased serum high-density lipoprotein } \\
\text { cholesterol and increased cholesterol and } \\
\text { low-density lipoprotein cholesterol } \\
\text { - } \quad \text { Increased liver MDA level and } \\
\quad \mathrm{H}_{2} \mathrm{O}_{2} \text { generation } \\
\text { - } \quad \text { Decreased GPX, SOD2, and catalase activity } \\
\text { - }\end{array}$ & [377] \\
\hline $\begin{array}{l}\text { Insecticide and } \\
\text { fungicide }\end{array}$ & $\begin{array}{l}\text { Benzimidazole and } \\
\text { organophosphorus }\end{array}$ & $\begin{array}{l}\text { Mixture carbendazim (0.02) } \\
\text { and chlorpyrifos }(0.001)\end{array}$ & $\begin{array}{l}\text { - } \quad \text { Female rats } \\
\text { Orally exposed during } 7 \text { day to } 50 \mathrm{mg} / \mathrm{kg} \\
\text { BW/day chlorpyrifos and } 10 \mathrm{mg} / \mathrm{kg} \\
\text { BW/day carbendazim }\end{array}$ & $\begin{array}{l}\text { - Decreased enzymatic activity and } \\
\text { non-enzymatic antioxidant component levels }\end{array}$ & [384] \\
\hline
\end{tabular}


Moreover, all mitochondrial complexes, except complex IV, are targets of at least one pesticide family (Table 4). In chloroplasts, herbicides are photosynthesis inhibitors and mediate their actions by inhibiting the electron transport chain. Some functional similarity between plant chloroplasts and mammalian mitochondria may explain the mitochondrial toxicity of the herbicide triazine, which in plants inhibits the photosynthetic process that it targets [147]. Indeed, the triazine herbicide blocks the activity of the oxidative phosphorylation complex I, the NADH dehydrogenase complex, in an animal model (Table 4) [148]. Atrazine inhibits complexes III and V [148,389]. Other herbicides such as Diuron and glyphosate inhibit complex III [390,391]. Organochlorine insecticides affect complexes II and III, which contain the enzyme succinate dehydrogenase, and causes inhibition of succinate translocation, likely explaining insecticide suppression of mitochondrial respiration [392]. Organophosphate insecticides inhibit mitochondrial complex I in birds [393], and effects on complex IV and/or V have been reported in mammalian models [394,395]. Complex V is also inhibited by imidacloprid, abamectin, and DDE [392,396,397].

The strobilurin family of fungicides, known as succinate dehydrogenase inhibitors (SDHIs), inhibits fungus mitochondrial respiration via blockade of electron transfer between cytochrome $b$ and cytochrome $c 1$, which results in oxidative stress [378]. In addition to the inhibitory effect on succinate dehydrogenase, other SDHI fungicides inhibit complex III (ubiquinol cytochrome $c$ reductase) with varying efficiency in human and animal cells [184,381,398,399]. The herbicide glyphosate targets the mitochondrial electron transport chain in duckweed, in particular complex III, resulting in ROS production; however, its impact on mammalian mitochondria is not yet documented [400]. Some pesticides may affect more than one mitochondrial complex [148,395] (Table 4). For example, SDHI fungicides act on mitochondrial complexes I, II, and III (Table 4). In brief, various chemical families of insecticides, except DDE, alter complex V, whereas rotenone and malathion act on complexes I and II and I, IV, and V, respectively. Fungicides affect complexes II and III of the mitochondrial respiratory chain, and herbicides target complexes I, III, and V (Table 4). It is noteworthy that some fungicides (fludioxonil and Maneb) and the herbicide paraquat induce oxidative stress by acting on both mitochondria complexes and cytosolic NADPH oxidase [401,402].

Pesticide exposure affects antioxidant enzyme expression and/or activity and/or levels of antioxidant compounds such as GSH (Table 3). Pesticides can influence antioxidant pathways by modifying the expression of Nrf2. In HepG2 cells, DDE exposure decreases Nrf2 protein level and subsequently glutamyl-cysteine synthase activity [403]. Changes in Nrf2 promoter methylation have been identified in germ cells from adult mice exposed to the herbicide methyl-parathion for 5 days [404]. The exposure of rats to the pyrethroid insecticide bifenthrin for 60 days at a high dose led to an induction in gene expression, including of Nrf2, in the hippocampus [405], and the fungicide prochloraz induced Nrf2 activity in a gene reporter assay [406]. Exposure to pesticides such as atrazine, chlorpyrifos, zinc dimethyldithiocarbamate, vinclozolin, paraquat, and rotenone alters Sirt expression (mainly Sirt1, 3, and 6) -all members of a $\mathrm{NAD}^{+}$-dependent type III deacetylase enzyme family considered to operate as stress adaptors under oxidative, genotoxic, and metabolic stresses [407-413]. The mitochondrial scavenger of ROS, UCP-2, is also induced by the organochlorine pesticide DDE [203]. Pesticides induce ER stress in association with the development of some pathologies but without metabolic disturbance [414]. Additionally, the antiparasitic niclosamide induces ROS generation that enhances ATF3 and CHOP expression and ER stress in hepatoma HepG2 cells [415]. However, the pyrethroid insecticide permethrin induces ROS production without inducing ER stress in HepG2 cells [366]. Altogether, these findings indicate that pesticides affect several processes that result in oxidative stress: the CYP450 system, mitochondrial respiration, antioxidant pathways, the stress adaptor system, and scavenger ROS activity. 
Table 4. Impact of pesticide on mitochondrial electron transport chain complexes.

\begin{tabular}{|c|c|c|c|c|c|c|c|c|}
\hline \multirow[b]{2}{*}{$\begin{array}{l}\text { Type of } \\
\text { Pesticide }\end{array}$} & \multirow[b]{2}{*}{$\begin{array}{c}\text { Active } \\
\text { Molecule }\end{array}$} & \multicolumn{5}{|c|}{ Electron Transport Chain Complexes } & \multirow[b]{2}{*}{ Model } & \multirow[b]{2}{*}{ References } \\
\hline & & $\begin{array}{c}\text { I } \\
\text { NADH-Coenzyme } Q \\
\text { Reductase }\end{array}$ & $\begin{array}{c}\text { II } \\
\text { Succinate-Coenzyme } \\
\text { Q Reductase }\end{array}$ & $\begin{array}{c}\text { III } \\
\text { Reduced Coenzyme } \\
\text { Q-Cytochrome C } \\
\text { Reductase }\end{array}$ & $\begin{array}{c}\text { IV } \\
\text { Cytochrome C } \\
\text { Oxidase }\end{array}$ & $\begin{array}{c}\mathrm{V} \\
\text { F0F1 ATPase }\end{array}$ & & \\
\hline \multirow{5}{*}{ Insecticide } & Rotenone & $\mathrm{x}$ & & & & & $\begin{array}{l}\text { Isolated mitochondria from } \\
\text { exposed HL-60 cells }\end{array}$ & [405] \\
\hline & DDT/DDE & & $\mathrm{x}$ & $\mathrm{x}$ & & $\mathrm{x}$ & $\begin{array}{c}\text { Rat liver or heavy beef heart } \\
\text { isolated mitochondria or } \\
\text { sonicated submitochondria } \\
\text { particles }\end{array}$ & [392] \\
\hline & Monocrotophos & & & & & $\mathrm{x}$ & $\begin{array}{c}\text { Rat muscle mitochondria } \\
\text { isolated from exposed animals }\end{array}$ & [394] \\
\hline & Imidacloprid & & & & & $x$ & Rat liver isolated mitochondria & [397] \\
\hline & Malathion & $\mathrm{x}$ & & & $\mathrm{x}$ & $\mathrm{x}$ & $\begin{array}{l}\text { Rat muscle mitochondria } \\
\text { isolated from exposed animals }\end{array}$ & [395] \\
\hline \multirow{4}{*}{ Herbicide } & \multirow{2}{*}{ Atrazine } & & & & & $\mathrm{x}$ & Rat liver, isolated mitochondria & [389] \\
\hline & & $x$ & & $\mathrm{x}$ & & & $\begin{array}{c}\text { Rat muscle mitochondria } \\
\text { isolated from exposed animals }\end{array}$ & [148] \\
\hline & Diuron & & & $\mathrm{x}$ & & & Rat liver, isolated mitochondria & [390] \\
\hline & Glyphosate & & & $\mathrm{x}$ & & & Duckweed & [391] \\
\hline \multirow{3}{*}{ Fungicide } & Propiconazole & & $\mathrm{x}$ & $\mathrm{x}$ & & & Exposed mouse whole liver & [381] \\
\hline & Azoxystrobin & & & $\mathrm{x}$ & & & Rat liver, isolated mitochondria & [184] \\
\hline & Manzate & & $\mathrm{x}$ & & & & $\begin{array}{c}\text { Exposed Caenorhabditis } \\
\text { elegans }\end{array}$ & [398] \\
\hline Insecticide & $\begin{array}{l}4 \text { Succinate } \\
\text { dehydrogenase } \\
\text { inhibitors }\end{array}$ & & $\mathrm{x}$ & $\mathrm{x}$ & & & Exposed HEK cells & [399] \\
\hline Antiparasitic & Abamectin & & & & & $\mathrm{x}$ & Rat liver, isolated mitochondria & [396] \\
\hline
\end{tabular}


Besides oxidative stress, pesticide exposure may lead to NAFLD through their impact on lipid metabolism by (i) modifying fatty acid uptake and efflux [171] and modulating FFA transport as described for insecticides and herbicides, (ii) increasing lipogenesis ([173,406] (Table 1), (iii) altering oxidation pathways [175]; insecticides, herbicides, and fungicides affect both $\beta$-oxidation and lipogenesis (Tables 1 and 2), (iv) interacting with nuclear receptors [416-421] involved in the control of metabolism as demonstrated for pyrethroid and neonicotinoid insecticides [176-178], and imidazole or triazole fungicides [158,382] or a pesticide mixture [193], but implication in NAFLD is not proven.

Some pesticides may ameliorate lipid metabolism. For example, environmental doses of Boscalid, a widely used fungicide, induce gene expression that promotes $\beta$-oxidation and inhibits lipogenesis in the zebrafish liver [179]. Similarly, oral exposure to the carbamate fungicide propamocarb in mice during a 4-week period leads to a down regulation of genes involved in glycolysis, TG, and fatty acid synthesis in the liver [180]. Pesticide alter glucose metabolism through activation of glucose uptake, glycogenolysis, gluconeogenesis (as reviewed for insecticides in [136]) or through inhibition of the mitochondrial respiratory complex (Table 4), and modulation of Chrebp gene expression levels [185], change in the expression of PPAR $\beta / \delta$ and genes involved in glucose metabolism (FoxO1 and CREB) [186]. Pesticides also induce insulin resistance by acting on insulin signaling pathways (for a review see [192]). Liver inflammation was also reported upon exposure to organophosphorus [188], OC [189], neonicotinoid [142,143] pyrethroid insecticides [144], or to triazole or imidazole fungicides [190] (Table 1).

In summary this section on the role of pesticides in oxidative stress in NAFLD shows that pesticides are pro-oxidant compounds that can induce ROS production through various mechanisms: (i) detoxification via P450-dependent processes, (ii) effects on mitochondrial respiratory complexes, and (iii) action on Sirt- and or Nrf2-dependent antioxidant responses (Figure 8). It is noteworthy that the data do not consistently come from studies performed in the liver and/or related to a metabolic impact of pesticides. Although pesticide exposure and NAFLD are not clearly correlated, the prooxidative properties of pesticides as well as their impact on various pathways involved in the regulation of metabolic homeostasis support their putative role in the development or in the progression of hepatopathy. Moreover, various experimental studies showed that pesticides could affect various pathways involved in the regulation of metabolic and hepatic homeostasis strongly suggesting their role in NAFLD. Pesticides affect oxidative stress in NAFLD, but in many studies (reported in Tables 1 and 2), animals were exposed to high doses of pesticide and durations of exposure that are not relevant for human exposure, making any human translation of results difficult. In fact, to better decipher the role of pesticide-induced oxidative stress in the development of NAFLD, more studies are needed that link different pesticide cellular targets and/or mechanisms of action underlying ROS production with hepatic processes involved in the control of energy metabolism, such as lipid metabolism, inflammation, and gene regulation by nuclear receptors. Interestingly, nuclear receptors, such as PPARs, progesterone receptor (PR), mineralocorticoid receptor (MR), glucocorticoid receptor (GR), aryl hydrocarbon receptor (AhR), retinoic acid receptors (RARs), farnesoid X receptor (FXR), and liver $X$ receptors (LXRs) are established or suspected targets of endocrine disrupting chemicals including diverse agrochemicals, but further analyses are needed to determine whether this can lead to the development of NAFLD/NASH [410,411]. 


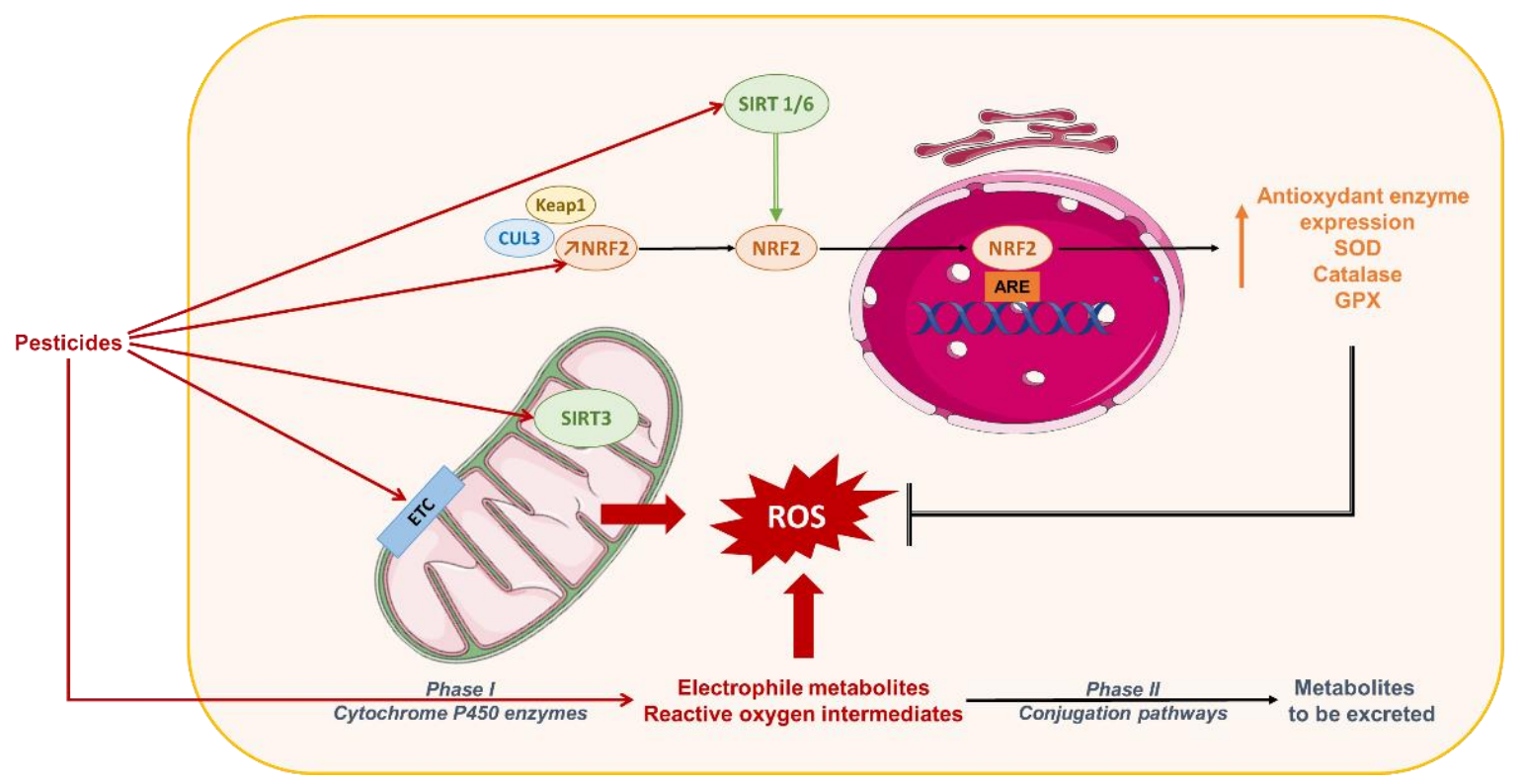

Figure 8. Mechanisms of pesticide-induced oxidative stress. Reactive oxygen species (ROS) can be produced from several sources during metabolism, as a result of biotransformation of pesticides by cytochrome P450 enzymes, which catalyze the oxidation reactions. Moreover, the mitochondrial complexes, except complex IV, are targets of at least one pesticide family, leading to a disruption in the electron transport chain (ETC) and ROS production. Pesticides can affect antioxidant pathways by (i) modifying the expression of erythroid2-like 2 (Nrf2), (ii) changing Nrf2 promoter methylation, and (iii) altering the expression of sirtuins (Sirts; mainly Sirt1, 3, and 6), which are members of a $\mathrm{NAD}^{+}$-dependent type III deacetylase enzyme family. They are considered to be stress adaptors to oxidative, genotoxic, and metabolic stress. ARE, antioxidant response element; SOD, superoxide dismutase; GPX glutathione peroxidase.

\section{Conclusions}

Many challenges remain in understanding the etiology of NAFLD because the precise staging of its progression in the absence of liver biopsy is not yet possible. Furthermore, no therapy has been approved by the U.S. Food and Drug Administration, and lifestyle modifications (diet, exercise) are difficult to implement and adhere to, which has contributed to the failure to reduce NAFLD prevalence. In terms of implemented therapeutic interventions, vitamin E and the PPAR $\gamma$ ligand pioglitazone have beneficial effects on steatosis and inflammation, but they do not improve fibrosis, the strongest indicator of mortality in NAFLD/NASH. However, sustained research has led to a better understanding of the pathogenesis and progression of this condition and to the development of promising compounds to block and possibly reverse fibrosis, which are presently in clinical trials [348,412]. It is well accepted that disturbances in lipid metabolism are key to the development of NAFLD and its progression. They can affect different ROS generators, such as mitochondria, ER, and NOX [226]. Although many aspects of the contributions of ROS generators to NAFLD remain unexplored, much progress has been made in understanding how increased ROS levels trigger changes in insulin sensitivity, the activity of key enzymes of lipid metabolism, innate immune system signaling, and the level of inflammatory responses. Both macro- and micronutrients impact oxidative stress in NAFLD pathogenesis. An excess of certain macronutrients, such as cholesterol and fructose, exerts pro-oxidant effects, whereas several micronutrients have the potential to decrease NAFLD through their antioxidant properties. However, human diets are complex, and it is challenging to mimic them in experimental models. The contribution of specific dietary nutrients to oxidative stress in NAFLD is not fully elucidated and needs further research. It is noteworthy that epidemiological studies did not report a correlation between pesticide exposure and NAFLD in human. However, pesticides exposure was correlated in occupationally exposed population with metabolic disorders. Moreover, various experimental studies showed that 
pesticides can affect various pathways involved in the regulation of metabolic and hepatic homeostasis strongly suggesting a role in NAFLD. Pesticides affect oxidative stress in NAFLD, but in many studies (reported in Tables 1 and 2), animals were exposed to high doses of pesticide and durations of exposure that are not relevant for human exposure, making any human translation of results difficult. In rodents, perinatal exposure to organophosphorus insecticides worsens metabolic perturbations induced by HFD [197] or by overfeeding $[198,206]$. The lifelong effects of perinatal exposure with respect to NAFLD/NASH development, and health in general, remain an open and crucial area of research.

Author Contributions: Conceptualization: L.G.-P., W.W. and H.G.; drafting the text: L.G.-P., W.W., C.R. and A.F.; manuscript review and editing: L.G.-P., W.W., C.R., A.F., S.E.-S., H.G. and N.L. All authors have read and agreed to the published version of the manuscript.

Funding: A.F. is supported by the AgreenSkills and fellowship program. W.W. was supported by the Start-Up Grant from the Lee Kong Chian School of Medicine, Nanyang Technological University Singapore. This work was also funded by ANR Syneract and by grants from Région Occitanie (L.G.P., N.L., H.G., W.W.).

Conflicts of Interest: The authors declare no conflict of interest.

\section{References}

1. Marjot, T.; Moolla, A.; Cobbold, J.F.; Hodson, L.; Tomlinson, J.W. Nonalcoholic fatty liver disease in adults: Current concepts in etiology, outcomes, and management. Endocr. Rev. 2020, 41. [CrossRef] [PubMed]

2. Wattacheril, J.; Sanyal, A.J. Lean NAFLD: An underrecognized outlier. Curr. Hepatol. Rep. 2016, 15, $134-139$. [CrossRef] [PubMed]

3. Younes, R.; Bugianesi, E. A spotlight on pathogenesis, interactions and novel therapeutic options in NAFLD. Nat. Rev. Gastroenterol. Hepatol. 2019, 16, 80-82. [CrossRef] [PubMed]

4. Sheka, A.C.; Adeyi, O.; Thompson, J.; Hameed, B.; Crawford, P.A.; Ikramuddin, S. Nonalcoholic steatohepatitis: A review. JAMA J. Am. Med. Assoc. 2020, 323, 1175-1183. [CrossRef] [PubMed]

5. Nobili, V.; Alisi, A.; Valenti, L.; Miele, L.; Feldstein, A.E.; Alkhouri, N. NAFLD in children: New genes, new diagnostic modalities and new drugs. Nat. Rev. Gastroenterol. Hepatol. 2019, 16, 517-530. [CrossRef]

6. Fitzpatrick, E.; Dhawan, A. Childhood and adolescent nonalcoholic fatty liver disease: Is it different from adults? J. Clin. Exp. Hepatol. 2019, 9, 716-722. [CrossRef]

7. Younossi, Z.M.; Koenig, A.B.; Abdelatif, D.; Fazel, Y.; Henry, L.; Wymer, M. Global epidemiology of nonalcoholic fatty liver disease-Meta-analytic assessment of prevalence, incidence, and outcomes. Hepatology 2016, 64, 73-84. [CrossRef]

8. Younossi, Z.M.; Tampi, R.P.; Racila, A.; Qiu, Y.; Burns, L.; Younossi, I.; Nader, F. Economic and clinical burden of nonalcoholic steatohepatitis in patients with type 2 diabetes in the U.S. Diabetes Care 2020, 43, $283-289$. [CrossRef]

9. Shetty, A.; Syn, W.-K. Current treatment options for nonalcoholic fatty liver disease. Curr. Opin. Gastroenterol. 2019, 35, 168-176. [CrossRef]

10. Burt, A.D.; Tiniakos, D.G.; Lackner, C. Diagnosis and assessment of NAFLD: Definitions and histopathological classification. Semin. Liver Dis. 2015, 35, 207-220. [CrossRef]

11. Lackner, C. Hepatocellular ballooning in nonalcoholic steatohepatitis: The pathologist's perspective. Expert Rev. Gastroenterol. Hepatol. 2011, 5, 223-231. [CrossRef] [PubMed]

12. Hagström, H.; Elfwén, O.; Hultcrantz, R.; Stål, P. Steatohepatitis is not associated with an increased risk for fibrosis progression in nonalcoholic fatty liver disease. Gastroenterol. Res. Pract. 2018, 1942648. [CrossRef] [PubMed]

13. Hagström, H.; Nasr, P.; Ekstedt, M.; Hammar, U.; Stål, P.; Hultcrantz, R.; Kechagias, S. Risk for development of severe liver disease in lean patients with nonalcoholic fatty liver disease: A long-term follow-up study. Hepatol. Commun. 2018, 2, 48-57. [CrossRef] [PubMed]

14. Buzzetti, E.; Pinzani, M.; Tsochatzis, E.A. The multiple-hit pathogenesis of non-alcoholic fatty liver disease (NAFLD). Metabolism 2016, 65, 1038-1048. [CrossRef] [PubMed]

15. Alonso, C.; Noureddin, M.; Lu, S.C.; Mato, J.M. Biomarkers and subtypes of deranged lipid metabolism in nonalcoholic fatty liver disease. World J. Gastroenterol. 2019, 25, 3009-3020. [CrossRef] 
16. Friedman, S.L.; Neuschwander-Tetri, B.A.; Rinella, M.; Sanyal, A.J. Mechanisms of NAFLD development and therapeutic strategies. Nat. Med. 2018, 24, 908-922. [CrossRef] [PubMed]

17. Donnelly, K.L.; Smith, C.I.; Schwarzenberg, S.J.; Jessurun, J.; Boldt, M.D.; Parks, E.J. Sources of fatty acids stored in liver and secreted via lipoproteins in patients with nonalcoholic fatty liver disease. J. Clin. Investig. 2005, 115, 1343-1351. [CrossRef]

18. Barbara, M.; Scott, A.; Alkhouri, N. New insights into genetic predisposition and novel therapeutic targets for nonalcoholic fatty liver disease. Hepatobiliary Surg. Nutr. 2018, 7, 372-381. [CrossRef]

19. Taliento, A.E.; Dallio, M.; Federico, A.; Prati, D.; Valenti, L. Novel insights into the genetic landscape of nonalcoholic fatty liver disease. Int. J. Environ. Res. Public Health 2019, 16, 2755. [CrossRef]

20. Luukkonen, P.K.; Ikonen, E.; Yki-järvinen, H.; Luukkonen, P.K.; Nick, A.; Hölttä-vuori, M.; Thiele, C.; Isokuortti, E.; Lallukka-brück, S.; Zhou, Y.; et al. Human PNPLA3-I148M variant increases hepatic retention of polyunsaturated fatty acids graphical abstract find the latest version: Human PNPLA3-I148M variant increases hepatic retention of polyunsaturated fatty acids. J. Clin. Investig. 2019, 4, e12902. [CrossRef]

21. Pingitore, P.; Dongiovanni, P.; Motta, B.M.; Meroni, M.; Lepore, M.; Mancina, R.M.; Pelusi, S.; Russo, C. PNPLA3 overexpression results in reduction of proteins predisposing to fibrosis. Hum. Mol. Genet. 2016, 25, 5212-5222. [CrossRef] [PubMed]

22. BasuRay, S.; Smagris, E.; Cohen, J.C.; Hobbs, H.H. The PNPLA3 Variant associated with fatty liver disease (I148M) accumulates on lipid droplets by evading ubiquitylation. Hepatology 2017, 66, 1111-1124. [CrossRef] [PubMed]

23. Kozlitina, J.; Smagris, E.; Stender, S.; Nordestgaard, B.G.; Zhou, H.H.; Tybjærg-Hansen, A.; Vogt, T.F.; Hobbs, H.H.; Cohen, J.C. Exome-wide association study identifies a TM6SF2 variant that confers susceptibility to nonalcoholic fatty liver disease. Nat. Genet. 2014, 46, 352-356. [CrossRef] [PubMed]

24. Holmen, O.L.; Zhang, H.; Fan, Y.; Hovelson, D.H.; Schmidt, E.M.; Zhou, W.; Guo, Y.; Zhang, J.; Langhammer, A.; Løchen, M.L.; et al. Systematic evaluation of coding variation identifies a candidate causal variant in TM6SF2 influencing total cholesterol and myocardial infarction risk. Nat. Genet. 2014, 46, 345-351. [CrossRef]

25. Mancina, R.M.; Dongiovanni, P.; Petta, S.; Pingitore, P.; Meroni, M.; Rametta, R.; Borén, J.; Montalcini, T.; Pujia, A.; Wiklund, O.; et al. The MBOAT7-TMC4 variant rs641738 increases risk of nonalcoholic fatty liver disease in individuals of european descent. Gastroenterology 2016, 150, 1219-1230.e6. [CrossRef]

26. Donati, B.; Dongiovanni, P.; Romeo, S.; Meroni, M.; McCain, M.; Miele, L.; Petta, S.; Maier, S.; Rosso, C.; De Luca, L.; et al. MBOAT7 rs641738 variant and hepatocellular carcinoma in non-cirrhotic individuals. Sci. Rep. 2017, 7, 2-11. [CrossRef]

27. Santoro, N.; Zhang, C.K.; Zhao, H.; Pakstis, A.J.; Kim, G.; Kursawe, R.; Dykas, D.J.; Bale, A.E.; Giannini, C.; Pierpont, B.; et al. Variant in the glucokinase regulatory protein (GCKR) gene is associated with fatty liver in obese children and adolescents. Hepatology 2012, 55, 781-789. [CrossRef]

28. Hernaez, R.; McLean, J.; Lazo, M.; Brancati, F.L.; Hirschhorn, J.N.; Borecki, I.B.; Harris, T.B.; Nguyen, T.; Kamel, I.R.; Bonekamp, S.; et al. Association between variants in or near PNPLA3, GCKR, and PPP1R3B with ultrasound-defined steatosis based on data from the third national health and nutrition examination survey. Clin. Gastroenterol. Hepatol. 2013, 11, 1183-1190.e2. [CrossRef]

29. Pirola, C.J.; Garaycoechea, M.; Flichman, D.; Arrese, M.; Martino, J.S.; Gazzi, C.; Castaño, G.O.; Sookoian, S. Splice Variant rs72613567 Prevents Worst Histologic Outcomes in Patients with Nonalcoholic Fatty Liver Disease. J. Lipid Res. 2019, 60, 176-185. [CrossRef]

30. Abul-Husn, N.S.; Cheng, X.; Li, A.H.; Xin, Y.; Schurmann, C.; Stevis, P.; Liu, Y.; Kozlitina, J.; Stender, S.; Wood, G.C.; et al. A protein-truncating HSD17B13 variant and protection from chronic liver disease. N. Engl. J. Med. 2018, 378, 1096-1106. [CrossRef]

31. Pirazzi, C.; Valenti, L.; Motta, B.M.; Pingitore, P.; Hedfalk, K.; Mancina, R.M.; Burza, M.A.; Indiveri, C.; Ferro, Y.; Montalcini, T.; et al. PNPLA3 has retinyl-palmitate lipase activity in human hepatic stellate cells. Hum. Mol. Genet. 2014, 23, 4077-4085. [CrossRef] [PubMed]

32. Nivukoski, U.; Niemelä, M.; Bloigu, A.; Bloigu, R.; Aalto, M.; Laatikainen, T.; Niemelä, O. Combined effects of lifestyle risk factors on fatty liver index. BMC Gastroenterol. 2020, 20, 1-10. [CrossRef] [PubMed]

33. Harrison, S.A.; Day, C.P. Recent advances in clinical practice: Benefits of lifestyle modification in NAFLD. Gut 2007, 56, 1760-1769. [CrossRef] [PubMed] 
34. Zelber-Sagi, S.; Nitzan-Kaluski, D.; Goldsmith, R.; Webb, M.; Blendis, L.; Halpern, Z.; Oren, R. Long term nutritional intake and the risk for non-alcoholic fatty liver disease (NAFLD): A population based study. J. Hepatol. 2007, 47, 711-717. [CrossRef]

35. Chung, G.E.; Youn, J.; Kim, Y.S.; Lee, J.E.; Yang, S.Y.; Lim, J.H.; Song, J.H.; Doo, E.Y.; Kim, J.S. Dietary patterns are associated with the prevalence of nonalcoholic fatty liver disease in Korean adults. Nutrition 2019, 62, 32-38. [CrossRef]

36. Zolfaghari, H.; Askari, G.; Siassi, F.; Feizi, A.; Sotoudeh, G. Intake of nutrients, fiber, and sugar in patients with nonalcoholic fatty liver disease in comparison to healthy individuals. Int. J. Prev. Med. 2016, 9, 98. [CrossRef]

37. Wong, V.W.S.; Wong, G.L.H.; Chan, R.S.M.; Shu, S.S.T.; Cheung, B.H.K.; Li, L.S.; Chim, A.M.L.; Chan, C.K.M.; Leung, J.K.Y.; Chu, W.C.W.; et al. Beneficial effects of lifestyle intervention in non-obese patients with non-alcoholic fatty liver disease. J. Hepatol. 2018, 69, 1349-1356. [CrossRef]

38. Berná, G.; Romero-Gomez, M. The role of nutrition in non-alcoholic fatty liver disease: Pathophysiology and management. Liver Int. 2020, 40, 102-108. [CrossRef]

39. He, K.; Li, Y.; Guo, X.; Zhong, L.; Tang, S. Food groups and the likelihood of non-alcoholic fatty liver disease: A systematic review and meta-analysis. Br. J. Nutr. 2020, 124, 1-13. [CrossRef]

40. Trovato, F.M.; Castrogiovanni, P.; Szychlinska, M.A.; Purrello, F.; Musumeci, G. Impact of western and mediterranean diets and vitamin D on muscle fibers of sedentary rats. Nutrients 2018, 10, 231. [CrossRef]

41. Baratta, F.; Pastori, D.; Polimeni, L.; Bucci, T.; Ceci, F.; Calabrese, C.; Ernesti, I.; Pannitteri, G.; Violi, F.; Angelico, F.; et al. Adherence to mediterranean diet and non-alcoholic fatty liver disease: Effect on insulin resistance. Am. J. Gastroenterol. 2017, 112, 1832-1839. [CrossRef] [PubMed]

42. Chan, R.; Wong, V.W.S.; Chu, W.C.W.; Wong, G.L.H.; Li, L.S.; Leung, J.; Chim, A.M.L.; Yeung, D.K.W.; Sea, M.M.M.; Woo, J.; et al. Diet-quality scores and prevalence of nonalcoholic fatty liver disease: A population study using proton-magnetic resonance spectroscopy. PLoS ONE 2015, 10, e0139310. [CrossRef] [PubMed]

43. Aller, R.; Izaola, O.; de la Fuente, B.; de Luis, D. La dieta mediterránea se asocia con la histología hepática en pacientes con enfermedad del hígado graso no alcohólico. Nutr. Hosp. 2015, 32, 2518-2524. [CrossRef] [PubMed]

44. Della Corte, C.; Mosca, A.; Vania, A.; Alterio, A.; Iasevoli, S.; Nobili, V. Good adherence to the Mediterranean diet reduces the risk for NASH and diabetes in pediatric patients with obesity: The results of an Italian Study. Nutrition 2017, 39-40, 8-14. [CrossRef]

45. Saeed, N.; Nadeau, B.; Shannon, C.; Tincopa, M. Evaluation of dietary approaches for the treatment of non-alcoholic fatty liver disease: A systematic review. Nutrients 2019, 11, 3064. [CrossRef]

46. Ryan, M.C.; Itsiopoulos, C.; Thodis, T.; Ward, G.; Trost, N.; Hofferberth, S.; O’Dea, K.; Desmond, P.V.; Johnson, N.A.; Wilson, A.M. The Mediterranean diet improves hepatic steatosis and insulin sensitivity in individuals with non-alcoholic fatty liver disease. J. Hepatol. 2013, 59, 138-143. [CrossRef]

47. Properzi, C.; O’Sullivan, T.A.; Sherriff, J.L.; Ching, H.L.; Jeffrey, G.P.; Buckley, R.F.; Tibballs, J.; MacQuillan, G.C.; Garas, G.; Adams, L.A. Ad libitum mediterranean and low-fat diets both significantly reduce hepatic steatosis: A randomized controlled trial. Hepatology 2018, 68, 1741-1754. [CrossRef]

48. Ma, J.; Hennein, R.; Liu, C.; Long, M.T.; Hoffmann, U.; Jacques, P.F.; Lichtenstein, A.H.; Hu, F.B.; Levy, D. Improved diet quality associates with reduction in liver fat, particularly in individuals with high genetic risk scores for nonalcoholic fatty liver disease. Gastroenterology 2018, 155, 107-117. [CrossRef]

49. Kontogianni, M.D.; Tileli, N.; Margariti, A.; Georgoulis, M.; Deutsch, M.; Tiniakos, D.; Fragopoulou, E.; Zafiropoulou, R.; Manios, Y.; Papatheodoridis, G. Adherence to the mediterranean diet is associated with the severity of non-alcoholic fatty liver disease. Clin. Nutr. 2014, 33, 678-683. [CrossRef]

50. Jensen, T.; Abdelmalek, M.F.; Sullivan, S.; Nadeau, K.J.; Green, M.; Roncal, C.; Nakagawa, T.; Kuwabara, M.; Sato, Y.; Kang, D.H.; et al. Fructose and sugar: A major mediator of non-alcoholic fatty liver disease. J. Hepatol. 2018, 68, 1063-1075. [CrossRef]

51. Jegatheesan, P.; De Bandt, J.P. Fructose and NAFLD: The Multifaceted Aspects of Fructose Metabolism. Nutrients 2017, 9, 230. [CrossRef] [PubMed]

52. Jang, C.; Wada, S.; Yang, S.; Gosis, B.; Zeng, X.; Zhang, Z.; Shen, Y.; Lee, G.; Arany, Z.; Rabinowitz, J.D. The small intestine shields the liver from fructose-induced steatosis. Nat. Metab. 2020, 2, 586-593. [CrossRef] [PubMed] 
53. Todoric, J.; Di Caro, G.; Reibe, S.; Henstridge, D.C.; Green, C.R.; Vrbanac, A.; Ceteci, F.; Conche, C.; McNulty, R.; Shalapour, S.; et al. Fructose stimulated de novo lipogenesis is promoted by inflammation. Nat. Metab. 2020. [CrossRef] [PubMed]

54. Ouyang, X.; Cirillo, P.; Sautin, Y.; McCall, S.; Bruchette, J.L.; Diehl, A.M.; Johnson, R.J.; Abdelmalek, M.F. Fructose consumption as a risk factor for non-alcoholic fatty liver disease. J. Hepatol. 2008, 48, 993-999. [CrossRef] [PubMed]

55. Abdelmalek, M.; Suzuki, A.; Guy, C.; Unalp-Arida, A.; Colvin, R.; Johnson, R.; Diehl, A. Increased fructose consumption is associated with fibrosis severity in patients with nafl. Hepatology. 2011, 51, 1961-1971. [CrossRef] [PubMed]

56. Tendler, D.; Lin, S.; Yancy, W.S.; Mavropoulos, J.; Sylvestre, P.; Rockey, D.C.; Westman, E.C. The effect of a low-carbohydrate, ketogenic diet on nonalcoholic fatty liver disease: A pilot study. Dig. Dis. Sci. 2007, 52, 589-593. [CrossRef] [PubMed]

57. Luukkonen, P.K.; Dufour, S.; Lyu, K.; Zhang, X.M.; Hakkarainen, A.; Lehtimäki, T.E.; Cline, G.W.; Petersen, K.F.; Shulman, G.I.; Yki-Järvinen, H. Effect of a ketogenic diet on hepatic steatosis and hepatic mitochondrial metabolism in nonalcoholic fatty liver disease. Proc. Natl. Acad. Sci. USA 2020, 117, 7347-7354. [CrossRef]

58. Yasutake, K.; Kohjima, M.; Kotoh, K.; Nakashima, M.; Nakamuta, M.; Enjoji, M. Dietary habits and behaviors associated with nonalcoholic fatty liver disease. World J. Gastroenterol. 2014, 20, 1756-1767. [CrossRef]

59. Wang, X.; Cai, B.; Yang, X.; Sonubi, O.O.; Zheng, Z.; Ramakrishnan, R.; Shi, H.; Valenti, L.; Pajvani, U.B.; Sandhu, J.; et al. Cholesterol stabilizes taz in hepatocytes to promote experimental non-alcoholic steatohepatitis. Cell Metab. 2020, 31, 969-986. [CrossRef]

60. Rosqvist, F.; Iggman, D.; Kullberg, J.; Cedernaes, J.; Johansson, H.; Larsson, A.; Johansson, L.; Ahlström, H.; Arner, P.; Dahlman, I.; et al. Overfeeding polyunsaturated and saturated fat causes distinct effects on liver and visceral fat accumulation in humans. Diabetes 2014, 63, 2356-2368. [CrossRef]

61. Green, C.J.; Hodson, L. The influence of dietary fat on liver fat accumulation. Nutrients 2014, 6, 5018-5033. [CrossRef] [PubMed]

62. Luukkonen, P.K.; Sädevirta, S.; Zhou, Y.; Kayser, B.; Ali, A.; Ahonen, L.; Lallukka, S.; Pelloux, V.; Gaggini, M.; Jian, C.; et al. Saturated fat is more metabolically harmful for the human liver than unsaturated fat or simple sugars. Diabetes Care 2018, 41, 1732-1739. [CrossRef] [PubMed]

63. Sekiya, M.; Yahagi, N.; Matsuzaka, T.; Najima, Y.; Nakakuki, M.; Nagai, R.; Ishibashi, S.; Osuga, J.I.; Yamada, N.; Shimano, H. Polyunsaturated fatty acids ameliorate hepatic steatosis in obese mice by SREBP-1 suppression. Hepatology 2003, 38, 1529-1539. [CrossRef] [PubMed]

64. Dentin, R.; Benhamed, F.; Pégorier, J.P.; Foufelle, F.; Viollet, B.; Vaulont, S.; Girard, J.; Postic, C. Polyunsaturated fatty acids suppress glycolytic and lipogenic genes through the inhibition of ChREBP nuclear protein translocation. J. Clin. Investig. 2005, 115, 2843-2854. [CrossRef]

65. Ducheix, S.; Montagner, A.; Polizzi, A.; Lasserre, F.; Marmugi, A.; Bertrand-Michel, J.; Podechard, N.; Al Saati, T.; Chétiveaux, M.; Baron, S.; et al. Essential fatty acids deficiency promotes lipogenic gene expression and hepatic steatosis through the liver X receptor. J. Hepatol. 2013, 58, 984-992. [CrossRef]

66. Musso, G.; Gambino, R.; De Michieli, F.; Cassader, M.; Rizzetto, M.; Durazzo, M.; Fagà, E.; Silli, B.; Pagano, G. Dietary habits and their relations to insulin resistance and postprandial lipemia in nonalcoholic steatohepatitis. Hepatology 2003, 37, 909-916. [CrossRef]

67. Hernández, E.; Kahl, S.; Seelig, A.; Begovatz, P.; Irmler, M.; Kupriyanova, Y.; Nowotny, B.; Nowotny, P.; Herder, C.; Barosa, C.; et al. Acute dietary fat intake initiates alterations in energy metabolism and insulin resistance. J. Clin. Investig. 2017, 1, 695-708. [CrossRef]

68. Markova, M.; Pivovarova, O.; Hornemann, S.; Sucher, S.; Frahnow, T.; Wegner, K.; Machann, J.; Petzke, K.J.; Hierholzer, J.; Lichtinghagen, R.; et al. Isocaloric diets high in animal or plant protein reduce liver fat and inflammation in individuals with type 2 diabetes. Gastroenterology 2017, 152, 571-585. [CrossRef]

69. Lang, S.; Martin, A.; Farowski, F.; Wisplinghoff, H.; Vehreschild, M.J.G.T.; Liu, J.; Krawczyk, M.; Nowag, A.; Kretzschmar, A.; Herweg, J.; et al. High protein intake is associated with histological disease activity in patients with NAFLD. Hepatol. Commun. 2020, 4, 681-695. [CrossRef]

70. Zelber-Sagi, S.; Salomone, F.; Mlynarsky, L. The Mediterranean dietary pattern as the diet of choice for non-alcoholic fatty liver disease: Evidence and plausible mechanisms. Liver Int. 2017, 37, 936-949. [CrossRef] 
71. Alferink, L.J.M.; Kiefte-De Jong, J.C.; Erler, N.S.; Veldt, B.J.; Schoufour, J.D.; De Knegt, R.J.; Ikram, M.A.; Metselaar, H.J.; Janssen, H.L.A.; Franco, O.H.; et al. Association of dietary macronutrient composition and non-alcoholic fatty liver disease in an ageing population: The Rotterdam study. Gut 2019, 68, 1088-1098. [CrossRef] [PubMed]

72. Pickett-Blakely, O.; Young, K.; Carr, R.M. Micronutrients in nonalcoholic fatty liver disease pathogenesis. Cell. Mol. Gastroenterol. Hepatol. 2018, 6, 451-462. [CrossRef] [PubMed]

73. Valenti, L.; Fracanzani, A.L.; Bugianesi, E.; Dongiovanni, P.; Galmozzi, E.; Vanni, E.; Canavesi, E.; Lattuada, E.; Roviaro, G.; Marchesini, G.; et al. HFE Genotype, parenchymal iron accumulation, and liver fibrosis in patients with nonalcoholic fatty liver disease. Gastroenterology 2010, 138, 905-912. [CrossRef] [PubMed]

74. Nelson, J.E.; Wilson, L.; Brunt, E.M.; Yeh, M.M.; David, E.; Unalp-arida, A.; Kowdley, K.V.; Crn, N. Relationship between pattern of hepatic iron deposition and histologic severity in nonalcoholic fatty liver disease. Hepatology 2011, 53, 448-457. [CrossRef] [PubMed]

75. Britton, L.J.; Subramaniam, V.N.; Crawford, D.H.G. Iron and non-alcoholic fatty liver disease. World J. Gastroenterol. 2016, 22, 8112-8122. [CrossRef] [PubMed]

76. Ryan, J.; Armitage, A.; Cobbold, J.; Barnejee, R.; Borsani, O.; Dongiovanni, P.; Neubauer, S.; Morovat, R.; Wang, L.; Pasricha, S.; et al. Hepatic iron is the major determinant of serum ferritin in NAFLD patients. Liver Int. 2018, 38, 164-173. [CrossRef]

77. Kowdley, K.V.; Wang, C.C.; Welch, S.; Roberts, H.; Brosgart, C.L. Prevalence of chronic hepatitis B among foreign-born persons living in the United States by country of origin. Hepatology 2012, 56, 422-433. [CrossRef]

78. Murali, A.R.; Gupta, A.; Brown, K. Systematic review and meta-analysis to determine the impact of iron depletion in dysmetabolic iron overload syndrome and non-alcoholic fatty liver disease. Hepatol. Res. 2018, 48, 30-41. [CrossRef]

79. Valenti, L.; Fracanzani, A.L.; Dongiovanni, P.; Rovida, S.; Rametta, R.; Fatta, E.; Pulixi, E.A.; Maggioni, M.; Fargion, S. A randomized trial of iron depletion in patients with nonalcoholic fatty liver disease and hyperferritinemia. World J. Gastroenterol. 2014, 20, 3002-3010. [CrossRef]

80. Khodadoostan, M.; Zamanidoost, M.; Shavakhi, A.; Sanei, H.; Shahbazi, M.; Ahmadian, M. Effects of phlebotomy on liver enzymes and histology of patients with nonalcoholic fatty liver disease. Adv. Biomed. Res. 2017, 6, 12. [CrossRef]

81. El Kochairi, I.; Montagner, A.; Rando, G.; Lohmann, C.; Matter, C.M.; Wahli, W. Beneficial effects of combinatorial micronutrition on body fat and atherosclerosis in mice. Cardiovasc. Res. 2011, 91, 732-741. [CrossRef] [PubMed]

82. Rotman, Y.; Sanyal, A.J. Current and upcoming pharmacotherapy for non-alcoholic fatty liver disease. Gut 2017, 66, 180-190. [CrossRef] [PubMed]

83. Sharifi-Rad, J.; Rodrigues, C.F.; Stojanović-Radić, Z.; Dimitrijević, M.; Aleksić, A.; Neffe-Skocińska, K.; Zielińska, D.; Kołożyn-Krajewska, D.; Salehi, B.; Prabu, S.M.; et al. Probiotics: Versatile bioactive components in promoting human health. Medicina 2020, 56, 433. [CrossRef] [PubMed]

84. Scorletti, E.; Afolabi, P.R.; Miles, E.A.; Smith, D.E.; Almehmadi, A.; Alshathry, A.; Childs, C.E.; Del Fabbro, S.; Bilson, J.; Moyses, H.E.; et al. Synbiotics alter fecal microbiomes, but not liver fat or fibrosis, in a randomized trial of patients with nonalcoholic fatty liver disease. Gastroenterology 2020, 158, 1597-1610.e7. [CrossRef] [PubMed]

85. Javadi, L.; Khoshbaten, M.; Safaiyan, A.; Ghavami, M.; Abbasi, M.M.; Gargari, B.P. Pro- and prebiotic effects on oxidative stress and inflammatory markers in non-alcoholic fatty liver disease. Asia Pac. J. Clin. Nutr. 2018, 27, 1031-1039. [CrossRef] [PubMed]

86. Bakhshimoghaddam, F.; Shateri, K.; Sina, M.; Hashemian, M.; Alizadeh, M. Daily consumption of synbiotic yogurt decreases liver steatosis in patients with nonalcoholic fatty liver disease: A randomized controlled clinical trial. J. Nutr. 2018, 148, 1276-1284. [CrossRef] [PubMed]

87. Chen, Y.T.; Lin, Y.C.; Lin, J.S.; Yang, N.S.; Chen, M.J. Sugary kefir strain lactobacillus mali APS1 ameliorated hepatic steatosis by regulation of SIRT-1/Nrf-2 and gut microbiota in rats. Mol. Nutr. Food Res. 2018, 62, 1-24. [CrossRef]

88. Kozmus, C.E.P.; Moura, E.; Serrão, M.P.; Real, H.; Guimarães, J.T.; Guedes-de-Pinho, P.; Duarte, B.P.; Marques, F.; Martins, M.J.; Vieira-Coelho, M.A. Influence of dietary supplementation with dextrin or oligofructose on the hepatic redox balance in rats. Mol. Nutr. Food Res. 2011, 55, 1735-1739. [CrossRef] 
89. Anhê, F.F.; Roy, D.; Pilon, G.; Dudonné, S.; Matamoros, S.; Varin, T.V.; Garofalo, C.; Moine, Q.; Desjardins, Y.; Levy, E.; et al. A polyphenol-rich cranberry extract protects from diet-induced obesity, insulin resistance and intestinal inflammation in association with increased Akkermansia spp. population in the gut microbiota of mice. Gut 2015, 64, 872-883. [CrossRef]

90. Koutoukidis, D.; Astbury, N.; Tudor, K.; Morris, E.; Henry, J.; Noreik, M.; Jebb, S.; Aveyard, P. Association of weight loss interventions with changesin biomarkers of nonalcoholic fatty liver diseasea systematic review and meta-analysis. JAMA Int. Med. 2019, 179. [CrossRef]

91. Wehmeyer, M.H.; Zyriax, B.C.; Jagemann, B.; Roth, E.; Windler, E.; Wiesch, J.S.Z.; Lohse, A.W.; Kluwe, J. Nonalcoholic fatty liver disease is associated with excessive calorie intake rather than a distinctive dietary pattern. Medicina 2016, 95. [CrossRef] [PubMed]

92. Duszka, K.; Gregor, A.; Guillou, H.; König, J.; Wahli, W. Peroxisome proliferator-activated receptors and caloric restriction-common pathways affecting metabolism, health, and longevity. Cells 2020, 9, 1708. [CrossRef] [PubMed]

93. Kirk, E.; Reeds, D.N.; Finck, B.N.; Mayurranjan, M.S.; Patterson, B.W.; Klein, S. Dietary fat and carbohydrates differentially alter insulin sensitivity during caloric restriction. Gastroenterology 2009, 136, 1552-1560. [CrossRef] [PubMed]

94. Haufe, S.; Engeli, S.; Kast, P.; Böhnke, J.; Utz, W.; Haas, V.; Hermsdorf, M.; Mähler, A.; Wiesner, S.; Birkenfeld, A.L.; et al. Randomized comparison of reduced fat and reduced carbohydrate hypocaloric diets on intrahepatic fat in overweight and obese human subjects. Hepatology 2011, 53, 1504-1514. [CrossRef] [PubMed]

95. Parry, S.A.; Hodson, L. Managing NAFLD in Type 2 Diabetes: The effect of lifestyle interventions, a narrative review. Adv. Ther. 2020, 37, 1381-1406. [CrossRef]

96. Negri, R.; Trinchese, G.; Carbone, F.; Caprio, M.G.; Stanzione, G.; di Scala, C.; Micillo, T.; Perna, F.; Tarotto, L.; Gelzo, M.; et al. Randomised clinical trial: Calorie restriction regimen with tomato juice supplementation ameliorates oxidative stress and preserves a proper immune surveillance modulating mitochondrial bioenergetics of T-lymphocytes in obese children affected by non-alco. J. Clin. Med. 2020, 9, 141. [CrossRef]

97. Kim, K.E.; Jung, Y.; Min, S.; Nam, M.; Heo, R.W.; Jeon, B.T.; Song, D.H.; Yi, C.O.; Jeong, E.A.; Kim, H.; et al. Caloric restriction of $\mathrm{db} / \mathrm{db}$ mice reverts hepatic steatosis and body weight with divergent hepatic metabolism. Sci. Rep. 2016, 6, 1-14. [CrossRef]

98. Tosti, V.; Bertozzi, B.; Fontana, L. Health benefits of the mediterranean diet: Metabolic and molecular mechanisms. J. Gerontol. Ser. A Biol. Sci. Med. Sci. 2018, 73, 318-326. [CrossRef]

99. Lambertz, J.; Weiskirchen, S.; Landert, S.; Weiskirchen, R. Fructose: A dietary sugar in crosstalk with microbiota contributing to the development and progression of non-alcoholic liver disease. Front. Immunol. 2017, 8. [CrossRef]

100. Dupas, J.; Goanvec, C.; Feray, A.; Guernec, A.; Alain, C.; Guerrero, F.; Mansourati, J. Progressive induction of type 2 diabetes: Effects of a reality-like fructose enriched diet in young Wistar rats. PLOS ONE 2016, 11, e0146821. [CrossRef]

101. Koh, A.; De Vadder, F.; Kovatcheva-Datchary, P.; Bäckhed, F. From dietary fiber to host physiology: Short-chain fatty acids as key bacterial metabolites. Cell 2016, 165, 1332-1345. [CrossRef] [PubMed]

102. Montagner, A.; Korecka, A.; Polizzi, A.; Lippi, Y.; Blum, Y.; Canlet, C.; Tremblay-Franco, M.; Gautier-Stein, A.; Burcelin, R.; Yen, Y.C.; et al. Hepatic circadian clock oscillators and nuclear receptors integrate microbiome-derived signals. Sci Rep. 2016, 6, 20127. [CrossRef] [PubMed]

103. Oh, H.Y.P.; Visvalingam, V.; Wahli, W. The PPAR-microbiota-metabolic organ trilogy to fine-tune physiology. FASEB J. 2019, 33, 9706-9730. [CrossRef] [PubMed]

104. Alvarez, Y.; Glotfelty, L.G.; Blank, N.; Dohnalová, L.; Thaiss, C.A. The microbiome as a circadian coordinator of metabolism. Endocrinology 2020, 161, 1-9. [CrossRef] [PubMed]

105. Quesada-Vázquez, S.; Aragonès, G.; Del Bas, J.M.; Escoté, X. Diet, gut microbiota and non-alcoholic fatty liver disease: Three parts of the same axis. Cells 2020, 9, 176. [CrossRef]

106. Kolodziejczyk, A.A.; Zheng, D.; Elinav, E. Diet-microbiota interactions and personalized nutrition. Nat. Rev. Microbiol. 2019, 17, 742-753. [CrossRef]

107. Schwenger, K.J.; Clermont-Dejean, N.; Allard, J.P. The role of the gut microbiome in chronic liver disease: The clinical evidence revised. JHEP Rep. 2019, 1, 214-226. [CrossRef] 
108. Gunnarsson, L.G.; Bodin, L. Parkinson's disease and occupational exposures: A systematic literature review and meta-analyses. Scand. J. Work. Environ. Health 2017, 43, 197-209. [CrossRef]

109. Piel, C.; Pouchieu, C.; Tual, S.; Migault, L.; Lemarchand, C.; Carles, C.; Boulanger, M.; Gruber, A.; Rondeau, V.; Marcotullio, E.; et al. Central nervous system tumors and agricultural exposures in the prospective cohort AGRICAN. Int. J. Cancer 2017, 141, 1771-1782. [CrossRef]

110. Montgomery, M.P.; Kame, F.; Saldana, T.M.; Alavanja, M.C.R.; Sandler, D.P. Incident diabetes and pesticide exposure among licensed pesticide applicators: Agricultural health study 1993-200. Am. J. Epidemiol. 2008, 167, 1235-1246. [CrossRef]

111. Cimino, A.M.; Boyles, A.L.; Thayer, K.A.; Perry, M.J. Environmental health perspectives effects of neonicotinoid pesticide exposure on human health: A systematic review. Environ. Health Perspect. 2017, 125, 155-162. [CrossRef] [PubMed]

112. Rebouillat, P.; Vidal, R.; Cravedi, J.-P.; Taupier-Letage, B.; Debrauwer, L.; Gamet-Payrastre, L.; Touvier, M.; Hercberg, S.; Lairon, D.; Baudry, J.; et al. Estimated dietary pesticide exposure from plant-based foods using NMF-derived profiles in a large sample of French adults. Eur. J. Nutr. 2020. [CrossRef] [PubMed]

113. Baudry, J.; Assmann, K.E.; Touvier, M.; Allès, B.; Seconda, L.; Latino-Martel, P.; Ezzedine, K.; Galan, P.; Hercberg, S.; Lairon, D.; et al. Association of frequency of organic food consumption with cancer risk: Findings from the NutriNet-Santé prospective cohort study. JAMA Int. Med. 2018, 178, 1597-1606. [CrossRef] [PubMed]

114. Baudry, J.; Lelong, H.; Adriouch, S.; Julia, C.; Allès, B.; Hercberg, S.; Touvier, M.; Lairon, D.; Galan, P.; Kesse-Guyot, E. Association between organic food consumption and metabolic syndrome: Cross-sectional results from the NutriNet-Santé study. Eur. J. Nutr. 2018, 57, 2477-2488. [CrossRef] [PubMed]

115. Mostafalou, S.; Abdollahi, M. Pesticides: An update of human exposure and toxicity. Arch. Toxicol. 2017, 91, 549-599. [CrossRef]

116. Marroqui, L.; Tudurí, E.; Alonso-Magdalena, P.; Quesada, I.; Nadal, Á.; Dos Santos, R.S. Mitochondria as target of endocrine-disrupting chemicals: Implications for type 2 diabetes. J. Endocrinol. 2018, 239, R27-R45. [CrossRef]

117. Alonso-Magdalena, P.; Quesada, I.; Nadal, A. Endocrine disruptors in the etiology of type 2 diabetes mellitus. Nat. Rev. Endocrinol. 2011, 7, 346-353. [CrossRef]

118. Gore, A.C.; Chappell, V.A.; Fenton, S.E.; Flaws, J.A.; Nadal, A.; Prins, G.S.; Toppari, J.; Zoeller, R.T. EDC-2: The endocrine society's second scientific statement on endocrine-disrupting chemicals. Endocr. Rev. 2015, 36, 1-150. [CrossRef]

119. Heindel, J.J.; Blumberg, B.; Cave, M.; Machtinger, R.; Mantovani, A.; Mendez, M.A.; Nadal, A.; Palanza, P.; Panzica, G.; Sargis, R.; et al. Metabolism disrupting chemicals and metabolic disorders. Reprod. Toxicol. 2017, 68, 3-33. [CrossRef]

120. Nadal, A.; Quesada, I.; Tudurí, E.; Nogueiras, R.; Alonso-Magdalena, P. Endocrine-disrupting chemicals and the regulation of energy balance. Nat. Rev. Endocrinol. 2017, 13, 536-546. [CrossRef]

121. Khan, F.; Hodjat, M.; Rahimifard, M.; Nigjeh, M.N.; Azizi, M.; Baeeri, M.; Bayrami, Z.; Gholami, M.; Hassani, S.; Abdollahi, M. Assessment of arsenic-induced modifications in the DNA methylation of insulin-related genes in rat pancreatic islets. Ecotoxicol. Environ. Saf. 2020, 201, 110802. [CrossRef] [PubMed]

122. Marmugi, A.; Ducheix, S.; Lasserre, F.; Polizzi, A.; Paris, A.; Priymenko, N.; Bertrand-Michel, J.; Pineau, T.; Guillou, H.; Martin, P.G.; et al. Low doses of bisphenol A induce gene expression related to lipid synthesis and trigger triglyceride accumulation in adult mouse liver. Hepatology 2012, 55, 395-407. [CrossRef] [PubMed]

123. Wahlang, B.; Jin, J.; Beier, J.I.; Hardesty, J.E.; Daly, E.F.; Schnegelberger, R.D.; Falkner, K.C.; Prough, R.A.; Kirpich, I.A.; Cave, M.C. Mechanisms of environmental contributions to fatty liver disease. Curr. Environ. Health Rep. 2019, 6, 80-94. [CrossRef] [PubMed]

124. Wahlang, B.; Appana, S.; Falkner, K.C.; McClain, C.J.; Brock, G.; Cave, M.C. Insecticide and metal exposures are associated with a surrogate biomarker for non-alcoholic fatty liver disease in the national health and nutrition examination survey 2003-2004. Environ. Sci. Pollut. Res. 2020, 27, 6476-6487. [CrossRef]

125. Evangelou, E.; Ntritsos, G.; Chondrogiorgi, M.; Kavvoura, F.K.; Hernández, A.F.; Ntzani, E.E.; Tzoulaki, I. Exposure to pesticides and diabetes: A systematic review and meta-analysis. Environ. Int. 2016, 91, 60-68. [CrossRef] 
126. Song, Y.; Chou, E.L.; Baecker, A.; You, N.C.Y.; Song, Y.; Sun, Q.; Liu, S. Endocrine-disrupting chemicals, risk of type 2 diabetes, and diabetes-related metabolic traits: A systematic review and meta-analysis. J. Diabetes 2016, 8, 516-532. [CrossRef]

127. Salihovic, S.; Ganna, A.; Fall, T.; Broeckling, C.D.; Prenni, J.E.; van Bavel, B.; Lind, P.M.; Ingelsson, E.; Lind, L. The metabolic fingerprint of p,p'-DDE and HCB exposure in humans. Environ. Int. 2016, 88, 60-66. [CrossRef]

128. Rosenbauma, P.F.; Weinstockb, R.S.; Silverstonec, A.E.; Sjödind, A.; Pavuk, M. Metabolic syndrome is associated with exposure to organochlorine pesticides in Anniston, AL, United States. Physiol. Behav. 2017, 176, 139-148. [CrossRef]

129. Cano-Sancho, G.; Salmon, A.G.; Merrill, M.A. La obesity: Integrated systematic review and meta-analysis. Env. Health Perspect 2017, 1-15.

130. Jaacks, L.M.; Staimez, L.R. Association of persistent organic pollutants and non-persistent pesticides with diabetes and diabetes-related health outcomes in Asia: A systematic review. Environ. Int. 2015, 76, 57-70. [CrossRef]

131. Corsini, E.; Sokooti, M.; Galli, C.L.; Moretto, A.; Colosio, C. Pesticide induced immunotoxicity in humans: A comprehensive review of the existing evidence. Toxicology 2013, 307, 123-135. [CrossRef] [PubMed]

132. Park, S.; Kim, S.; Kim, J.; Lee, K.; Ran, J. Exposure to pesticides and the prevalence of diabetes in a rural population in Korea. Neurotoxicology 2019, 70, 12-18. [CrossRef] [PubMed]

133. Kongtip, P.; Nankongnab, N.; Tipayamongkholgul, M.; Bunngamchairat, A.; Yimsabai, J.; Pataitiemthong, A.; Woskie, S. A cross-sectional investigation of cardiovascular and metabolic biomarkers among conventional and organic farmers in thailand. Int. J. Environ. Res. Public Health 2018, 15, 2590. [CrossRef] [PubMed]

134. Zhang, P.; Zhu, W.; Wang, D.; Yan, J.; Wang, Y.; Zhou, Z.; He, L. A combined NMR- and HPLC-MS/MS-based metabolomics to evaluate the metabolic perturbations and subacute toxic effects of endosulfan on mice. Environ. Sci. Pollut. Res. 2017, 24, 18870-18880. [CrossRef]

135. Czajka, M.; Matysiak-Kucharek, M.; Jodłowska-Jędrych, B.; Sawicki, K.; Fal, B.; Drop, B.; Kruszewski, M.; Kapka-Skrzypczak, L. Organophosphorus pesticides can influence the development of obesity and type 2 diabetes with concomitant metabolic changes. Environ. Res. 2019, 178, 108685. [CrossRef]

136. Yang, J.S.; Park, Y. Insecticide Exposure and Development of Nonalcoholic Fatty Liver Disease. J. Agric. Food Chem. 2018, 66, 10132-10138. [CrossRef]

137. Aouey, B.; Derbali, M.; Chtourou, Y.; Bouchard, M.; Khabir, A.; Fetoui, H. Pyrethroid insecticide lambda-cyhalothrin and its metabolites induce liver injury through the activation of oxidative stress and proinflammatory gene expression in rats following acute and subchronic exposure. Environ. Sci. Pollut. Res. 2017, 24, 5841-5856. [CrossRef]

138. Martínez, M.; Ares, I.; Rodríguez, J.; Martínez, M.; Roura-martínez, D.; Castellano, V.; Lopez-torres, B.; Anadón, A. Pyrethroid insecticide lambda -cyhalothrin induces hepatic cytochrome P450 enzymes, oxidative stress and apoptosis in rats. Sci. Total Environ. 2018, 631-632, 1371-1382. [CrossRef]

139. Ince, S.; Arslan-acaroz, D.; Huseyin, H.; Varol, N. Taurine alleviates malathion induced lipid peroxidation, oxidative stress, and proin fl ammatory cytokine gene expressions in rats. Biomed. Pharmacother. 2017, 96, 263-268. [CrossRef]

140. Lassiter, T.L.; Brimijoin, S. Rats gain excess weight after developmental exposure to the organophosphorothionate pesticide, chlorpyrifos. Neurotox. Teratol. 2008, 30, 125-130. [CrossRef]

141. Toor, H.K.; Sangha, G.K.; Khera, K.S. Imidacloprid induced histological and biochemical alterations in liver of female albino rats. Pestic. Biochem. Physiol. 2013, 105, 1-4. [CrossRef] [PubMed]

142. Vohra, P.; Khera, K.S. A Three Generation Study with Effect of Imidacloprid in Rats: Biochemical and Histopathological Investigation. Toxico. Int. 2015, 22, 119-124. [CrossRef] [PubMed]

143. El Okle, O.S.; El Euony, O.I.; Khafaga, A.F.; Lebda, M.A. Thiamethoxam induced hepatotoxicity and pro-carcinogenicity in rabbits via motivation of oxidative stress, inflammation, and anti-apoptotic pathway. Environ. Sci. Pollut. Res. 2018, 25, 4678-4689. [CrossRef] [PubMed]

144. Maalej, A.; Mahmoudi, A.; Bouallagui, Z.; Fki, I.; Marrekchi, R.; Sayadi, S. Olive phenolic compounds attenuate deltamethrin-induced liver and kidney toxicity through regulating oxidative stress, inflammation and apoptosis. Food Chem. Toxicol. 2017, 106, 455-465. [CrossRef] 
145. Hocine, L.; Merzouk, H.; Merzouk, S.A.; Ghorzi, H.; Youbi, M.; Narce, M. The effects of alpha-cypermethrin exposure on biochemical and redox parameters in pregnant rats and their newborns. Pestic. Biochem. Physiol. 2016, 134, 49-54. [CrossRef]

146. Ghorzi, H.; Merzouk, H.; Hocine, L.; Merzouk, S.A. Long term biochemical changes in offspring of rats fed diet containing alpha-cypermethrin. Pestic. Biochem. Physiol. 2017, 142, 133-140. [CrossRef]

147. Wahlang, B.; Beier, J.I.; Clair, H.B.; Bellis-Jones, H.J.; Falkner, K.C.; McClain, C.J.; Cave, M.C. Toxicant-associated steatohepatitis. Toxicol. Pathol. 2013, 41, 343-360. [CrossRef]

148. Lim, S.; Ahn, S.Y.; Song, I.C.; Chung, M.H.; Jang, H.C.; Park, K.S.; Lee, K.U.; Pak, Y.K.; Lee, H.K. Chronic exposure to the herbicide, atrazine, causes mitochondrial dysfunction and insulin resistance. PLoS ONE 2009, 4. [CrossRef]

149. De Long, N.; Holloway, A. Early-life chemical exposures and risk of metabolic syndrome. Diabetes Metab. Syndr. Obes. Targets Ther. 2017, 101-109. [CrossRef]

150. Ren, X.; Dai, P.; Perveen, A.; Tang, Q.; Zhao, L.; Jia, X.; Li, Y.; Li, C. Effects of chronic glyphosate exposure to pregnant mice on hepatic lipid metabolism in offspring. Environ. Pollut. 2019, 254, 112906. [CrossRef]

151. Mesnage, R.; Renney, G.; Séralini, G.; Ward, M.; Antoniou, M.N. Multiomics reveal non-alcoholic fatty liver disease in rats following chronic exposure to an ultra-low dose of Roundup herbicide. Nat. Publ. Gr. 2017, 1-15. [CrossRef] [PubMed]

152. Armstrong, L.E.; Guo, G.L. Understanding environmental contaminants' direct effects on non-alcoholic fatty liver disease progression. Curr. Environ. Health Rep. 2019, 6, 95-104. [CrossRef] [PubMed]

153. Tang, J.; Hu, P.; Li, Y.; Li, C. Ion imbalance is involved in the mechanisms of liver oxidative damage in rats exposed to glyphosate. Front. Physiol. 2017, 8, 1-12. [CrossRef] [PubMed]

154. Ahmad, M.I.; Zafeer, M.F.; Javed, M.; Ahmad, M. Pendimethalin-induced oxidative stress, DNA damage and activation of anti-inflammatory and apoptotic markers in male rats. Sci. Rep. 2018, 8, 1-9. [CrossRef] [PubMed]

155. Troudi, A.; Amara, I.B.; Samet, A.M.; Zeghal, N. Oxidative stress induced by 2, 4-phenoxyacetic acid in liver of female rats and their progeny: Biochemical and histopathological studies. Environ. Toxicol. 2010, 137-145. [CrossRef] [PubMed]

156. Meng, Z.; Liu, L.; Jia, M.; Li, R.; Yan, S.; Tian, S.; Sun, W.; Zhou, Z.; Zhu, W. Impacts of penconazole and its enantiomers exposure on gut microbiota and metabolic profiles in mice. J. Agric. Food Chem. 2019. [CrossRef]

157. Marx-Stoelting, P.; Ganzenberg, K.; Knebel, C.; Schmidt, F.; Rieke, S.; Hammer, H.; Schmidt, F.; Pötz, O.; Schwarz, M.; Braeuning, A. Hepatotoxic effects of cyproconazole and prochloraz in wild-type and hCAR/hPXR mice. Arch. Toxicol. 2017, 91, 2895-2907. [CrossRef]

158. Heise, T.; Schmidt, F.; Knebel, C.; Rieke, S.; Haider, W.; Geburek, I.; Niemann, L.; Marx-Stoelting, P. Hepatotoxic combination effects of three azole fungicides in a broad dose range. Arch. Toxicol. 2018, 92, 859-872. [CrossRef]

159. Jin, C.; Luo, T.; Fu, Z.; Jin, Y. Chronic exposure of mice to low doses of imazalil induces hepatotoxicity at the physiological, biochemical, and transcriptomic levels. Environ. Toxicol. 2018, 33, 650-658. [CrossRef]

160. Jin, C.; Zeng, Z.; Fu, Z.; Jin, Y. Chemosphere Oral imazalil exposure induces gut microbiota dysbiosis and colonic in $\mathrm{fl}$ ammation in mice. Chemosphere 2016, 160, 349-358. [CrossRef]

161. Regnier, S.M.; Kirkley, A.G.; Ye, H.; El-Hashani, E.; Zhang, X.; Neel, B.A.; Kamau, W.; Thomas, C.C.; Williams, A.K.; Hayes, E.T.; et al. Dietary exposure to the endocrine disruptor tolylfluanid promotes global metabolic dysfunction in male mice. Endocrinology 2015, 156, 896-910. [CrossRef] [PubMed]

162. Valvi, D.; Mendez, M.A.; Martinez, D.; Grimalt, J.O.; Torrent, M.; Sunyer, J.; Vrijheid, M. Prenatal concentrations of polychlorinated biphenyls, DDE, and DDT and overweight in children: A prospective birth cohort study. Environ. Health Perspect. 2012, 120, 451-457. [CrossRef] [PubMed]

163. Debost-Legrand, A.; Warembourg, C.; Massart, C.; Chevrier, C.; Bonvallot, N.; Monfort, C.; Rouget, F.; Bonnet, F.; Cordier, S. Prenatal exposure to persistent organic pollutants and organophosphate pesticides, and markers of glucose metabolism at birth. Environ. Res. 2016, 146, 207-217. [CrossRef] [PubMed]

164. Jurewicz, J.; Hanke, W.; Makowiec-Dąbrowska, T.; Sobala, W. Exposure to pesticides and heavy work in greenhouses during pregnancy: Does it effect birth weight? Int. Arch. Occup. Environ. Health 2005, 78, 418-426. [CrossRef] [PubMed]

165. Liu, Y.; Peterson, K.E. Maternal exposure to synthetic chemicals and obesity in the offspring-recent findings. Curr. Environ. Health Rep. 2015, 139-148. [CrossRef] 
166. Reygner, J.; Lichtenberger, L.; Elmhiri, G.; Dou, S.; Bahi-Jaber, N.; Rhazi, L.; Depeint, F.; Bach, V.; Khorsi-Cauet, H.; Abdennebi-Najar, L. Inulin supplementation lowered the metabolic defects of prolonged exposure to chlorpyrifos from gestation to young adult stage in offspring rats. PLOS ONE 2016, 11, e0164614. [CrossRef]

167. Svingen, T.; Ramhøj, L.; Mandrup, K.; Christiansen, S.; Axelstad, M.; Vinggaard, A.M.; Hass, U. Effects on metabolic parameters in young rats born with low birth weight after exposure to a mixture of pesticides. Sci. Rep. 2018, 8, 1-10. [CrossRef]

168. Bonvallot, N.; Tremblay-Franco, M.; Chevrier, C.; Canlet, C.; Warembourg, C.; Cravedi, J.P.; Cordier, S. Metabolomics tools for describing complex pesticide exposure in pregnant women in brittany (france). PLOS ONE 2013, 8, e64433. [CrossRef]

169. Slotkin, T.A. Does early-life exposure to organophosphate insecticides lead to prediabetes and obesity? Reprod. Toxicol. 2011, 31, 297-301. [CrossRef]

170. Genoveva, F.; De Oca, G.; López-gonzález, M.D.L. Vinclozolin modulates hepatic cytochrome P450 isoforms during pregnancy. Reprod. Toxicol. 2015, 53, 119-126. [CrossRef]

171. Ward, A.B.; Dail, M.B.; Chambers, J.E. In Vitro effect of DDE exposure on the regulation of lipid metabolism and secretion in McA-RH7777 hepatocytes: A potential role in dyslipidemia which may increase the risk of type 2 diabetes mellitus. Toxicol. Vitr. 2016, 37, 9-14. [CrossRef] [PubMed]

172. Howell, G.E.; McDevitt, E.; Henein, L.; Mulligan, C.; Young, D. Alterations in cellular lipid metabolism produce neutral lipid accumulation following exposure to the organochlorine compound trans-nonachlor in rat primary hepatocytes. Environ. Toxicol. 2018, 33, 962-971. [CrossRef] [PubMed]

173. Howell 3rd, G.E.; Mulligan, C.; Young, D.; Kondakala, S. Exposure to chlorpyrifos increases neutral lipid accumulation with accompanying increased de novo lipogenesis and decreased triglyceride secretion in McArdle-RH7777 hepatoma cells. Toxic. Vitr. 2016, 32, 181-189. [CrossRef] [PubMed]

174. Mesnage, R.; Biserni, M.; Wozniak, E.; Xenakis, T.; Mein, C.A.; Antoniou, M.N. Comparison of transcriptome responses to glyphosate, isoxa fl utole, quizalofop-p-ethyl and mesotrione in the HepaRG cell line. Toxicol. Rep. 2018, 5, 819-826. [CrossRef] [PubMed]

175. Yang, J.S.; Qi, W.; Farias-pereira, R.; Choi, S.; Clark, J.M.; Kim, D.; Park, Y. Permethrin and ivermectin modulate lipid metabolism in steatosis-induced HepG2 hepatocyte. Food Chem. Toxicol. 2020, 125, 595-604. [CrossRef] [PubMed]

176. Kojima, H.; Sata, F.; Takeuchi, S.; Sueyoshi, T.; Nagai, T. Comparative study of human and mouse pregnane $X$ receptor agonistic activity in 200 pesticides using in vitro reporter gene assays. Toxicology 2011, 280, 77-87. [CrossRef]

177. Xiang, D.; Chu, T.; Li, M.; Wang, Q.; Zhu, G. Effects of pyrethroid pesticide cis -bifenthrin on lipogenesis in hepatic cell line. Chemosphere 2018, 201, 840-849. [CrossRef]

178. Lichtenstein, D.; Luckert, C.; Alarcan, J.; de Sousa, G.; Gioutlakis, M.; Katsanou, E.S.; Konstantinidou, P.; Machera, K.; Milani, E.S.; Peijnenburg, A.; et al. An adverse outcome pathway-based approach to assess steatotic mixture effects of hepatotoxic pesticides in vitro. Food Chem. Toxicol. 2020, 139, 111283. [CrossRef]

179. Qian, L.; Zhang, J.; Chen, X.; Qi, S.; Wu, P.; Wang, C.; Wang, C. Toxic effects of boscalid in adult zebra fish (Danio rerio) on carbohydrate and lipid metabolism. Environ. Pollut. 2019, 247, 775-782. [CrossRef]

180. Wu, S.; Jin, C.; Wang, Y.; Fu, Z.; Jin, Y. Exposure to the fungicide propamocarb causes gut microbiota dysbiosis and metabolic disorder in mice. Environ. Pollut. 2018, 237, 775-783. [CrossRef]

181. Teimouri, F.; Amirkabirian, N.; Esmaily, H.; Mohammadirad, A.; Aliahmadi, A.; Abdollahi, M. Alteration of hepatic cells glucose metabolism as a non-cholinergic detoxication mechanism in counteracting diazinon-induced oxidative stress. Hum. Exp. Toxicol. 2006, 25, 697-703. [CrossRef] [PubMed]

182. Begum, K.; Rajini, P.S. Augmentation of hepatic and renal oxidative stress and disrupted glucose homeostasis by monocrotophos in streptozotocin-induced diabetic rats. Chem. Biol. Interact. 2011, 193, 240-245. [CrossRef] [PubMed]

183. Karami-Mohajeri, S.; Abdollahi, M. Toxic influence of organophosphate, carbamate, and organochlorine pesticides on cellular metabolism of lipids, proteins, and carbohydrates: A systematic review. Hum. Exp. Toxicol. 2011, 30, 1119-1140. [CrossRef] [PubMed]

184. Gao, A.; Fu, Y.; Zhang, K.; Zhang, M.; Jiang, H.; Fan, L.; Nan, F.; Yuan, C.; Li, J.; Zhou, Y.; et al. Azoxystrobin, a mitochondrial complex III $\mathrm{Q}$ o site inhibitor, exerts bene fi cial metabolic effects in vivo and in vitro. BBA Gen. Subj. 2014, 1840, 2212-2221. [CrossRef] 
185. Jin, Y.; Lin, X.; Miao, W.; Wu, T.; Shen, H.; Chen, S.; Li, Y.; Pan, Q.; Fu, Z. Chronic exposure of mice to environmental endocrine-disrupting chemicals disturbs their energy metabolism. Toxicol. Lett. 2014, 225, 392-400. [CrossRef] [PubMed]

186. Sun, H.; Shao, W.; Liu, H.; Jiang, Z. Exposure to 2,4-dichlorophenoxyacetic acid induced PPAR $\beta$-dependent disruption of glucose metabolism in HepG2 cells. Environ. Sci. Pollut. Res. 2018, 25, 17050-17057. [CrossRef] [PubMed]

187. Lasram, M.M.; Dhouib, I.B.; Bouzid, K.; Lamine, A.J.; Annabi, A.; Belhadjhmida, N.; Ahmed, M.B.; Fazaa, S.E.; Abdelmoula, J.; Gharbi, N. Association of inflammatory response and oxidative injury in the pathogenesis of liver steatosis and insulin resistance following subchronic exposure to malathion in rats. Environ. Toxicol. Pharmacol. 2014, 38, 542-553. [CrossRef] [PubMed]

188. Yousefizadeh, S.; Farkhondeh, T.; Samarghandian, S. Age-related diazinon toxicity impact on blood glucose, lipid profile and selected biochemical indices in male rats. Curr. Aging Sci. 2019, 12, 49-54. [CrossRef]

189. Lasram, M.M.; Bouzid, K.; Douib, I.B.; Annabi, A.; El Elj, N.; El Fazaa, S.; Abdelmoula, J.; Gharbi, N. Lipid metabolism disturbances contribute to insulin resistance and decrease insulin sensitivity by malathion exposure in Wistar rat. Drug Chem. Toxicol. 2015, 38, 227-234. [CrossRef]

190. Meng, Z.; Liu, L.; Xi, Y.; Jia, M.; Yan, S.; Tian, S.; Sun, W.; Zhu, W.; Li, X.; Zhou, Z. Different effects of exposure to penconazole and its enantiomers on hepatic glycolipid metabolism of male mice. Environ. Pollut. 2020, 257, 113555. [CrossRef]

191. Jin, C.; Zeng, Z.; Wang, C.; Luo, T.; Wang, S.; Zhou, J.; Ni, Y.; Fu, Z.; Jin, Y. Insights into a possible mechanism underlying the connection of carbendazim-induced lipid metabolism disorder and gut microbiota dysbiosis in mice. Toxicol. Sci. 2018, 166, 382-393. [CrossRef] [PubMed]

192. Lukowicz, C.; Ellero-simatos, S.; Régnier, M.; Polizzi, A.; Lasserre, F.; Montagner, A.; Lippi, Y.; Jamin, E.L.; Martin, J.; Naylies, C.; et al. Metabolic effects of a chronic dietary exposure to a low-dose pesticide cocktail in mice: Sexual dimorphism and role of the constitutive androstane receptor. Environ. Health Perspect. 2018, 126, 1-18. [CrossRef] [PubMed]

193. Jellali, R.; José, M.; Gilard, F.; Pandolfi, V.; Legendre, A.; Leclerc, E. Metabolomics-on a chip approach to study hepatotoxicity of DDT, permethrin and their mixtures. J. App. Toxic. 2018, 1121-1134. [CrossRef] [PubMed]

194. Ghose, R.; Omoluabi, O.; Gandhi, A.; Shah, P.; Strohacker, K.; Carpenter, K.; McFarlin, B.; Guo, T. Role of high-fat diet in regulation of gene expression of drug metabolizing enzymes and transporters. Life Sci. 2011, 4, 57-64. [CrossRef]

195. Howell Iii, G.E.; Kondakala, S.; Holdridge, J.; Lee, J.H.; Ross, M.K. Inhibition of cholinergic and non-cholinergic targets following subacute exposure to chlorpyrifos in normal and high fat fed male C57BL/6J mice. Food Chem. Toxic. 2019, 118, 821-829. [CrossRef]

196. Kondakala, S.; Lee, J.H.; Ross, M.K.; Howell, G.E. Effects of acute exposure to chlorpyrifos on cholinergic and non-cholinergic targets in normal and high-fat fed male C57BL/6J mice. Toxicol. Appl. Pharmacol. 2017, 337, 67-75. [CrossRef]

197. Lassiter, T.L.; Ryde, I.T.; Mackillop, E.A.; Brown, K.K.; Levin, E.D.; Seidler, F.J.; Slotkin, T.A. Exposure of neonatal rats to parathion elicits sex-selective reprogramming of metabolism and alters the response to a high-fat diet in adulthood. Environ. Health Perspect. 2008, 116, 1456-1462. [CrossRef]

198. Prates, V.K.; Ribeiro, T.; AudreiSaavedra, L.P.; Moreira, V.; da Silva Sliveira, S.; Martins, I.; Francisco, F.; Ferreira Junoior, M.D.; Alves, V.; Tofolo, L.; et al. Potential attenuation of early-life overfeeding-induced metabolic dysfunction by chronic maternal acetylcholinesterase inhibitor exposure. Toxicology 2019, 425, 152250. [CrossRef]

199. Sun, Q.; Xiao, X.; Kim, Y.; Kim, D.; Yoon, K.S.; Clark, J.M.; Park, Y. Imidacloprid Promotes High Fat Diet-Induced Adiposity and Insulin Resistance in Male C57BL/6J Mice. J. Agric. Food Chem. 2016, 64, 9293-9306. [CrossRef]

200. Jin, L.; Wang, R.; Zhu, Y.; Zheng, W.; Han, Y.; Guo, F.; Ye, F.B.; Li, Y. Selective targeting of nuclear receptor FXR by avermectin analogues with therapeutic effects on nonalcoholic fatty liver disease. Sci. Rep. 2015, 5, 1-15. [CrossRef]

201. Jin, L.; Feng, X.; Rong, H.; Pan, Z.; Inaba, Y.; Qiu, L.; Zheng, W.; Lin, S.; Wang, R.; Wang, Z.; et al. The antiparasitic drug ivermectin is a novel FXR ligand that regulates metabolism. Nat. Commun. 2013, 4, 1-8. [CrossRef] [PubMed] 
202. Mulligan, C.; Kondakala, S.; Yang, E.J.; Stokes, J.V.; Stewart, J.A.; Kaplan, B.L.; Howell, G.E., 3rd. Exposure to an environmentally relevant mixture of organochlorine compounds and polychlorinated biphenyls Promotes hepatic steatosis in male $\mathrm{Ob} / \mathrm{Ob}$ mice. Environ. Toxicol. 2016. [CrossRef]

203. Migliaccio, V.; Scudiero, R.; Sica, R.; Lionetti, L.; Putti, R. Oxidative stress and mitochondrial uncoupling protein 2 expression in hepatic steatosis induced by exposure to xenobiotic DDE and high fat diet in male Wistar rats. PLoS ONE 2019, 14, 1-24. [CrossRef] [PubMed]

204. Rodriguez-Alcala, L.M.; Sa, C.; Pimentel, L.L.; Pestana, D.; Teixeira, D.; Faria, A.; Calhau, C.; Gomes, A. Endocrine disruptor DDE associated with a high-fat diet enhances the impairment of liver fatty acid composition in rats. J. Agric. Food Chem. 2015. [CrossRef]

205. Howell III, G.; Mulligan, C.; Meek, E.; Chambers, J.E.; State, M.; State, M. Effect of chronic $\mathrm{p}, \mathrm{p}^{\prime}$-dichlorodiphenyldichloroethylene (DDE) exposure on high fat diet-induced alterations in glucose and lipid metabolism in male C57BL/6H mice. Toxicology 2019, 112-122. [CrossRef]

206. La Merrill, M.; Karey, E.; Moshier, E.; Lindtner, C.; La Frano, M.R.; Newman, J.W.; Buettner, C. Perinatal exposure of mice to the pesticide DDT impairs energy expenditure and metabolism in adult female offspring. PLoS ONE 2014, 9, 1-11. [CrossRef]

207. Wang, D.; Wang, X.; Zhang, P.; Wang, Y.; Zhang, R.; Yan, J.; Zhou, Z.; Zhu, W. The fate of technical-grade chlordane in mice fed a high-fat diet and its roles as a candidate obesogen. Environ. Pollut. 2017, 222, 532-542. [CrossRef]

208. Xiao, X.; Sun, Q.; Kim, Y.; Yang, S.H.; Qi, W.; Kim, D.; Yoon, K.S.; Clark, J.M.; Park, Y. Exposure to permethrin promotes high fat diet-induced weight gain and insulin resistance in male C57BL/6J mice. Food Chem. Toxicol. 2018, 111, 405-416. [CrossRef]

209. Liang, Y.; Zhan, J.; Liu, D.; Luo, M.; Han, J.; Liu, X.; Liu, C.; Cheng, Z.; Zhou, Z.; Wang, P. Organophosphorus pesticide chlorpyrifos intake promotes obesity and insulin resistance through impacting gut and gut microbiota. Microbiome 2019, 7, 1-15. [CrossRef]

210. Fang, B.; Li, J.W.; Zhang, M.; Ren, F.Z.; Pang, G.F. Chronic chlorpyrifos exposure elicits diet-specific effects on metabolism and the gut microbiome in rats. Food Chem. Toxicol. 2018, 111, 144-152. [CrossRef]

211. Migliaccio, V.; Di Gregorio, I.; Putti, R.; Lionetti, L. Mitochondrial involvement in the adaptive response to chronic exposure to environmental pollutants and high-fat feeding in a rat liver and testis. Cells 2019, 8, 834 . [CrossRef] [PubMed]

212. Claus, S.P.; Guillou, H.; Ellero-Simatos, S. The gut microbiota: A major player in the toxicity of environmental pollutants? NPJ Biofilms Microbiomes 2016, 2, 16003. [CrossRef] [PubMed]

213. Tsiaoussis, J.; Antoniou, M.N.; Koliarakis, I.; Mesnage, R.; Vardavas, C.I.; Izotov, B.N.; Psaroulaki, A.; Tsatsakis, A. Effects of single and combined toxic exposures on the gut microbiome: Current knowledge and future directions. Toxicol. Lett. 2019, 312, 72-97. [CrossRef] [PubMed]

214. Yim, Y.J.; Seo, J.; Kang, S.I.; Ahn, J.H.; Hur, H.G. Reductive dechlorination of methoxychlor and DDT by human intestinal bacterium Eubacterium limosum under anaerobic conditions. Arch. Environ. Contam. Toxicol. 2008, 54, 406-411. [CrossRef] [PubMed]

215. Liu, Q.; Wang, Q.; Xu, C.; Shao, W.; Zhang, C.; Liu, H.; Jiang, Z.; Gu, A. Organochloride pesticides impaired mitochondrial function in hepatocytes and aggravated disorders of fatty acid metabolism. Sci. Rep. 2017, 7, 1-11. [CrossRef]

216. Mao, Q.; Manservisi, F.; Panzacchi, S.; Mandrioli, D.; Menghetti, I.; Vornoli, A.; Bua, L.; Falcioni, L.; Lesseur, C.; Chen, J.; et al. The Ramazzini Institute 13-week pilot study on glyphosate and roundup administered at human-equivalent dose to Sprague Dawley rats: Effects on the microbiome. Environ. Health Glob. Access Sci. Source 2018, 17, 1-12. [CrossRef]

217. Mesnage, R.; Oestreicher, N.; Poirier, F.; Nicolas, V.; Boursier, C.; Vélot, C. Transcriptome profiling of the fungus Aspergillus nidulans exposed to a commercial glyphosate-based herbicide under conditions of apparent herbicide tolerance. Environ. Res. 2020, 182, 109116. [CrossRef] [PubMed]

218. Serino, M.; Luche, E.; Gres, S.; Baylac, A.; Bergé, M.; Cenac, C.; Waget, A.; Klopp, P.; Iacovoni, J.; Klopp, C.; et al. Metabolic adaptation to a high-fat diet is associated with a change in the gut microbiota. Gut 2012, 61, 543-553. [CrossRef]

219. Yan, A.; Fouts, D.; Brandl, J.; Starkel, P.; Torralba, M.; Schott, E.; Tsukamoto, H.; Nelson, K.; Brenner, D.; Schnabl, B. Enteric dysbiosis associated with a mouse model of alcoholic liver disease. Hepatology 2011, 53, 96-105. [CrossRef] 
220. Selmanoğlu, G. Carbendazim-induced haematological, biochemical and histopathological changes to the liver and kidney of male rats. Hum. Exp. Toxicol. 2001, 20, 625-630. [CrossRef]

221. Jin, Y.; Wang, L.; Chen, G.; Lin, X.; Miao, W.; Fu, Z. Exposure of mice to atrazine and its metabolite diaminochlorotriazine elicits oxidative stress and endocrine disruption. Environ. Toxicol. Pharmacol. 2014, 37, 782-790. [CrossRef] [PubMed]

222. Chavez-Tapia, N.C.; Lizardi-Cervera, J.; Perez-Bautista, O.; Ramos-Ostos, M.H.; Uribe, M. Smoking is not associated with nonalcoholic fatty liver disease. World J. Gastroenterol. 2006, 12, 5196-5200. [PubMed]

223. Akhavan Rezayat, A.; Dadgar Moghadam, M.; Ghasemi Nour, M.; Shirazinia, M.; Ghodsi, H.; Rouhbakhsh Zahmatkesh, M.R.; Tavakolizadeh Noghabi, M.; Hoseini, B.; Akhavan Rezayat, K. Association between smoking and non-alcoholic fatty liver disease: A systematic review and meta-analysis. SAGE Open Med. 2018, 6, 205031211774522. [CrossRef] [PubMed]

224. Petroni, M.L.; Brodosi, L.; Marchignoli, F.; Musio, A.; Marchesini, G. Moderate alcohol intake in non-alcoholic fatty liver disease: To drink or not to drink? Nutrients 2019, 11, 3048. [CrossRef] [PubMed]

225. Cioboată, R.; Găman, A.; Traşcă, D.; Ungureanu, A.; Docea, A.O.; Tomescu, P.; Gherghina, F.; Arsene, A.L.; Badiu, C.; Tsatsakis, A.M.; et al. Pharmacological management of non-alcoholic fatty liver disease: Atorvastatin versus pentoxifylline. Exp. Ther. Med. 2017, 13, 2375-2381. [CrossRef]

226. Chen, Z.; Tian, R.; She, Z.; Cai, J.; Li, H. Role of oxidative stress in the pathogenesis of nonalcoholic fatty liver disease. Free Radic. Biol. Med. 2020, 152, 116-141. [CrossRef]

227. Omokaro, S.O.; Golden, J.K. The regulatory state of nonalcoholic steatohepatitis and metabolism. Endocrinol. Diab. Metab. 2020, 3, e00113. [CrossRef]

228. Farrell, G.; Schattenberg, J.M.; Leclercq, I.; Yeh, M.M.; Goldin, R.; Teoh, N.; Schuppan, D. Mouse models of nonalcoholic steatohepatitis: Toward optimization of their relevance to human nonalcoholic steatohepatitis. Hepatology 2019, 69, 2241-2257. [CrossRef]

229. Santhekadur, P.K.; Kumar, D.P.; Sanyal, A.J. Preclinical models of non-alcoholic fatty liver disease. J. Hepatol. 2018, 68, 230-237. [CrossRef]

230. Jahn, D.; Kircher, S.; Hermanns, H.M.; Geier, A. Animal models of NAFLD from a hepatologist's point of view. Biochim. Biophys. Acta Mol. Basis Dis. 2019, 1865, 943-953. [CrossRef]

231. Ore, A.; Akinloye, O.A. Oxidative stress and antioxidant biomarkers in clinical and experimental models of non-alcoholic fatty liver disease. Medicina 2019, 55, 26. [CrossRef] [PubMed]

232. Świderska, M.; Maciejczyk, M.; Zalewska, A.; Pogorzelska, J.; Flisiak, R.; Chabowski, A. Oxidative stress biomarkers in the serum and plasma of patients with non-alcoholic fatty liver disease (NAFLD). Can plasma AGE be a marker of NAFLD? Oxidative stress biomarkers in NAFLD patients. Free Radic. Res. 2019, 53, 841-850. [CrossRef] [PubMed]

233. Kim, H.J.; Lee, Y.; Fang, S.; Kim, W.; Kim, H.J.; Kim, J.-W. GPx7 ameliorates non-alcoholic steatohepatitis by regulating oxidative stress. BMB Rep. 2020. [CrossRef]

234. Simon, J.; Nuñez-García, M.; Fernández-Tussy, P.; Barbier-Torres, L.; Fernández-Ramos, D.; Gómez-Santos, B.; Buqué, X.; Lopitz-Otsoa, F.; Goikoetxea-Usandizaga, N.; Serrano-Macia, M.; et al. Targeting hepatic glutaminase 1 ameliorates non-alcoholic steatohepatitis by restoring very-low-density lipoprotein triglyceride assembly. Cell Metab. 2020, 31, 605-622.e10. [CrossRef]

235. Milaciu, M.V.; Vesa Ștefan, C.; Bocșan, I.C.; Ciumărnean, L.; Sâmpelean, D.; Negrean, V.; Pop, R.M.; Matei, D.M.; Pașca, S.; Răchișan, A.L.; et al. Paraoxonase-1 serum concentration and PON1 gene polymorphisms: Relationship with non-alcoholic fatty liver disease. J. Clin. Med. 2019, 8, 2200. [CrossRef]

236. Shin, S.K.; Cho, H.W.; Song, S.E.; Song, D.K. Catalase and nonalcoholic fatty liver disease. Pflugers Arch. Eur. J. Physiol. 2018, 470, 1721-1737. [CrossRef]

237. Hwang, I.; Uddin, M.J.; Pak, E.S.; Kang, H.; Jin, E.J.; Jo, S.; Kang, D.; Lee, H.; Ha, H. The impaired redox balance in peroxisomes of catalase knockout mice accelerates nonalcoholic fatty liver disease through endoplasmic reticulum stress. Free Radic. Biol. Med. 2020, 148, 22-32. [CrossRef]

238. Nerstedt, A.; Kurhe, Y.; Cansby, E.; Caputo, M.; Gao, L.; Vorontsov, E.; Ståhlman, M.; Nuñez-Durán, E.; Borén, J.; Marschall, H.-U.; et al. Lipid droplet-associated kinase STK25 regulates peroxisomal activity and metabolic stress response in steatotic liver. J. Chem. Inf. Model. 2020, 53, 45-50. [CrossRef] 
239. Sharma, R.S.; Harrison, D.J.; Kisielewski, D.; Cassidy, D.M.; McNeilly, A.D.; Gallagher, J.R.; Walsh, S.V.; Honda, T.; McCrimmon, R.J.; Dinkova-Kostova, A.T.; et al. Experimental nonalcoholic steatohepatitis and liver fibrosis are ameliorated by pharmacologic activation of Nrf2 (NF-E2 p45-related factor 2). Cell. Mol. Gastroenterol. Hepatol. 2018, 5, 367-398. [CrossRef]

240. Solano-Urrusquieta, A.; Morales-González, J.A.; Castro-Narro, G.E.; Cerda-Reyes, E.; Flores-Rangel, P.D.; Fierros-Oceguera, R. Nrf-2 and nonalcoholic fatty liver disease. Ann. Hepatol. 2020. [CrossRef]

241. Meakin, P.J.; Chowdhry, S.; Sharma, R.S.; Ashford, F.B.; Walsh, S.V.; McCrimmon, R.J.; Dinkova-Kostova, A.T.; Dillon, J.F.; Hayes, J.D.; Ashford, M.L.J. Susceptibility of Nrf2-null mice to steatohepatitis and cirrhosis upon consumption of a high-fat diet is associated with oxidative stress, perturbation of the unfolded protein response, and disturbance in the expression of metabolic enzymes but not with I. Mol. Cell. Biol. 2014, 34, 3305-3320. [CrossRef] [PubMed]

242. Chowdhry, S.; Nazmy, M.H.; Meakin, P.J.; Dinkova-Kostova, A.T.; Walsh, S.V.; Tsujita, T.; Dillon, J.F.; Ashford, M.L.J.; Hayes, J.D. Loss of Nrf2 markedly exacerbates nonalcoholic steatohepatitis. Free Radic. Biol. Med. 2010, 48, 357-371. [CrossRef] [PubMed]

243. Wang, C.; Cui, Y.; Li, C.; Zhang, Y.; Xu, S.; Li, X.; Li, H.; Zhang, X. Nrf2 deletion causes "benign" simple steatosis to develop into nonalcoholic steatohepatitis in mice fed a high-fat diet. Lipids Health Dis. 2013, $12,1$. [CrossRef] [PubMed]

244. Teimouri, M.; Hosseini, H.; Shabani, M.; Koushki, M.; Noorbakhsh, F.; Meshkani, R. Inhibiting miR-27a and miR-142-5p attenuate nonalcoholic fatty liver disease by regulating Nrf2 signaling pathway. IUBMB Life 2020, 72, 361-372. [CrossRef] [PubMed]

245. Yu, H.T.; Fu, X.Y.; Liang, B.; Wang, S.; Liu, J.K.; Wang, S.R.; Feng, Z.H. Oxidative damage of mitochondrial respiratory chain in different organs of a rat model of diet-induced obesity. Eur. J. Nutr. 2018, 57, 1957-1967. [CrossRef]

246. García-Ruiz, I.; Fernández-Moreira, D.; Solís-Muñoz, P.; Rodríguez-Juan, C.; Díaz-Sanjuán, T.; Muñoz-Yagüe, T.; Solís-Herruzo, J.A. Mitochondrial complex i subunits are decreased in murine nonalcoholic fatty liver disease: Implication of peroxynitrite. J. Proteome Res. 2010, 9, 2450-2459. [CrossRef]

247. Nassir, F.; Ibdah, J.A. Sirtuins and nonalcoholic fatty liver disease. World J. Gastroenterol. 2016, 22, 10084-10092. [CrossRef]

248. Satapati, S.; Browning, J.D.; Shawn, C.; Satapati, S.; Kucejova, B.; Duarte, J.A.G.; Fletcher, J.A.; Reynolds, L.; Sunny, N.E.; He, T.; et al. Mitochondrial metabolism mediates oxidative stress and inflammation in fatty liver. J. Clin. Investig. 2016, 125, 4447-4462. [CrossRef]

249. Krishnasamy, Y.; Gooz, M.; Li, L.; Lemasters, J.J.; Zhong, Z. 512-Role of mitochondrial depolarization and disrupted mitochondrial homeostasis in non-alcoholic steatohepatitis and fibrosis. Gastroenterology 2018, 154, 1095-1096. [CrossRef]

250. Win, S.; Than, T.A.; Win, M.M.R.; Aghajan, M.; Kaplowitz, N. JNK mediates mouse liver injury through a novel Sab (SH3BP5) dependent pathway leading to inactivation of intramitochondrial src sanda. Hepatology 2017, 176, 139-148. [CrossRef]

251. Win, S.; Than, T.A.; Zhang, J.; Oo, C.; Win, R.W.M.; Kaplowitz, N. New insights into the role and mechanism of c-Jun-N-terminal kinase signaling in the pathobiology of liver diseases. Hepatology 2018, 176, 139-148. [CrossRef] [PubMed]

252. Hinchy, E.C.; Gruszczyk, A.V.; Willows, R.; Navaratnam, N.; Hall, A.R.; Bates, G.; Bright, T.P.; Krieg, T.; Carling, D.; Murphy, M.P. Mitochondria-derived ROS activate AMP-activated protein kinase (AMPK) indirectly. J. Biol. Chem. 2018, 293, 17208-17217. [CrossRef] [PubMed]

253. Mansouri, A.; Gattolliat, C.H.; Asselah, T. Mitochondrial dysfunction and signaling in chronic liver diseases. Gastroenterology 2018, 155, 629-647. [CrossRef] [PubMed]

254. Kim, M.H.; Seong, J.B.; Huh, J.W.; Bae, Y.C.; Lee, H.S.; Lee, D.S. Peroxiredoxin 5 ameliorates obesity-induced non-alcoholic fatty liver disease through the regulation of oxidative stress and AMP-activated protein kinase signaling. Redox Biol. 2020, 28, 101315. [CrossRef] [PubMed]

255. Zhao, P.; Sun, X.; Chaggan, C.; Liao, Z.; Wong, K.I.; He, F.; Singh, S.; Loomba, R.; Karin, M.; Witztum, J.L.; et al. An AMPK-caspase-6 axis controls liver damage in nonalcoholic steatohepatitis. Science 2020, 367, 652-660. [CrossRef] [PubMed]

256. Simões, I.C.M.; Fontes, A.; Pinton, P.; Zischka, H.; Wieckowski, M.R. Mitochondria in non-alcoholic fatty liver disease. Int. J. Biochem. Cell Biol. 2018, 95, 93-99. [CrossRef] 
257. Masarone, M.; Rosato, V.; Dallio, M.; Gravina, A.G.; Aglitti, A.; Loguercio, C.; Federico, A.; Persico, M. Role of oxidative stress in pathophysiology of nonalcoholic fatty liver disease. Oxid. Med. Cell. Longev. 2018, 2018. [CrossRef]

258. Kim, J.Y.; Garcia-Carbonell, R.; Yamachika, S.; Zhao, P.; Dhar, D.; Loomba, R.; Kaufman, R.J.; Saltiel, A.R.; Karin, M. ER stress drives lipogenesis and steatohepatitis via caspase-2 activation of S1P. Cell 2018, 175, 133-145. [CrossRef]

259. Greene, M.W.; Burrington, C.M.; Ruhoff, M.S.; Johnson, A.K.; Chongkrairatanakul, T.; Kangwanpornsiri, A. PKC $\delta$ is activated in a dietary model of steatohepatitis and regulates endoplasmic reticulum stress and cell death. J. Biol. Chem. 2010, 285, 42115-42129. [CrossRef]

260. Lai, S.; Li, Y.; Kuang, Y.; Cui, H.; Yang, Y.; Sun, W.; Liu, K.; Chen, D.; Yan, Q.; Wen, L. PKC $\delta$ silencing alleviates saturated fatty acid induced ER stress by enhancing SERCA activity. Biosci. Rep. 2017, 37, 1-10. [CrossRef]

261. Zhang, B.; Li, M.; Zou, Y.; Guo, H.; Zhang, B.; Xia, C.; Zhang, H.; Yang, W.; Xu, C. NFkB/Orai1 facilitates endoplasmic reticulum stress by oxidative stress in the pathogenesis of non-alcoholic fatty liver disease. Front. Cell Dev. Biol. 2019, 7, 1-13. [CrossRef]

262. Luo, L.; Jiang, W.; Liu, H.; Bu, J.; Tang, P.; Du, C.; Xu, Z.; Luo, H.; Liu, B.; Xiao, B.; et al. De-silencing Grb10 contributes to acute ER stress-induced steatosis in mouse liver. J. Mol. Endocrinol. 2018, 60, 285-297. [CrossRef] [PubMed]

263. Ipsen, D.H.; Lykkesfeldt, J.; Tveden-Nyborg, P. Molecular mechanisms of hepatic lipid accumulation in non-alcoholic fatty liver disease. Cell. Mol. Life Sci. 2018, 75, 3313-3327. [CrossRef] [PubMed]

264. Huang, B.; Bao, J.; Cao, Y.R.; Gao, H.F.; Jin, Y. Cytochrome P450 1A1 (CYP1A1) catalyzes lipid peroxidation of oleic acid-induced HepG2 cells. Biochemistry 2018, 83, 595-602. [CrossRef] [PubMed]

265. Gao, H.; Cao, Y.; Xia, H.; Zhu, X.; Jin, Y. CYP4A11 is involved in the development of nonalcoholic fatty liver disease via ROS-induced lipid peroxidation and inflammation. Int. J. Mol. Med. 2020, 45, 1121-1129. [CrossRef]

266. Abdelmegeed, M.A.; Ha, S.-K.; Choi, Y.; Akbar, M.; Song, B.-J. Role of CYP2E1 in mitochondrial dysfunction and hepatic injury by alcohol and Non-alcoholic substances. Curr. Mol. Pharmacol. 2017, 10, 207-225. [CrossRef]

267. Huang, Y.S.; Chang, C.H.; Lin, T.L.; Perng, C.L. Genetic variations of superoxide dismutase 2 and cytochrome P450 2E1 in non-alcoholic steatohepatitis. Liver Int. 2014, 34, 931-936. [CrossRef]

268. Chen, G.; Renfan, X.; Zhang, S.; Wang, Y.; Wang, P.; Edin, M.L.; Zeldin, D.C.; Wang, D.W. CYP2J2 overexpression attenuates nonalcoholic fatty liver disease induced by high-fat diet in mice. Am. J. Physiol. Endocrinol. Metab. 2015, 308, E97-E110. [CrossRef]

269. Rabelo, F.; Stefano, J.T.; Cavaleiro, A.M.; Lima, R.V.C.; de Campos Mazo, D.F.; Carrilho, F.J.; Correa-Giannella, M.L.; Oliveira, C.P. Association between the CYBA and NOX4 genes of NADPH oxidase and its relationship with metabolic syndrome in non-alcoholic fatty liver disease in Brazilian population. Hepatobiliary Pancreat. Dis. Int. 2018, 17, 330-335. [CrossRef]

270. García-Ruiz, I.; Solís-Muñoz, P.; Fernández-Moreira, D.; Grau, M.; Muñoz-Yagüe, T.; Solís-Herruzo, J.A. NADPH oxidase is implicated in the pathogenesis of oxidative phosphorylation dysfunction in mice fed a high-fat diet. Sci. Rep. 2016, 6, 1-13. [CrossRef]

271. Loffredo, L.; Zicari, A.M.; Perri, L.; Carnevale, R.; Nocella, C.; Angelico, F.; Del Ben, M.; Mosca, A.; Zaffina, S.; Panera, N.; et al. Does Nox2 overactivate in children with nonalcoholic fatty liver disease. Antioxid. Redox Signal. 2019, 30, 1325-1330. [CrossRef] [PubMed]

272. Del Ben, M.; Polimeni, L.; Carnevale, R.; Bartimoccia, S.; Nocella, C.; Baratta, F.; Loffredo, L.; Pignatelli, P.; Violi, F.; Angelico, F. NOX2-generated oxidative stress is associated with severity of ultrasound liver steatosis in patients with non-alcoholic fatty liver disease. BMC Gastroenterol. 2014, 14, 1-8. [CrossRef] [PubMed]

273. García-Ruiz, I.; Solís-Muñoz, P.; Fernández-Moreira, D.; Grau, M.; Colina, F.; Muñoz-Yagüe, T.; Solís-Herruzo, J.A. High-fat diet decreases activity of the oxidative phosphorylation complexes and causes nonalcoholic steatohepatitis in mice. DMM Dis. Model. Mech. 2014, 7, 1287-1296. [CrossRef] [PubMed]

274. Long, Z.; Cao, M.; Su, S.; Wu, G.; Meng, F.; Wu, H.; Liu, J.; Yu, W.; Atabai, K.; Wang, X. Inhibition of hepatocyte nuclear factor $1 \mathrm{~b}$ induces hepatic steatosis through DPP4/NOX1-mediated regulation of superoxide. Free Radic. Biol. Med. 2017, 113, 71-83. [CrossRef] 
275. Matsumoto, M.; Zhang, J.; Zhang, X.; Liu, J.; Jiang, J.X.; Yamaguchi, K.; Taruno, A.; Katsuyama, M.; Iwata, K.; Ibi, M.; et al. The NOX1 isoform of NADPH oxidase is involved in dysfunction of liver sinusoids in nonalcoholic fatty liver disease. Free Radic. Biol. Med. 2018, 115, 412-420. [CrossRef]

276. Joy, A.B.; Jiang, X.; Sasaki, Y.; Chao, T.-I.; Kiss, Z.; Chen, X.; Tian, J.; Katsuyama, M.; Yabe-Nishimura, C.; $\mathrm{X}$, Y.; et al. Hepatocyte NADPH oxidase 4 regulates stress signaling, fibrosis, and insulin sensitivity during development of steatohepatitis in mice. Gastroenterology 2015, 149, 468-480. [CrossRef]

277. Schnabl, B.; Choi, Y.H.; Olsen, J.C.; Hagedorn, C.H.; Brenner, D.A. Generated by ectopic telomerase expression. Lab. Investig. 2002, 82, 323-333. [CrossRef] [PubMed]

278. Sun, J.S.X.; Seidman, P.Z.; Christopher, K.S.T.; Glass, J.L.W. Neutralization of oxidized phospholipids article neutralization of oxidized phospholipids ameliorates non-alcoholic steatohepatitis. Cell Metab. 2020, 1-18. [CrossRef]

279. Mendel, I.; Yacov, N.; Shoham, A.; Ishai, E.; Breitbart, E. Treatment with oxidized phospholipids directly inhibits nonalcoholic steatohepatitis and liver fibrosis without affecting steatosis. Dig. Dis. Sci. 2016, 61, 2545-2553. [CrossRef]

280. Valenti, L.; Rametta, R.; Dongiovanni, P.; Motta, B.M.; Canavesi, E.; Pelusi, S.; Pulixi, E.A.; Fracanzani, A.L.; Fargion, S. The A736V TMPRSS6 polymorphism influences hepatic iron overload in nonalcoholic fatty liver disease. PLOS ONE 2012, 7, e48804. [CrossRef]

281. Kowdley, K.V.; Belt, P.; Wilson, L.A.; Yeh, M.M.; Neuschwander-Tetri, B.A.; Chalasani, N.; Sanyal, A.J.; Nelson, J.E. Serum ferritin is an independent predictor of histologic severity and advanced fibrosis in patients with nonalcoholic fatty liver disease. Hepatology 2012, 55, 77-85. [CrossRef] [PubMed]

282. Mehta, K.J.; Farnaud, S.J.; Sharp, P.A. Iron and liver fibrosis: Mechanistic and clinical aspects. World J. Gastroenterol. 2019, 25, 521-538. [CrossRef] [PubMed]

283. Claus, S.P.; Tsang, T.M.; Wang, Y.; Cloarec, O.; Skordi, E.; Martin, F.P.; Rezzi, S.; Ross, A.; Kochhar, S.; Holmes, E.; et al. Systemic multicompartmental effects of the gut microbiome on mouse metabolic phenotypes. Mol. Syst. Biol. 2008, 4, 1-14. [CrossRef] [PubMed]

284. Mardinoglu, A.; Shoaie, S.; Bergentall, M.; Ghaffari, P.; Zhang, C.; Larsson, E.; Bäckhed, F.; Nielsen, J. The gut microbiota modulates host amino acid and glutathione metabolism in mice. Mol. Syst. Biol. 2015, 11, 834. [CrossRef] [PubMed]

285. Saeedi, B.J.; Liu, K.H.; Owens, J.A.; Hunter-Chang, S.; Camacho, M.C.; Eboka, R.U.; Chandrasekharan, B.; Baker, N.F.; Darby, T.M.; Robinson, B.S.; et al. Gut-resident lactobacilli activate hepatic Nrf2 and protect against oxidative liver injury. Cell Metab. 2020, 31, 956-968.e5. [CrossRef] [PubMed]

286. Meng, X.; Li, S.; Li, Y.; Gan, R.Y.; Li, H. Bin Gut microbiota's relationship with liver disease and role in hepatoprotection by dietary natural products and probiotics. Nutrients 2018, 10, 1457. [CrossRef] [PubMed]

287. Ji, Y.; Yin, Y.; Sun, L.; Zhang, W. The molecular and mechanistic insights based on gut-liver axis: Nutritional target for non-alcoholic fatty liver disease (NAFLD) improvement. Int. J. Mol. Sci. 2020, 21, 3066. [CrossRef]

288. Wang, B.; Jiang, X.; Cao, M.; Ge, J.; Bao, Q.; Tang, L.; Chen, Y.; Li, L. Altered fecal microbiota correlates with liver biochemistry in nonobese patients with non-alcoholic fatty liver disease. Sci. Rep. 2016, 6, 1-11. [CrossRef]

289. Boursier, J.; Rawls, J.F.; Diehl, A.M. Obese humans with nonalcoholic fatty liver disease display alterations in fecal microbiota and volatile organic compounds. Clin. Gastroenterol. Hepatol. 2013, 11, 876-878. [CrossRef]

290. Machado, M.V.; Ravasco, P.; Jesus, L.; Marques-Vidal, P.; Oliveira, C.R.; Proença, T.; Baldeiras, I.; Camilo, M.E.; Cortez-Pinto, H. Blood oxidative stress markers in non-alcoholic steatohepatitis and how it correlates with diet. Scand. J. Gastroenterol. 2008, 43, 95-102. [CrossRef]

291. Yamaguchi, K.; Yang, L.; McCall, S.; Huang, J.; Xing, X.Y.; Pandey, S.K.; Bhanot, S.; Monia, B.P.; Li, Y.X.; Diehl, A.M. Inhibiting triglyceride synthesis improves hepatic steatosis but exacerbates liver damage and fibrosis in obese mice with nonalcoholic steatohepatitis. Hepatology 2007, 45, 1366-1374. [CrossRef] [PubMed]

292. Puri, P.; Baillie, R.A.; Wiest, M.M.; Mirshahi, F.; Choudhury, J.; Cheung, O.; Sargeant, C.; Contos, M.J.; Sanyal, A.J. A lipidomic analysis of nonalcoholic fatty liver disease. Hepatology 2007, 46, 1081-1090. [CrossRef] [PubMed]

293. Sengupta, A.; Ghosh, M. Comparison of native and capric acid-enriched mustard oil effects on oxidative stress and antioxidant protection in rats. Br. J. Nutr. 2012, 107, 845-849. [CrossRef] [PubMed]

294. Sengupta, A.; Ghosh, M.; Bhattacharyya, D.K. Antioxidative effect of rice bran oil and medium chain fatty acid rich rice bran oil in arsenite induced oxidative stress in rats. J. Oleo Sci. 2014, 63, 1117-1124. [CrossRef] 
295. Wang, D.; Wei, Y.; Pagliassotti, M.J. Saturated fatty acids promote endoplasmic reticulum stress and liver injury in rats with hepatic steatosis. Endocrinology 2006, 147, 943-951. [CrossRef]

296. Nakamura, H.; Tsujiguchi, H.; Kambayashi, Y.; Hara, A.; Miyagi, S.; Yamada, Y.; Nguyen, T.T.T.; Shimizu, Y.; Hori, D.; Nakamura, H. Relationship between saturated fatty acid intake and hypertension and oxidative stress. Nutrition 2019, 61, 8-15. [CrossRef]

297. Ghazali, R.; Mehta, K.J.; Bligh, S.W.A.; Tewfik, I.; Clemens, D.; Patel, V.B. High omega arachidonic acid/docosahexaenoic acid ratio induces mitochondrial dysfunction and altered lipid metabolism in human hepatoma cells. World J. Hepatol. 2020, 12, 84-98. [CrossRef]

298. Jeyapal, S.; Kona, S.R.; Mullapudi, S.V.; Putcha, U.K.; Gurumurthy, P.; Ibrahim, A. Substitution of linoleic acid with $\alpha$-linolenic acid or long chain $n-3$ polyunsaturated fatty acid prevents Western diet induced nonalcoholic steatohepatitis. Sci. Rep. 2018, 8, 1-14. [CrossRef]

299. García-Ruiz, C.; Fernández-Checa, J.C. Mitochondrial oxidative stress and antioxidants balance in fatty liver disease. Hepatol. Commun. 2018, 2, 1425-1439. [CrossRef]

300. Domínguez-Pérez, M.; Simoni-Nieves, A.; Rosales, P.; Nuño-Lámbarri, N.; Rosas-Lemus, M.; Souza, V.; Miranda, R.U.; Bucio, L.; Uribe Carvajal, S.; Marquardt, J.U.; et al. Cholesterol burden in the liver induces mitochondrial dynamic changes and resistance to apoptosis. J. Cell. Physiol. 2019, 234, 7213-7223. [CrossRef]

301. Püschel, G.P.; Henkel, J. Dietary cholesterol does not break your heart but kills your liver. Porto Biomed. J. 2018, 3, e12. [CrossRef] [PubMed]

302. Savard, G.; Tartaglione, E.; Kuver, R.; Haigh, W.; Farrell, G.; Subramanian, S.; Chait, A.; Yeh, M.; Quinn, L.; Ioannou, G. Synergistic interaction of dietary cholesterol and dietary fat in inducing experimental steatohepatitis christopher. Hepatology 2013, 57, 81-92. [CrossRef] [PubMed]

303. Bellanti, F.; Villani, R.; Tamborra, R.; Blonda, M.; Iannelli, G.; di Bello, G.; Facciorusso, A.; Poli, G.; Iuliano, L.; Avolio, C.; et al. Synergistic interaction of fatty acids and oxysterols impairs mitochondrial function and limits liver adaptation during nafld progression. Redox Biol. 2018, 15, 86-96. [CrossRef] [PubMed]

304. Henkel, J.; Coleman, C.D.; Schraplau, A.; Jöhrens, K.; Weber, D.; Castro, J.P.; Hugo, M.; Schulz, T.J.; Krämer, S.; Schürmann, A.; et al. Induction of steatohepatitis (NASH) with insulin resistance in wild-type B6 mice by a western-type diet containing soybean oil and cholesterol. Mol. Med. 2017, 23, 70-82. [CrossRef] [PubMed]

305. Kephart, W.C.; Mumford, P.W.; Mao, X.; Romero, M.A.; Hyatt, H.W.; Zhang, Y.; Mobley, C.B.; Quindry, J.C.; Young, K.C.; Beck, D.T.; et al. The 1-week and 8-month effects of a ketogenic diet or ketone salt supplementation on multi-organ markers of oxidative stress and mitochondrial function in rats. Nutrients 2017, 9, 1019. [CrossRef] [PubMed]

306. Lanaspa, M.A.; Sanchez-Lozada, L.G.; Choi, Y.J.; Cicerchi, C.; Kanbay, M.; Roncal-Jimenez, C.A.; Ishimoto, T.; Li, N.; Marek, G.; Duranay, M.; et al. Uric acid induces hepatic steatosis by generation of mitochondrial oxidative stress: Potential role in fructose-dependent and -independent fatty liver. J. Biol. Chem. 2012, 287, 40732-40744. [CrossRef]

307. Cho, Y.E.; Kim, D.K.; Seo, W.; Gao, B.; Yoo, S.H.; Song, B.J. Fructose promotes leaky gut, endotoxemia, and liver fibrosis through ethanol-inducible cytochrome P450-2E1-mediated oxidative and nitrative stress. Hepatology 2019, 1-16. [CrossRef]

308. Castro, M.C.; Francini, F.; Schinella, G.; Caldiz, C.I.; Zubiría, M.G.; Gagliardino, J.J.; Massa, M.L. Apocynin administration prevents the changes induced by a fructose-rich diet on rat liver metabolism and the antioxidant system. Clin. Sci. 2012, 123, 681-692. [CrossRef]

309. Francini, F.; Castro, M.C.; Schinella, G.; García, M.E.; Maiztegui, B.; Raschia, M.A.; Gagliardino, J.J.; Massa, M.L. Changes induced by a fructose-rich diet on hepatic metabolism and the antioxidant system. Life Sci. 2010, 86, 965-971. [CrossRef]

310. Castro, M.C.; Massa, M.L.; Arbeláez, L.G.; Schinella, G.; Gagliardino, J.J.; Francini, F. Fructose-induced inflammation, insulin resistance and oxidative stress: A liver pathological triad effectively disrupted by lipoic acid. Life Sci. 2015, 137, 1-6. [CrossRef]

311. Oliveira, L.S.; Caetano, B.; Miranda, R.A.; Souza, A.F.P.; Cordeiro, A.; Woyames, J.; Andrade, C.B.V.; Atella, G.C.; Takiya, C.M.; Fortunato, R.S.; et al. Differentiated hepatic response to fructose intake during adolescence reveals the increased susceptibility to non-alcoholic fatty liver disease of maternal high-fat diet male rat offspring. Mol. Nutr. Food Res. 2020, 64, 1-10. [CrossRef] [PubMed] 
312. Fujita, N.; Miyachi, H.; Tanaka, H.; Takeo, M.; Nakagawa, N.; Kobayashi, Y.; Iwasa, M.; Watanabe, S.; Takei, Y. Iron overload is associated with hepatic oxidative damage to DNA in nonalcoholic steatohepatitis. Cancer Epidemiol. Biomark. Prev. 2009, 18, 424-432. [CrossRef] [PubMed]

313. Atarashi, M.; Izawa, T.; Miyagi, R.; Ohji, S.; Hashimoto, A.; Kuwamura, M.; Yamate, J. Dietary iron supplementation alters hepatic inflammation in a rat model of nonalcoholic steatohepatitis. Nutrients 2018, 10, 175. [CrossRef] [PubMed]

314. Handa, P.; Morgan-Stevenson, V.; Maliken, B.D.; Nelson, J.E.; Washington, S.; Westerman, M.; Yeh, M.M.; Kowdley, K.V. Iron overload results in hepatic oxidative stress, immune cell activation, and hepatocellular ballooning injury, leading to nonalcoholic steatohepatitis in genetically obese mice. Am. J. Physiol. Gastrointest. Liver Physiol. 2016, 310, G117-G127. [CrossRef] [PubMed]

315. Protchenko, O.; Baratz, E.; Jadhav, S.; Li, F.; Shakoury-Elizeh, M.; Gavrilova, O.; Ghosh, M.C.; Cox, J.E.; Maschek, J.A.; Tyurin, V.A.; et al. Iron chaperone PCBP1 protects murine liver from lipid peroxidation and steatosis. Hepatology 2020. [CrossRef]

316. Hagström, H.; Nasr, P.; Bottai, M.; Ekstedt, M.; Kechagias, S.; Hultcrantz, R.; Stål, P. Elevated serum ferritin is associated with increased mortality in non-alcoholic fatty liver disease after 16 years of follow-up. Liver Int. 2016, 36, 1688-1695. [CrossRef]

317. Kim, H.B.; Lee, H.S.; Lee, Y.J. Association of serum ferritin levels with non-alcoholic fatty liver disease in postmenopausal women. Climacteric 2018, 21, 509-514. [CrossRef]

318. Ahmad, M.I.; Ijaz, M.U.; ul Haq, I.; Li, C. The role of meat protein in generation of oxidative stress and pathophysiology of metabolic syndromes. Food Sci. Anim. Resour. 2020, 40, 1-10. [CrossRef]

319. Parker, H.M.; Johnson, N.A.; Burdon, C.A.; Cohn, J.S.; O'Connor, H.T.; George, J. Omega-3 supplementation and non-alcoholic fatty liver disease: A systematic review and meta-analysis. J. Hepatol. 2012, 56, 944-951. [CrossRef]

320. Guo, X.F.; Yang, B.; Tang, J.; Li, D. Fatty acid and non-alcoholic fatty liver disease: Meta-analyses of case-control and randomized controlled trials. Clin. Nutr. 2018, 37, 113-122. [CrossRef]

321. Musa-Veloso, K.; Venditti, C.; Lee, H.Y.; Darch, M.; Floyd, S.; West, S.; Simon, R. Systematic review and meta-analysis of controlled intervention studies on the effectiveness of long-chain omega-3 fatty acids in patients with nonalcoholic fatty liver disease. Nutr. Rev. 2018, 76, 581-602. [CrossRef] [PubMed]

322. Chen, L.-H.; Wang, Y.-F.; Xu, Q.-H.; Chen, S.S. Omega-3 fatty acids as a treatment for non-alcoholic fatty liver disease in children: A systematic review and meta-analysis of randomized controlled trials. Clin. Nutr. 2018, 37, 516-521. [CrossRef] [PubMed]

323. Yang, J.; Fernández-Galilea, M.; Martínez-Fernández, L.; González-Muniesa, P.; Pérez-Chávez, A.; Martínez, J.A.; Moreno-Aliaga, M.J. Oxidative stress and non-alcoholic fatty liver disease: Effects of omega-3 fatty acid supplementation. Nutrients 2019, 11, 872. [CrossRef] [PubMed]

324. Scorletti, E.; Byrne, C.D. Omega-3 fatty acids and non-alcoholic fatty liver disease: Evidence of efficacy and mechanism of action. Mol. Asp. Med. 2018, 64, 135-146. [CrossRef]

325. Valenzuela, R.; Videla, L.A. Impact of the co-administration of $n-3$ fatty acids and olive oil components in preclinical nonalcoholic fatty liver disease models: A mechanistic view. Nutrients 2020, 12, 499. [CrossRef] [PubMed]

326. Valenzuela, R.; Espinosa, A.; González-Mañán, D.; D’Espessailles, A.; Fernández, V.; Videla, L.A.; Tapia, G. N-3 Long-Chain Polyunsaturated Fatty Acid Supplementation Significantly Reduces Liver Oxidative Stress in High Fat Induced Steatosis. PLoS ONE 2012, 7, e46400. [CrossRef]

327. Jump, D.B.; Depner, C.M.; Tripathy, S.; Lytle, K.A. Potential for dietary $\omega-3$ fatty acids to prevent nonalcoholic fatty liver disease and reduce the risk of primary liver cancer. Adv. Nutr. 2015, 6, 694-702. [CrossRef]

328. Gao, L.; Wang, J.; Sekhar, K.R.; Yin, H.; Yared, N.F.; Schneider, S.N.; Sasi, S.; Dalton, T.P.; Anderson, M.E.; Chan, J.Y; et al. Novel n-3 fatty acid oxidation products activate Nrf2 by destabilizing the association between Keap1 and Cullin3. J. Biol. Chem. 2007, 282, 2529-2537. [CrossRef]

329. Depner, C.; Philbrick, K.; Jump, D. Docosahexaenoic Acid Attenuates Hepatic Inflammation, Oxidative Stress, and Fibrosis without Decreasing Hepatosteatosis in a Ldlr-/- Mouse Model of Western Diet. J. Nutr. 2013, 143, 315-323. [CrossRef]

330. Soto-Alarcon, S.A.; Valenzuela, R.; Valenzuela, A.; Videla, L.A. Liver protective effects of extra virgin olive oil: Interaction between its chemical composition and the cell-signaling pathways involved in protection. Endocr. Metab. Immune Disord. Drug Targets 2017, 18, 75-84. [CrossRef] 
331. Rincón-Cervera, M.A.; Valenzuela, R.; Hernandez-Rodas, M.C.; Marambio, M.; Espinosa, A.; Mayer, S.; Romero, N.; Barrera M Sc, C.; Valenzuela, A.; Videla, L.A. Supplementation with antioxidant-rich extra virgin olive oil prevents hepatic oxidative stress and reduction of desaturation capacity in mice fed a high-fat diet: Effects on fatty acid composition in liver and extrahepatic tissues. Nutrition 2016, 32, 1254-1267. [CrossRef] [PubMed]

332. Chakravarthy, M.V.; Waddell, T.; Banerjee, R.; Guess, N. Nutrition and nonalcoholic fatty liver disease: Current perspectives. Gastroenterol. Clin. N. Am. 2020, 49, 63-94. [CrossRef] [PubMed]

333. Mardinoglu, A.; Bjornson, E.; Zhang, C.; Klevstig, M.; Söderlund, S.; Ståhlman, M.; Adiels, M.; Hakkarainen, A.; Lundbom, N.; Kilicarslan, M.; et al. Personal model-assisted identification of NAD + and glutathione metabolism as intervention target in NAFLD. Mol. Syst. Biol. 2017, 13, 916. [CrossRef] [PubMed]

334. Aissa, A.F.; Tryndyak, V.; de Conti, A.; Melnyk, S.; Gomes, T.D.U.H.; Bianchi, M.L.P.; James, S.J.; Beland, F.A.; Antunes, L.M.G.; Pogribny, I.P. Effect of methionine-deficient and methionine-supplemented diets on the hepatic one-carbon and lipid metabolism in mice. Mol. Nutr. Food Res. 2014, 58, 1502-1512. [CrossRef]

335. Anstee, Q.; Goldin, R.D. Mouse models in non-alcoholic fatty liver disease and steatohepatitis research. Int. J. Exp. Path 2006, 87, 1-16. [CrossRef]

336. Larter, C.Z.; Yeh, M.M. Animal models of NASH: Getting both pathology and metabolic context right. J. Gastroenterol. Hepatol. 2008, 23, 1635-1648. [CrossRef]

337. Rinella, M.E.; Green, R.M. The methionine-choline deficient dietary model of steatohepatitis does not exhibit insulin resistance. J. Hepatol. 2004, 40, 47-51. [CrossRef]

338. Drake, A.J.; Lyall, M.J.; Cartier, J.; Richards, J.A.; Cobice, D.; Thomson, J.P.; Meehan, R.R.; Anderton, S.M. Methyl donor deficient diets cause distinct alterations in lipid metabolism but are poorly representative of human NAFLD [version 1; referees: 2 approved]. Wellcome Open Res. 2017, 2, 1-19. [CrossRef]

339. Murakami, S.; Ono, A.; Kawasaki, A.; Takenaga, T.; Ito, T. Taurine attenuates the development of hepatic steatosis through the inhibition of oxidative stress in a model of nonalcoholic fatty liver disease in vivo and in vitro. Amino Acids 2018, 50, 1279-1288. [CrossRef]

340. Shenkin, A. The key role of micronutrients. Clin. Nutr. 2006, 25, 1-13. [CrossRef]

341. Chen, G.; Ni, Y.; Nagata, N.; Xu, L.; Ota, T. Micronutrient antioxidants and nonalcoholic fatty liver disease. Int. J. Mol. Sci. 2016, 17, 1379. [CrossRef] [PubMed]

342. Karatayli, E.; Stokes, C.S.; Lammert, F. Vitamin D in preclinical models of fatty liver disease. Anticancer Res. 2020, 40, 527-534. [CrossRef] [PubMed]

343. Eliades, M.; Spyrou, E.; Agrawal, N.; Lazo, M.; Brancati, F.L.; Potter, J.J.; Koteish, A.A.; Clark, J.M.; Guallar, E.; Hernaez, R. Meta-analysis: Vitamin D and non-alcoholic fatty liver disease. Aliment. Pharmacol. Ther. 2013, 38, 246-254. [CrossRef]

344. Sato, K.; Gosho, M.; Yamamoto, T.; Kobayashi, Y.; Ishii, N.; Ohashi, T.; Nakade, Y.; Ito, K.; Fukuzawa, Y.; Yoneda, M. Vitamin E has a beneficial effect on nonalcoholic fatty liver disease: A meta-analysis of randomized controlled trials. Nutrition 2015, 31, 923-930. [CrossRef] [PubMed]

345. Liu, S.; Liu, Y.; Wan, B.; Zhang, H.; Wu, S.; Zhu, Z.; Lin, Y.; Wang, M.; Zhang, N.; Lin, S.; et al. Association between vitamin $\mathrm{d}$ status and non-alcoholic fatty liver disease: A population-based study. J. Nutr. Sci. Vitaminol. 2019, 65, 303-308. [CrossRef] [PubMed]

346. Sanyal, A.J.; Chalasani, N.; Kowdley, K.; McCullough, A.; Diehl, A.; Bass, N.; Neuschwander-Tetri, B.; Lavine, J.; Tonascia, J.; Unalp, A.; et al. Pioglitazone, vitamin E, or placebo for nonalcoholic steatohepatitis. N. Engl. J. Med. 2010, 362, 1675-1685. [CrossRef] [PubMed]

347. Nagashimada, M.; Ota, T. Role of vitamin E in nonalcoholic fatty liver disease. IUBMB Life 2019, 71, 516-522. [CrossRef] [PubMed]

348. Fougerat, A.; Montagner, A.; Loiseau, N.; Guillou, H.; Wahli, W. Peroxisome Proliferator-Activated Receptors and Their Novel Ligands as Candidates for the Treatment of Non-Alcoholic Fatty Liver Disease. Cells 2020, 9, 1638. [CrossRef] [PubMed]

349. Salomone, F.; Godos, J.; Zelber-Sagi, S. Natural antioxidants for non-alcoholic fatty liver disease: Molecular targets and clinical perspectives. Liver Int. 2016, 36, 5-20. [CrossRef] [PubMed]

350. Rodriguez-Ramiro, I.; Vauzour, D.; Minihane, A.M. Polyphenols and non-alcoholic fatty liver disease: Impact and mechanisms. Proc. Nutr. Soc. 2016, 75, 47-60. [CrossRef] [PubMed] 
351. Elvira-Torales, L.I.; García-Alonso, J.; Periago-Castón, M.J. Nutritional importance of carotenoids and their effect on liver health: A review. Antioxidants 2019, 8, 229. [CrossRef] [PubMed]

352. Hill, C.; Guarner, F.; Reid, G.; Gibson, G.R.; Merenstein, D.J.; Pot, B.; Morelli, L.; Canani, R.B.; Flint, H.J.; Salminen, S.; et al. Expert consensus document: The international scientific association for probiotics and prebiotics consensus statement on the scope and appropriate use of the term probiotic. Nat. Rev. Gastroenterol. Hepatol. 2014, 11, 506-514. [CrossRef]

353. Ritze, Y.; Bárdos, G.; Claus, A.; Ehrmann, V.; Bergheim, I.; Schwiertz, A.; Bischoff, S.C. Lactobacillus rhamnosus GG Protects against non-alcoholic fatty liver disease in mice. PLoS ONE 2014, 9, e80169. [CrossRef] [PubMed]

354. Jang, H.R.; Park, H.J.; Kang, D.; Chung, H.; Nam, M.H.; Lee, Y.; Park, J.H.; Lee, H.Y. A protective mechanism of probiotic Lactobacillus against hepatic steatosis via reducing host intestinal fatty acid absorption. Exp. Mol. Med. 2019, 51. [CrossRef] [PubMed]

355. Ling, X.; Linglong, P.; Weixia, D.; Hong, W. Protective effects of bifidobacterium on intestinal barrier function in LPS-induced enterocyte barrier injury of Caco-2 monolayers and in a rat NEC model. PLoS ONE 2016, 11, e0161635. [CrossRef]

356. Liver, F.; Nafld, D. Chitosan Oligosaccharide Ameliorates Nonalcoholic. Mar. Drugs 2019, 17, 391. [CrossRef]

357. Pan, L.; Farouk, M.H.; Qin, G.; Zhao, Y.; Bao, N. The influences of soybean agglutinin and functional oligosaccharides on the intestinal tract of monogastric animals. Int. J. Mol. Sci. 2018, 19, 554. [CrossRef]

358. Kumar, J.; Rani, K.; Datt, C. Molecular link between dietary fibre, gut microbiota and health. Mol. Biol. Rep. 2020, 47, 6229-6237. [CrossRef]

359. Zhou, D.; Fan, J.G. Microbial metabolites in non-alcoholic fatty liver disease. World J. Gastroenterol. 2019, 25, 2019-2028. [CrossRef]

360. Sellmann, C.; Baumann, A.; Brandt, A.; Jin, C.J.; Nier, A.; Bergheim, I. Oral supplementation of glutamine attenuates the progression of nonalcoholic steatohepatitis in C57BL/6J mice. J. Nutr. 2017, 147, 2041-2049. [CrossRef]

361. Clugston, R.D. Carotenoids and fatty liver disease: Current knowledge and research gaps. Biochim. Biophys. Acta Mol. Cell Biol. Lipids 2020, 1865, 158597. [CrossRef] [PubMed]

362. Uchida, D.; Takaki, A.; Adachi, T.; Okada, H. Beneficial and paradoxical roles of anti-oxidative nutritional support for non-alcoholic fatty liver disease. Nutrients 2018, 10, 977. [CrossRef] [PubMed]

363. Wang, X.; Anad, A.; Wu, Q.; Qiao, F.; Ares, I.; Yuan, Z. Mechanism of neonicotinoid toxicity: Impact on oxidative stress and metabolism. Annu. Rev. Pharmacol. Toxicol. 2018, 58, 471-507. [CrossRef] [PubMed]

364. Wang, X.; Martínez, M.A.; Dai, M.; Chen, D.; Ares, I.; Romero, A.; Castellano, V.; Martínez, M.; Rodríguez, J.L.; Martínez-Larrañaga, M.R.; et al. Permethrin-induced oxidative stress and toxicity and metabolism. A review. Environ. Res. 2016, 149, 86-104. [CrossRef] [PubMed]

365. Lu, Q.; Sun, Y.; Ares, I.; Anadón, A.; Martínez, M. Deltamethrin toxicity: A review of oxidative stress and metabolism. Environ. Res. 2019, 170, 260-281. [CrossRef] [PubMed]

366. Yang, J.S.; Symington, S.; Clark, J.M.; Park, Y.; Sciences, B.; Sciences, A. Permethrin, a pyrethroid insecticide, regulates ERK1/2 activation through membrane depolarization-mediated pathway in HepG2 hepatocytes. Food Chem. Toxicol. 2019, 121, 387-395. [CrossRef]

367. Mu, X.; Shen, G.; Huang, Y.; Luo, J.; Zhu, L.; Qi, S. The enantioselective toxicity and oxidative stress of betacypermethrin on zebra fi sh *. Environ. Pollut. 2017, 229, 312-320. [CrossRef]

368. Jin, Y.; Wang, J.; Pan, X.; Wang, L.; Fu, Z. Cis-bifenthrin enantioselectively induces hepatic oxidative stress in mice. Pestic. Biochem. Physiol. 2013, 107, 61-67. [CrossRef]

369. Dar, M.A.; Khan, A.M.; Raina, R.; Verma, P.K.; Wani, N.M. Effect of bifenthrin on oxidative stress parameters in the liver, kidneys, and lungs of rats. Environ. Sci. Pollut. Res. 2019, 26, 9365-9370. [CrossRef]

370. Zhang, Y.; Lu, M.; Zhou, P.; Wang, C.; Zhang, Q.; Zhao, M. Multilevel evaluations of potential liver injury of bifenthrin. Pestic. Biochem. Physiol. 2015, 122, 29-37. [CrossRef]

371. Tuzmen, N.; Candan, N.; Kaya, E.; Demiryas, N. Biochemical effects of chlorpyrifos and deltamethrin on altered antioxidative defense mechanisms and lipid peroxidation in rat liver. Cell Biochem. Funct. 2008, 119-124. [CrossRef] [PubMed]

372. Migliaccio, V.; Lionetti, L.; Putti, R.; Scudiero, R. Exposure to dichlorodiphenyldichloroethylene (DDE) and metallothionein levels in rats fed with normocaloric or high-fat diet: A review. Int. J. Mol. Sci. 2020, 21, 1903. [CrossRef] [PubMed] 
373. Soudani, N.; Chaâbane, M.; Ghorbel, I.; Elwej, A.; Boudawara, T. Glyphosate disrupts redox status and up-regulates metallothionein I and II genes expression in the liver of adult rats. Alleviation by quercetin. Gen. Physiol. Biophys. 2019, 123-134. [CrossRef] [PubMed]

374. Bailey, D.C.; Todt, C.E.; Burchfield, S.L.; Pressley, A.S.; Denney, R.D.; Snapp, I.B.; Negga, R.; Traynor, W.L.; Fitsanakis, V.A. Chronic exposure to a glyphosate-containing pesticide leads to mitochondrial dysfunction and increased reactive oxygen species production in Caenorhabditis elegans. Environ. Toxicol. Pharmacol. 2018, 57, 46-52. [CrossRef] [PubMed]

375. Tayeb, W.; Nakbi, A.; Cheraief, I.; Miled, A.; Hammami, M. Alteration of lipid status and lipid metabolism, induction of oxidative stress and lipid peroxidation by 2,4-dichlorophenoxyacetic herbicide in rat liver. Toxicol. Mech. Methods 2013, 23, 449-458. [CrossRef] [PubMed]

376. de Oliveira, B.; Pereira, L.C.; Pazin, M.; Franco-Bernanrdes, M.F.; Dorta, D.J. Do trifluralin and tebuthiuron impair isolated rat liver mitochondria? Pestic. Biochem. Physiol. 2020, 163, 175-184. [CrossRef]

377. Ben Amara, I.; Ben Saad, H.; Hamdaoui, L.; Karray, A.; Boudawara, T.; Ben Ali, Y.; Zeghal, N. Maneb disturbs expression of superoxide dismutase and glutathione peroxidase, increases reactive oxygen species production, and induces genotoxicity in liver of adult mice. Environ. Sci. Pollut. Res. 2015, 22, 12309-12322. [CrossRef] [PubMed]

378. Han, Y.; Liu, T.; Wang, J.; Wang, J.; Zhang, C.; Zhu, L. Genotoxicity and oxidative stress induced by the fungicide azoxystrobin in zebra fish (Danio rerio) livers. YPEST 2016, 133, 13-19. [CrossRef]

379. Jia, W.; Mao, L.; Zhang, L.; Zhang, Y.; Jiang, H. Effects of two strobilurins (azoxystrobin and picoxystrobin) on embryonic development and enzyme activities in juveniles and adult fish livers of zebrafish (Danio rerio). Chemosphere 2018, 207, 573-580. [CrossRef] [PubMed]

380. Hamdi, H.; Othmène, Y.B.; Ammar, O.; Klifi, A.; Hallara, E.; Ghali, F.B.; Houas, Z.; Najjar, M.F.; Abid-Essefi, S. Oxidative stress, genotoxicity, biochemical and histopathological modifications induced by epoxiconazole in liver and kidney of wistar rats. Environ. Sci. Pollut. Res. 2019, 26, 17535-17547. [CrossRef]

381. Bruno, M.; Moore, T.; Nesnow, S.; Ge, Y. Protein carbonyl formation in response to propiconazole-induced oxidative stress. J. Proteome Res. 2009, 8, 2070-2078. [CrossRef] [PubMed]

382. Nesnow, S.; Padgett, W.T.; Moore, T. Propiconazole induces alterations in the hepatic metabolome of mice: Relevance to propiconazole-induced hepatocarcinogenesis. Toxicol. Sci. 2011, 120, 297-309. [CrossRef] [PubMed]

383. Di Yang, J.; Liu, S.H.; Liao, M.H.; Chen, R.M.; Liu, P.Y.; Ueng, T.H. Effects of tebuconazole on cytochrome P450 enzymes, oxidative stress, and endocrine disruption in male rats. Environ. Toxicol. 2018, 33, 899-907. [CrossRef] [PubMed]

384. Abolaji, A.O.; Awogbindin, I.O.; Adedara, I.A.; Farombi, E.O. Insecticide chlorpyrifos and fungicide carbendazim, common food contaminants mixture, induce hepatic, renal, and splenic oxidative damage in female rats. Hum. Exp. Toxicol. 2016, 1-11. [CrossRef] [PubMed]

385. Klaunig, J.E.; Kamendulis, L.M. THE role of oxidative stress in carcinogenesis. Annu. Rev. Pharmacol. Toxicol. 2004, 44, 239-267. [CrossRef] [PubMed]

386. Parke, D.V. The cytochromes $\mathrm{P} 450$ and mechanisms of chemical carcinogenesis. Environ. Health Perspect. 1994, 102, 852-853. [CrossRef]

387. Gonzalez, F.J. Role of cytochromes P450 in chemical toxicity and oxidative stress: Studies with CYP2E1. Mutat. Res. Fundam. Mol. Mech. Mutagen. 2005, 569, 101-110. [CrossRef]

388. Ibtissem, B.A.; Hajer, B.S.; Ahmed, H.; Awatef, E.; Choumous, K.; Ons, B.; Mounir, Z.K.; Najiba, Z. Oxidative stress and histopathological changes induced by methylthiophanate, a systemic fungicide, in blood, liver and kidney of adult rats. Afr. Health Sci. 2017, 17, 154-163. [CrossRef]

389. Hase, Y.; Tatsuno, M.; Nishi, T.; Kataoka, K. Atrazine binds to F 1 F 0 -ATP synthase and inhibits mitochondrial function in sperm. Biochem. Biophys. Res. Comun. 2008, 366, 66-72. [CrossRef]

390. Simões, S.; Bracht, L.; Parizotto, A.V.; Comar, J.F.; Peralta, R.M.; Bracht, A. The metabolic effects of diuron in the rat liver. Environ. Toxicol. Pharmacol. 2017, 54, 53-61. [CrossRef]

391. Gomes, M.P.; Juneau, P. Oxidative stress in duckweed (Lemna minor L.) induced by glyphosate: Is the mitochondrial electron transport chain a target of this herbicide? Environ. Pollut. 2016, 218, 402-409. [CrossRef]

392. Elmore, S.E.; La Merrill, M.A. Oxidative phosphorylation impairment by DDT and DDE. Front. Endocrinol. (Lausanne). 2019, 10. [CrossRef] [PubMed] 
393. Salama, M.; El-Morsy, D.; El-Gamal, M.; Shabka, O.; Mohamed, W.M.Y. Mitochondrial complex I inhibition as a possible mechanism of chlorpyrifos induced neurotoxicity. Ann. Neurosci. 2014, 21, 85-89. [CrossRef] [PubMed]

394. Venkatesh, S.; Ramachandran, A.; Zachariah, A.; Oommen, A. Mitochondrial ATP synthase inhibition and nitric oxide are involved in muscle weakness that occurs in acute exposure of rats to monocrotophos. Toxicol. Mech. Methods 2009, 19, 239-245. [CrossRef] [PubMed]

395. Karami-Mohajeri, S.; Hadian, M.R.; Fouladdel, S.; Azizi, E.; Ghahramani, M.H.; Hosseini, R.; Abdollahi, M. Mechanisms of muscular electrophysiological and mitochondrial dysfunction following exposure to malathion, an organophosphorus pesticide. Hum. Exp. Toxicol. 2014, 33, 251-263. [CrossRef] [PubMed]

396. Castanha Zanoli, J.C.; Maioli, M.A.; Medeiros, H.C.D.; Mingatto, F.E. Abamectin affects the bioenergetics of liver mitochondria: A potential mechanism of hepatotoxicity. Toxicol. Vitr. 2012, 26, 51-56. [CrossRef] [PubMed]

397. Bizerra, P.F.V.; Guimarães, A.R.J.S.; Maioli, M.A.; Fábio, E. Imidacloprid affects rat liver mitochondrial bioenergetics by inhibiting F o F 1 -ATP synthase activity. J. Toxicol. Environ. Health Part A 2018, 1-11. [CrossRef] [PubMed]

398. Bailey, D.C.; Todt, C.E.; Orfield, S.E.; Denney, R.D.; Snapp, I.B.; Negga, R.; Montgomery, K.M.; Bailey, A.C.; Pressley, A.S.; Traynor, W.L.; et al. Caenorhabditis elegans chronically exposed to a Mn/Zn ethylene-bis-dithiocarbamate fungicide show mitochondrial Complex I inhibition and increased reactive oxygen species. Neurotoxicology 2016, 56, 170-179. [CrossRef]

399. Bénit, P.; Kahn, A.; Chretien, D.; Bortoli, S.; Huc, L.; Schiff, M.; Gimenez-Roqueplo, A.P.; Favier, J.; Gressens, P.; Rak, M.; et al. Evolutionarily conserved susceptibility of the mitochondrial respiratory chain to SDHI pesticides and its consequence on the impact of SDHIs on human cultured cells. PLoS ONE 2019, 14, e0224132. [CrossRef]

400. Gomes, J.; Lloyd, O.L. Oral exposure of mice to formulations of organophosphorous pesticides: Gestational and litter outcomes. Int. J. Environ. Health Res. 2009, 19, 125-137. [CrossRef]

401. Brandhorst, T.T.; Klein, B.S. Uncertainty surrounding the mechanism and safety of the post-harvest fungicide fludioxonil. Food Chem. Toxicol. 2019, 123, 561-565. [CrossRef] [PubMed]

402. Shukla, S.; Singh, D.; Kumar, V.; Chauhan, A.K.; Singh, S.; Ahmad, I.; Pandey, H.P.; Singh, C. NADPH oxidase mediated maneb- and paraquat-induced oxidative stress in rat polymorphs: Crosstalk with mitochondrial dysfunction. Pestic. Biochem. Physiol. 2015, 123, 74-86. [CrossRef] [PubMed]

403. Jin, X.T.; Song, L.; Li, Z.Y.; Newton, I.P.; Zhao, M.R.; Liu, W.P. Dichlorodiphenyldichloroethylene exposure reduces r-GCS via suppressed Nrf2 in HepG2 cells. Environ. Toxicol. 2016, 31, 350-359. [CrossRef] [PubMed]

404. Hernandez-Cortes, D.; Alvarado-Cru, I.; Solís-Heredia, M.J.; Quintanilla-Vega, B. Epigenetic modulation of Nrf2 and Ogg1 gene expression in testicular germ cells by methyl parathion exposure. Toxicol. Appl. Pharmacol. 2018, 346, 19-27. [CrossRef] [PubMed]

405. Gargouri, B.; Yousif, N.M.; Attaai, A.; Bouchard, M. Neurochemistry International pyrethroid bifenthrin induces oxidative stress, neuroin $\mathrm{fl}$ ammation, and neuronal damage, associated with cognitive and memory impairment in murine hippocampus. Neurochem. Int. 2018, 120, 121-133. [CrossRef] [PubMed]

406. Lundqvist, J.; Hellman, B.; Oskarsson, A. Fungicide prochloraz induces oxidative stress and DNA damage in vitro. Food Chem. Toxicol. 2016, 91, 36-41. [CrossRef] [PubMed]

407. Sagarkar, S.; Gandhi, D.; Devi, S.; Sakharkar, A.; Kapley, A. atrazin exposure causes mitochondrial toxicuty in liver and muscle cell lines. Indian J. Pharmacol. 2016, 48, 200-207. [CrossRef] [PubMed]

408. Pu, M.Z.; Zhao, Y.L. Chlorpyrifos activates cell pyroptosis and increases susceptibility on oxidative stress-induced toxicity by miR-181/SIRT1/PGC-1 $\alpha / \mathrm{Nrf2}$ signaling pathway in human neuroblastoma SH-SY5Y cells. Environ. Toxicol. 2019, 699-707. [CrossRef]

409. Xie, L.; Li, X.; Mo, J.; Li, L.; Chen, X.; Chen, L.; Ma, L.; Chen, Y.; Ge, F.; Zhao, J.; et al. Delayed puberty by ziram is associated with down regulation of testicular phosphorylated AKT1 and SIRT1/PGC-1 $\alpha$ signaling. Chem. Res. Toxicol. 2018, 31, 1315-1322. [CrossRef]

410. Gorczyca, G.; Wartalski, K.; Tabarowski, Z.; Duda, M. Effects of vinclozolin exposure on the expression and activity of SIRT1 and SIRT6 in the porcine ovary. J. Physiol. Pharmacol. 2019, 70, 153-165. [CrossRef]

411. Li, S.; Zhao, G.; Chen, L.; Ding, Y.; Lian, J.; Hong, G.; Lu, Z. Resveratrol protects mice from paraquat-induced lung injury: The important role of SIRT1 and Nrf2 antioxidant pathways. Mol. Med. Rep. 2016, 13, 1833-1838. [CrossRef] [PubMed] 
412. Deng, J.Z.Y.; Zhang, M.; Su, H. SIRT3 Acts as a neuroprotective agent in rotenone-induced parkinson cell model. Neurochem. Res. 2016. [CrossRef]

413. Mostafalou, S.; Abdollahi, M. Pesticides and human chronic diseases: Evidences, mechanisms, and perspectives. Toxicol. Appl. Pharmacol. 2013, 268, 157-177. [CrossRef] [PubMed]

414. Weng, S.; Zhou, L.; Deng, Q.; Wang, J.; Yu, Y.; Zhu, J.; Yuan, Y. Niclosamide induced cell apoptosis via upregulation of ATF3 and activation of PERK in hepatocellular carcinoma cells. BMC Gastroenterol. 2016, 16,1-10. [CrossRef] [PubMed]

415. Mesnage, R.; Biserni, M.; Balu, S.; Frainay, C.; Poupin, N.; Jourdan, F.; Wozniak, E.; Xenakis, T.; Mein, C.A.; Antoniou, M.N. Integrated transcriptomics and metabolomics reveal signatures of lipid metabolism dysregulation in HepaRG liver cells exposed to PCB 126. Arch. Toxicol. 2018, 92, 2533-2547. [CrossRef] [PubMed]

416. Lemaire, G.; Mnif, W.; Pascussi, J.M.; Pillon, A.; Rabenoelina, F.; Fenet, H.; Gomez, E.; Casellas, C.; Nicolas, J.C.; Cavaillès, V.; et al. Identification of new human pregnane $\mathrm{X}$ receptor ligands among pesticides using a stable reporter cell system. Toxicol. Sci. 2006, 91, 501-509. [CrossRef] [PubMed]

417. Yoshimaru, S.; Shizu, R.; Tsuruta, S.; Amaike, Y.; Kano, M.; Hosaka, T.; Sasaki, T.; Yoshinari, K. Acceleration of murine hepatocyte proliferation by imazalil through the activation of nuclear receptor PXR. J. Toxicol. Sci. 2018, 43, 443-450. [CrossRef]

418. Luckert, C.; Braeuning, A.; De Sousa, G.; Durinck, S.; Katsanou, E.S.; Konstantinidou, P.; Machera, K.; Milani, E.S.; Peijnenburg, A.A.C.M.; Rahmani, R.; et al. Adverse outcome pathway-driven analysis of liver steatosis in vitro: A case study with cyproconazole. Chem. Res. Toxicol. 2018, 31, 784-798. [CrossRef]

419. Toporova, L.B.P. Nuclear receptors are the major targets of endocrine disrupting chemicals. Mol. Cell. Endocrinol. 2020, 502, 165. [CrossRef]

420. Genoa, R.W.; Mourikes, V.N.A.B.E.F.J. Mechanisms of action of agrochemicals acting as endocrine disrupting chemicals. Mol. Cell. Endocrinol. 2020, 502, 110680. [CrossRef]

421. Oseini, A.M.; Sanyal, A.J. Therapies in non-alcoholic steatohepatitis (NASH). Liver Int. 2017, 37, 97-103. [CrossRef] [PubMed]

Publisher's Note: MDPI stays neutral with regard to jurisdictional claims in published maps and institutional affiliations.

(C) 2020 by the authors. Licensee MDPI, Basel, Switzerland. This article is an open access article distributed under the terms and conditions of the Creative Commons Attribution (CC BY) license (http://creativecommons.org/licenses/by/4.0/). 